AUS DER MEDIZINSCHEN KLINIK UND POLIKLINIK II

der Universität Würzburg

Direktor: Professor Dr. med. Hermann Einsele

\title{
Allelische Verlustanalyse der chromosomalen Regionen 8p22 und 18q21.1 bei kolorektalen Karzinomen
}

\author{
Inaugural-Dissertation \\ zur Erlangung der Doktorwürde der \\ Medizinischen Fakultät der \\ Julius-Maximilians-Universität Würzburg \\ vorgelegt von \\ Eduard Rosler \\ aus Freiberg am Neckar
}

Würzburg, Oktober 2007 
Referent: Prof. Dr. med. Michael Scheurlen

Koreferent:: Priv.Doz. Dr. med. Stephan Timm

Dekan: Prof. Dr. med. Matthias Frosch

Tag der mündlichen Prüfung: 22.10.2008

Der Promovend ist Arzt 


\section{INHALTSVERZEICHNIS}

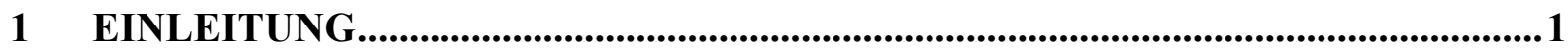

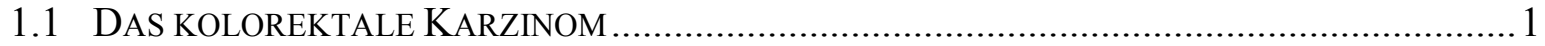

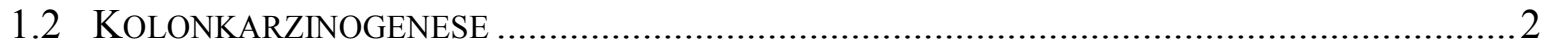

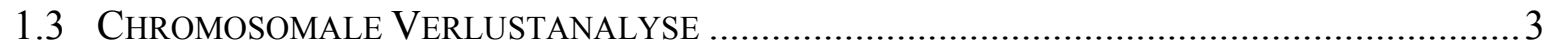

1.3.1 Die chromosomale Region 18q21.1 ......................................................... 4

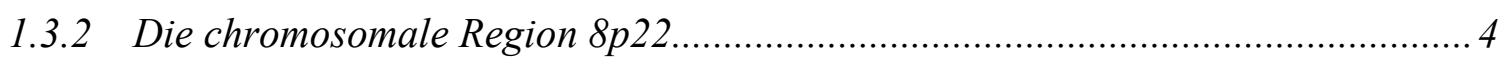

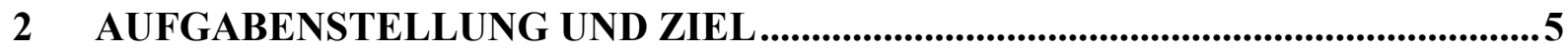

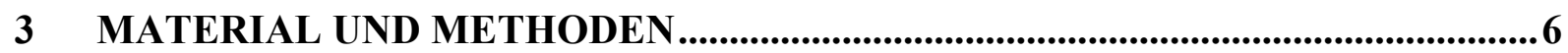

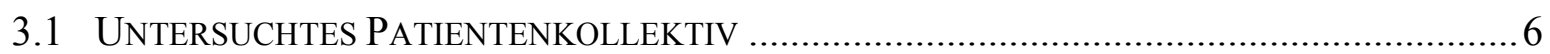

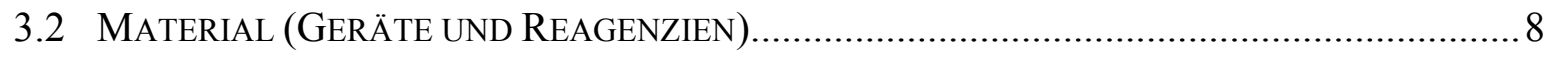

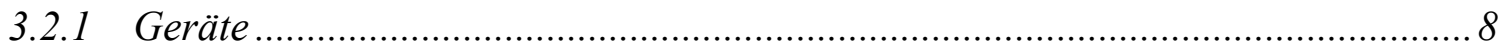

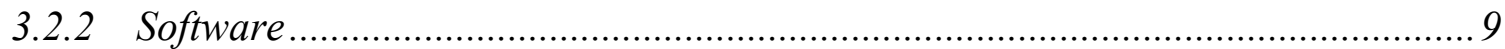

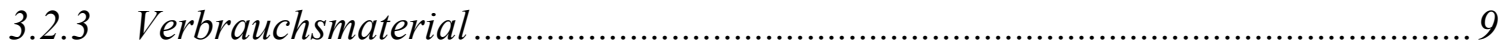

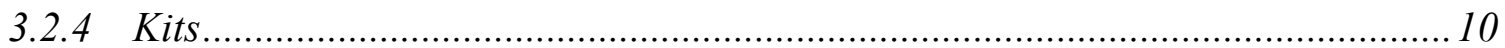

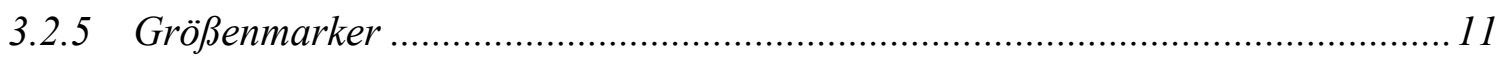

3.2.6 Chemikalien ............................................................................................... 11

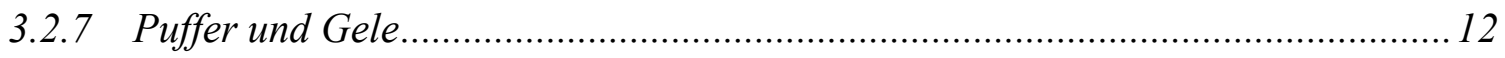

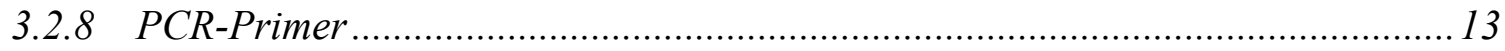

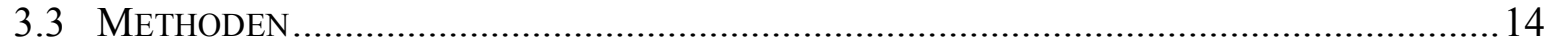

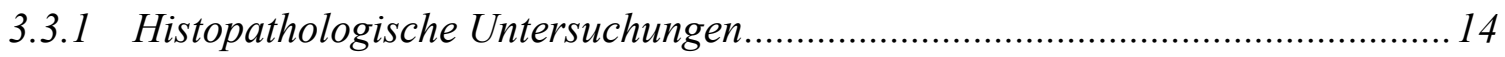

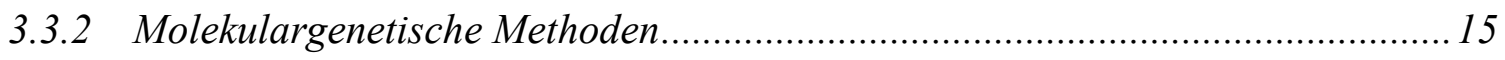

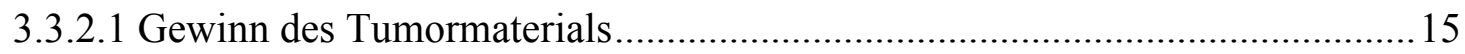

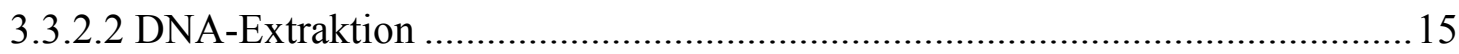

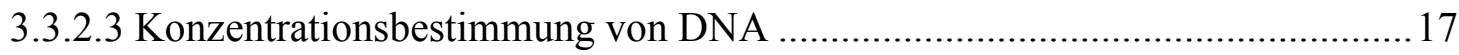

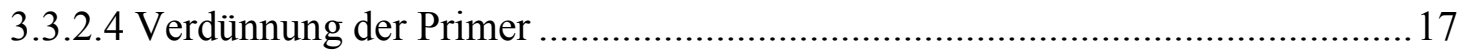

3.3.2.5 Polymerase-Ketten-Reaktion (engl. Polymerase chain reaction, PCR) ........... 17

3.3.2.6 Nachbearbeitung der amplifizierten DNA .................................................20

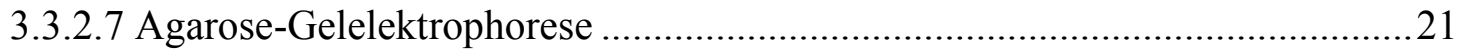

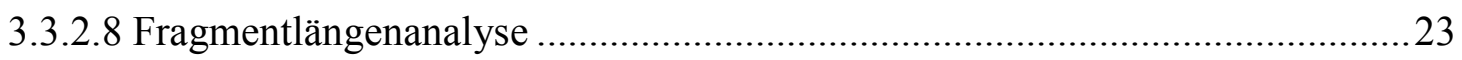

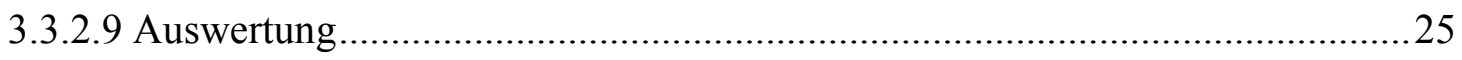

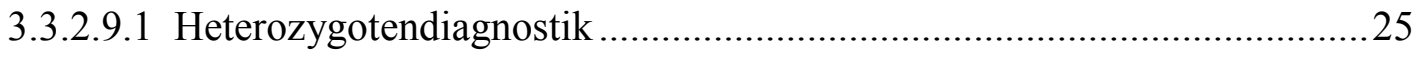




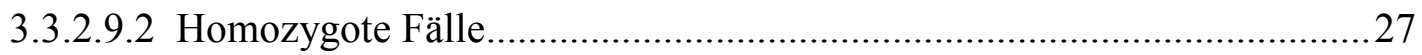

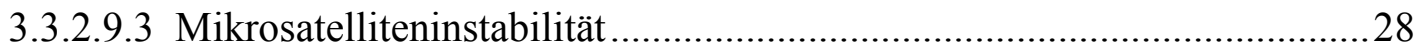

3.3.2.10 Korrelation mit den histopathologischen Daten .........................................29

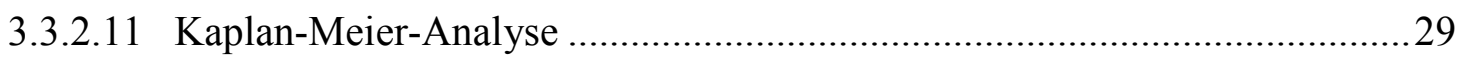

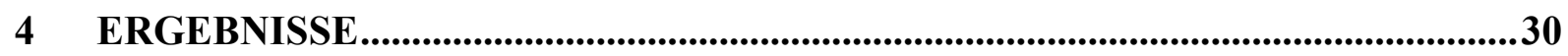

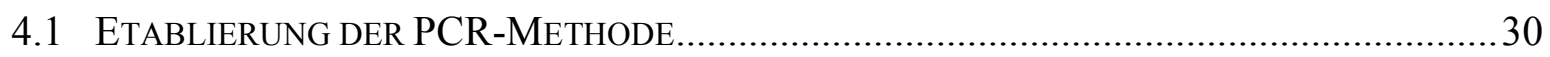

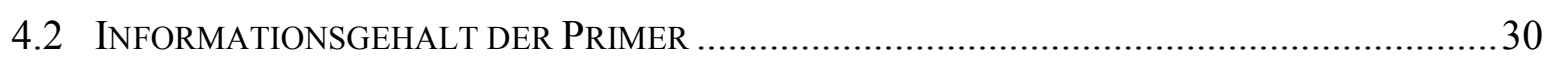

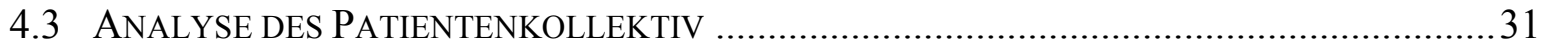

4.4 KORRELATION EINES CHROMOSOMALEN VERLUSTES MIT KLINISCHEN UND

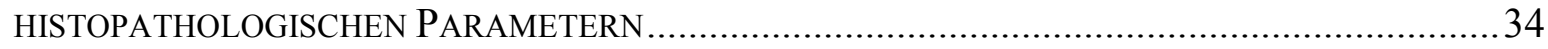

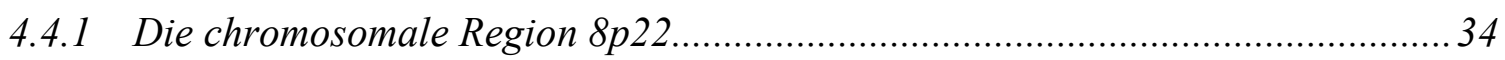

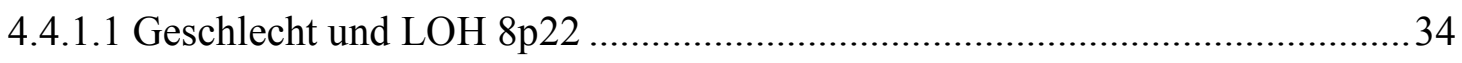

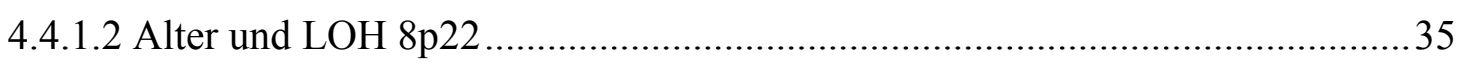

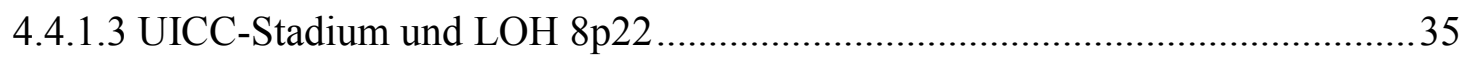

4.4.1.4 pT-, pN-, pM-Kategorie und LOH 8p22 ….................................................... 36

4.4.1.5 Differenzierungsgrad (Grading) und LOH 8p22 …...................................... 37

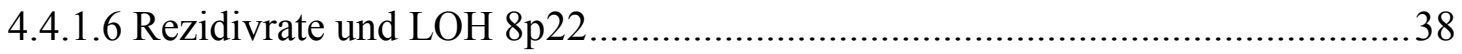

4.4.1.7 Unterscheidung des Patientenkollektivs nach dem Geschlecht.........................38

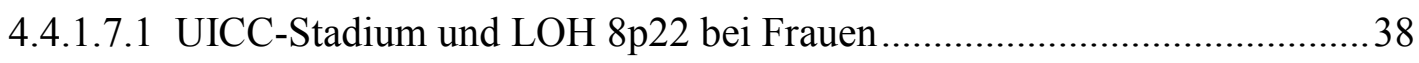

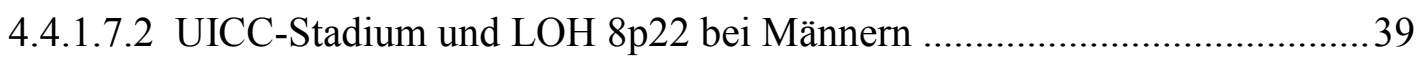

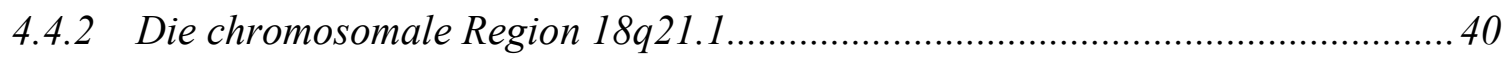

4.4.2.1 Geschlecht und LOH 18q21.1 …................................................................. 40

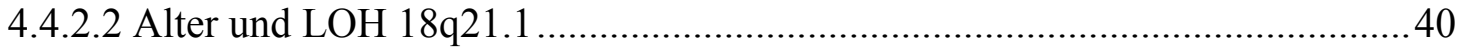

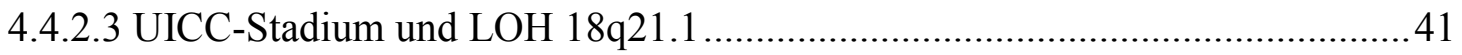

4.4.2.4 pT-, pN-, pM-Kategorie und LOH 18q21.1 ................................................ 42

4.4.2.5 Differenzierungsgrad (Grading) und LOH 18q21.1 .....................................43

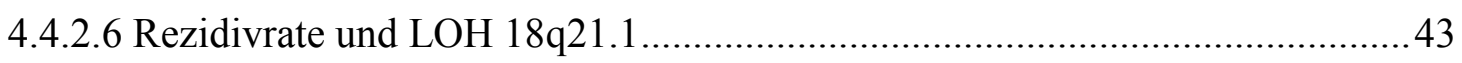

4.4.2.7 Unterscheidung des Patientenkollektivs nach dem Geschlecht....................... 44

4.4.2.7.1 UICC-Stadium und LOH 18q21.1 bei Frauen........................................4

4.4.2.7.2 UICC-Stadium und LOH 18q21.1 bei Männern .....................................45

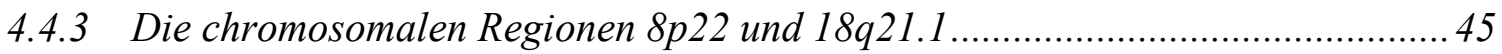

4.4.3.1 UICC-Stadium und LOH 8p22 und 18q21.1 bei Frauen .................................46

4.4.3.2 UICC-Stadium und LOH 8p22 und 18q21.1 bei Männern ............................. 47

4.4.4 Korrelation mit den klinischen Verlaufsparametern ...................................... 48 
4.4.4.1 Verlust der Heterozygotie der Region 8p22 und Patientenprognose .48

4.4.4.2 Verlust der Heterozygotie der Region 18q21.1 und Patientenprognose

4.4.4.3 Verlust der Heterozygotie der Regionen 8p22 und 18q21.1 und

Patientenprognose 55

5 DISKUSSION. 56

5.1 Prognostische RelEVANZ EINES ALLELISCHEN VERLUSTES DES MARKERS D8S254.56

5.1.1 Potentielle Tumorsuppressorgene auf $8 p 22$. 58

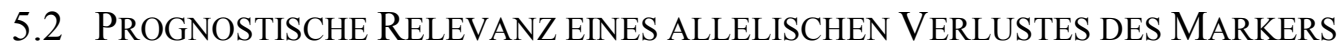

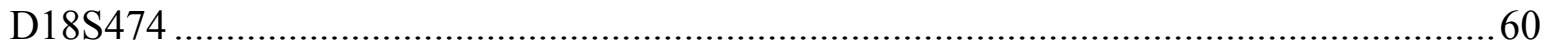

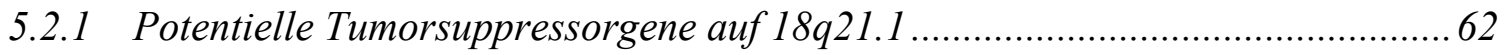

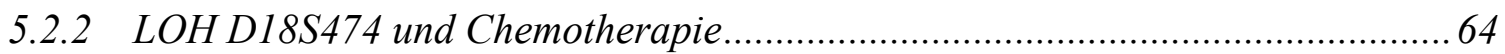

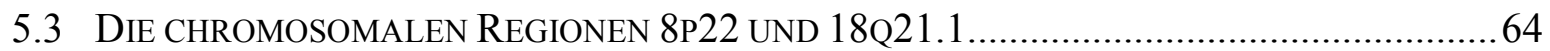

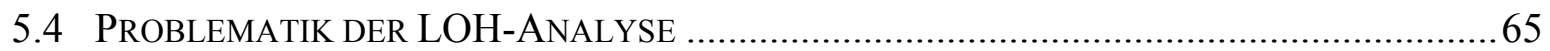

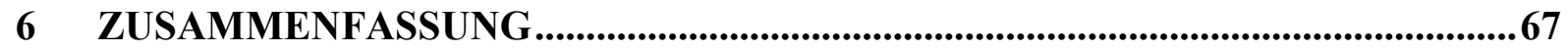

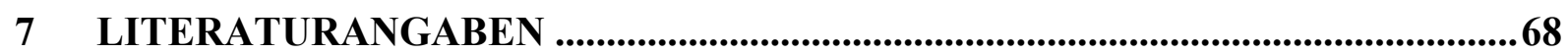




\section{Abkürzungen:}

5-FU: 5-Fluorouracil

5-JÜR: 5-Jahres-Überlebensrate

APC-Gen: Adenomatous polyposis coli-Gen

Bp: Basenpaare

CIN: chromosomale Instabilität

CRC: Kolorektales Karzinom

CRCS: colorectal cancer suppressor

dATP: Desoxyadenintriphosphat

dCTP: Desoxycytosintriphosphat

dGTP: Desoxyguanintriphosphat

dTTP: Desoxythymintriphosphat

dNTP: Desoxynukleotidtriphosphat

DCC: deleted in colon cancer

DNA: Desoxyribonukleinsäure

DPC: deleted in pancreatic carcinoma

FAP: Familiäre adenomatöse Polypose

FISH: Fluorezenz-in-situ Hybridisierung

HNPCC: hereditäres nicht-polypöses Kolonkarzinom

Kb: Kilobasen

LOH: Loss of heterozygosity

MADH: Mothers against decapentaplegic homologue

Mb: Megabasen

MSI: Mikrosatelliteninstabilität

PCR: Polymerase Kettenreaktion (engl. Polymerase chain reaction)

Rb-Gen: Retinoblastom-Gen

SMAD: similar to mothers against decapentaplegic

TGF $\beta$ : Transforming growth factor $\beta$

Ts-Gen: Tumorsuppressorgen

UICC:Union internationale contre le cancer 


\section{$1.1 \quad$ Das kolorektale Karzinom}

Das kolorektale Karzinom stellt weltweit eine der häufigsten tumorbedingten Todesursachen dar. Jedes Jahr entwickeln mehr als 945000 Menschen weltweit solch ein Karzinom; ca. 492000 sterben jährlich daran (Weitz et al., 2005). Die Inzidenz des kolorektalen Karzinoms betrug in Deutschland 2002 ca. 60/100.000 Einwohner. Das kolorektale Karzinom war 2002 bei Männern weltweit der vierthäufigste maligne Tumor mit einer Inzidenz von 20/10000 hinter dem Lungen-, dem Prostata- und dem Magen-Karzinom, bei den Frauen der dritthäufigste nach dem Mamma- und dem Zervix-Karzinom (Parkin et al., 2005). Bei der tumorbedingten Sterberate lag das Kolonkarzinom 2002 weltweit bei Männern und Frauen an dritter Stelle nach dem Bronchialkarzinom an erster Stelle, gefolgt von dem Prostata-, bzw. dem Mamma-Karzinom (Parkin et al., 2005). Der Häufigkeitsgipfel bei beiden Geschlechtern liegt zwischen dem 50. und 70. Lebensjahr, wobei die Inzidenzrate ab dem 50. Lebensjahr exponentiell ansteigt. Über 50\% der Menschen in den USA werden mit Erreichen des 70. Lebensjahres einen adenomatösen Polypen entwickeln haben, davon gehen jedoch lediglich $10 \%$ ein ein invasives Karzinom über. Das lebenslange Risiko, ein kolorektales Karzinom zu entwickeln beträgt etwa 5-6\% (Johns und Houlston, 2001). Ätiologisch sind beim kolorektalen Karzinom sowohl endogene als auch exogene Faktoren von Bedeutung. Besonders ernährungsbedingte Einflüsse, wie fettreiche und fleischreiche Kost sowie Übergewicht, langjähriger Nikotin- und Alkoholkonsum werden als Risikofaktoren angesehen (Potter et al., 1982; Willet et al., 1990). Dahingegen wirken sich eine faserreiche Kost und eine schnelle Darmpassage eher protektiv aus (Scheppach et al., 2000). Den endogenen Faktoren liegen genetische Veränderungen zugrunde, die sowohl erworben als auch angeboren sein können. Als Präkanzerosen sind kolorektale Adenome, multiple Adenome bei der familiären Adenomatosis coli (FAP) und die Colitis ulcerosa gesichert. Allgemein kann man sagen, dass kolorektale Karzinome aufgrund von kumulativen Effekten multipler aufeinander folgender genetische Alterationen erfolgen (siehe Adenom-Karzinom-Sequenz nach Fearon und Vogelstein, 1990, Kapitel 1.2, Seite 2). Diese Mutationen können einerseits erworben, wie in den sporadischen Karzinomen, oder angeboren sein. Der Hauptteil der kolorektalen Karzinome tritt sporadisch auf, lediglich 5-6\% haben einen genetischen Hintergrund. 


\section{$1.2 \quad$ Kolonkarzinogenese}

Die Entwicklung normaler Epithelzellen zu einem Adenokarzinom folgt normalerweise einer bestimmten Abfolge histologischer Veränderungen und diesen $\mathrm{zu}$ Grunde liegenden genetischen und epigenetischen Aberrationen. Weiterfolgende Alterationen, die zu einer klonalen Expansion führen, sind Konsequenzen progressiver Ereignisse, die diesen veränderten Zellen Wachstumsvorteile verschaffen, wie z.B. den Verlust der Zell-ZellKontakt-Inhibierung. Kolorektale Karzinome entwickeln sich allmählich über 10 bis 15 Jahre hinweg. Der Tumor entsteht über eine Abfolge multipler genetischer und morphologischer Schritte, von denen die genomische Instabilität ein Schlüsselschritt in der molekularen und pathophysiologischen Entwicklung ist (Fearon und Vogelstein, 1990). Durch Fearon und Vogelstein wurde 1990 das Modell der Adenom-Karzinom-Sequenz postuliert. Nach ihnen entwickeln sich bösartige Karzinome aus dem normalen Dickdarmepithel über mikroskopisch erkennbare atypische Krypten mit übermäßiger Proliferation und daraus entstehenden Adenomen. Begleitend kommt es zur Inaktivierung der Tumorsuppressorgene APC, p53, SMAD4, sowie zur Aktivierung des Onkogens k-ras (siehe Abbildung 1).

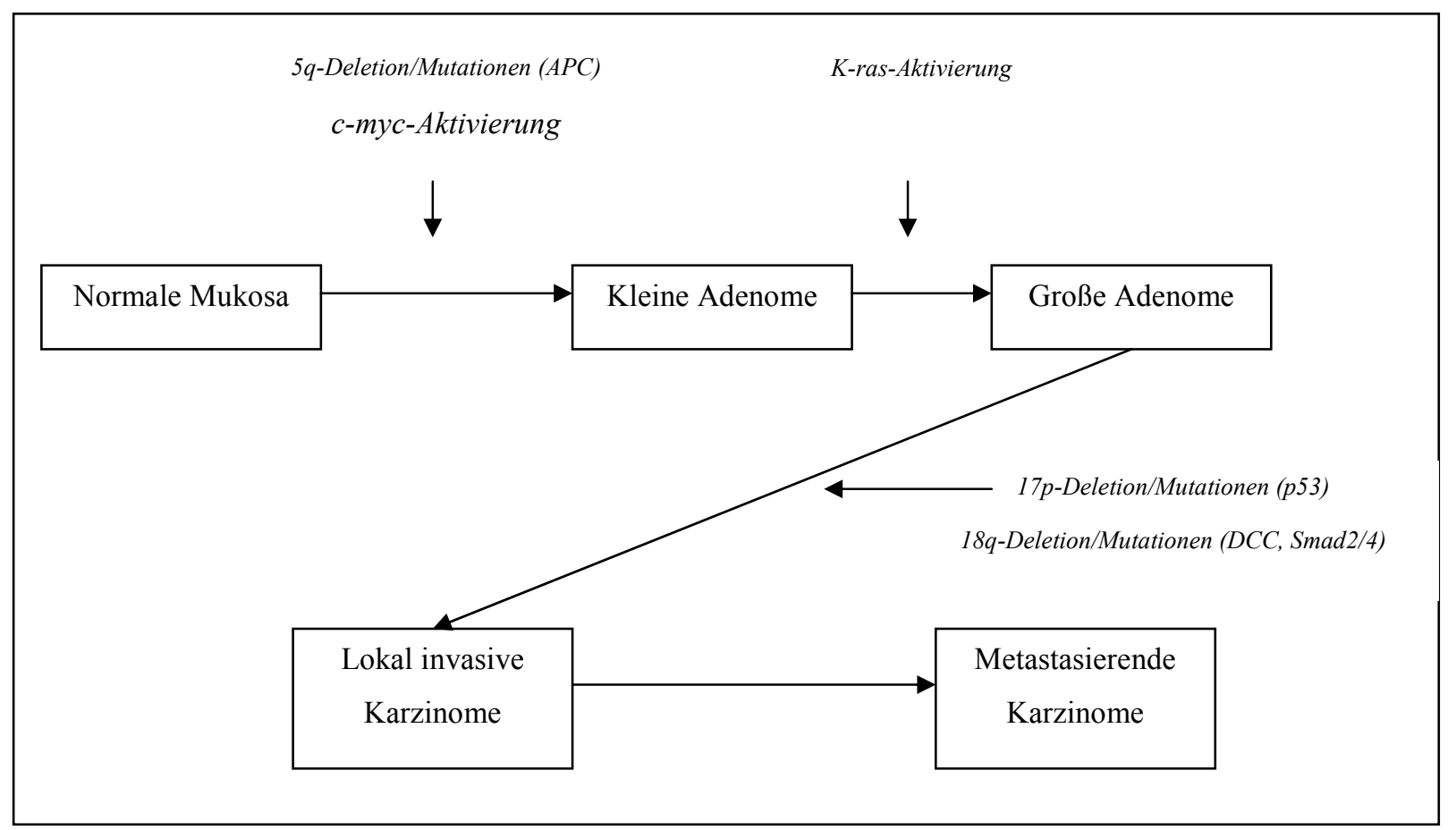

Abbildung 1: Schematische Darstellung der Adenom-Karzinom-Sequenz nach Fearon und Vogelstein (1990) und der Angriffspunkte der verschiedenen Mutationen und Deletionen (aus Wildi et al., 1999) 


\subsection{Chromosomale Verlustanalyse}

Der Test auf Heterozygotie bzw. den Verlust der Heterozygotie wird oft angewandt, um die chromosomale Position von Tumorsuppressorgenen zu ermitteln. 1983 stellten Cavenee und Mitarbeiter in Versuchen beim Retinoblastom fest, dass somatische, genetische Veränderungen einen Verlust der Heterozygotie (engl. loss of heterzygosity, LOH) bei Markern hervorrufen, die in der Nähe des Retinoblastom-Genlokus (Rb-Gen) liegen. Dieser Ansatz folgt dem 1971 von Knudson beschriebenen theoretischen Konzept der doppelten Inaktivierung der Ts-Gene. Ein LOH hat laut der Two-Hit-Hypothese nach Knudson eine signifikante Bedeutung für die endgültige Inaktivierung von Ts-Genen sowohl in hereditären als auch in sporadischen Karzinomerkrankungen. Aus diesem Grund wurde der Verlust von genetischem Material in bestimmten chromosomalen Regionen in einem Tumor als Hinweis auf das Vorhandensein von Ts-Genen angesehen (Canzian et al., 1996; Gruis et al., 1993). Der Schlüsselschritt dabei ist die somatische Inaktivierung des zweiten (Wildtyp-) Allels des Gens, die meist durch einen Verlust der Heterozygotie vollzogen wird. Die erste Kopie des Gens ist bereits zuvor durch eine Keimbahnmutation oder eine somatische Mutation inaktiviert (Knudson, 1971). Analysiert man nun korrespondierende Schleimhaut- und Tumorproben mithilfe von Markern, die über das gesamte Genom verteilt sind, kann ein indirekter Hinweis auf neue, bis jetzt noch nicht identifizierte Ts-Gene gefunden werden. Fearon und Vogelstein haben als erste 1990 durch die Analyse von Mikrosatellitenregionen ihre Theorie der Adenom-Karzinom-Sequenz aufgestellt (siehe Abbildung 1, Seite 2). In der LOH-Analyse werden polymorphe Marker zum spezifischen Nachweis homologer Allele eingesetzt. Hierbei haben sich so genannte „Mikrosatellitenmarker“ mit variabler Anzahl von kurzen Di- Tri- oder Tetranukleotidwiederholungen als äußerst nützlich und den klassischen RFLP-Markern (Restriktionsfragmentlängen-Polymorphismen) überlegen erwiesen.

Durch die verschiedene Anzahl von Wiederholungs-Einheiten innerhalb einer solchen Mikrosatellitensequenz ergeben sich nach Amplifizierung mittels Polymerase Ketten Reaktion in der Normal- und der Tumor-DNA jeweils zwei in der Größe verschiedene Fragmente, die sich elektrophoretisch auftrennen und durch entsprechende Färbetechniken nachweisen lassen. Ein LOH in der Tumor-DNA zeigt sich durch einen Verlust bzw. eine signifikante Reduktion eines der beiden in der Normal-DNA nachgewiesenen Allelfragmente (Niederacher und Beckmann, 1998). Um die Anzahl der nichtinformativen Fälle, in denen die Allele für einen Marker homozygot -und somit nicht auswertbar- sind, müssen hochpolymorphe Mikrosatellitenmarker ausgewählt werden. Also solche, die eine hohe 
Allelfrequenz und somit einen hohen Grad an Heterozygotie in der Bevölkerung besitzen. Solche Mikrosatellitenmarker sind z.B. D8S254 für die Region 8p22 und D18S474 für die Region 18q21.1 (siehe Kapitel 3.2.8, Seite 13).

Die beiden Regionen 8p22 und 18q21.1 sind dabei von besonderem Interesse, da auf ihnen bereits Regionen identifiziert wurden, die auf Ts-Gene rückschließen lassen.

\subsubsection{Die chromosomale Region 18q21.1}

Allelische Verluste der Region 18q21.1 treten in bis zu 70\% der kolorektalen Karzinome auf und werden für deren Entwicklung verantwortlich gemacht (Vogelstein et al., 1988; Cho und Fearon, 1995). Das bzw. die Tumorsuppressorgene dieser Region konnten noch nicht genau definiert werden. Es konnte lediglich eine Region minimalen Verlustes von 16Mb eingegrenzt werden, die drei in Frage kommende Ts-Gene (DCC, SMAD2 und DPC4/SMAD4) enthält (Thiagalingam et al., 1996; Riggins et al., 1996). Besonders das SMAD4-Gen scheint das Tumorsuppressorgen $\mathrm{zu}$ sein, das für die Aufrechterhaltung des normalen Zellzyklus verantwortlich ist und dessen Mutation eine maligne Transformation der Kolonschleimhaut bedingt, nicht der ursprüngliche Kandidat DCC (Fazeli et al., 1997, White, 1998, WoodfordRichens et al., 2001a). Aber auch SMAD2 kommt dafür in Frage (siehe Kapitel 5.2.1, Seite 62). In zahlreichen Studien konnte nachgewiesen werden, dass ein chromosomaler Verlust dieser Region bei kolorektalen Karzinomen häufig zu finden und signifikant mit einer schlechteren Patientenprognose assoziiert ist (Jen et al., 1994; Ookawa et al., 1993; Iino et al., 1994; Kato et al., 1996; Ogunbiyi et al., 1998; Arai et al., 1998a; Lanza et al., 1998; MartinezLopez et al., 1998; Jernvall et al., 1999; Font et al., 2001). Allerdings konnte dies nicht in allen Studien bestätigt werden (Halling et al., 1999; Cohn et al., 1997; Carethers et al., 1998). Ferner konnte ein Zusammenhang zwischen dem Metastasierungsweg und SMAD4-Mutation beim kolorektalen Karzinom nachgewiesen werden (Losi et al., 2004). Der für diese Region verwendete Mikrosatellitenmarker D18S474 liegt unmittelbar proximal des SMAD4-Gens, lediglich 100kb entfernt (Hahn et al., 1996).

\subsubsection{Die chromosomale Region 8p22}

Das Verhalten eines LOH auf 8p ist sehr komplex und auf mindestens zwei Regionen verteilt. Diese beiden Regionen sind 8p22 und 8p12-21 (Levy et al., 1999; Fujiwara et al., 1993). Die eine Region ist 8p22, die in verschiedenen Karzinomen identifiziert und kartiert wurde. Dazu gehörten Untersuchungen am kolorektalen Karzinom (van der Bosch et al., 1992; Yaremko et 
al., 1994; Fujiwara et al., 1994), am Prostata-Karzinom (Kagan et al., 1995; Bova et al., 1993), dem Larynx-Karzinom (Sunwoo et al., 1996; El-Naggar et al., 1998), am nichtkleinzelligen Bronchial-Karzinom (Fujiwara et al., 1994, Ohata et al., 1993), am hepatozellulären Karzinom (Fujiwara et al., 1994), am Mamma-Karzinom (Yaremko et al., 1995 \& 1996), und am Ovarial-Karzinom (Wright et al., 1998). Etwas weiter proximal liegt die zweite interessante Region 8p11-12, die ebenfalls in mehreren Karzinom-Typen einen Verlust der Heterozygotie aufweist. Dazu gehört das kolorektale (Chughtai et al., 1999), das Prostata-(Vocke et al., 1996; Macoska et al., 1995; Haggman et al., 1997; Trapman et al., 1994), das Nieren-(Schullerus et al., 1997), das Mamma-(Seitz et al., 1997; Chuaqui et al., 1995), und das oropharyngeale Karzinom (Wu et al., 1997). Beim Prostata-Karzinom zum Beispiel ist ein Verlust des kurzen Armes des Chromosom 8 (8p) am häufigsten von allen chromosomalen Verlusten zu finden (Bergerheim et al., 1991; Visakorpi et al., 1994).

Die Region, auf die in dieser Arbeit eingegangen werden soll ist die Region 8p22, deren Verlust beim kolorektalen Karzinom von anderen Gruppen mit einem höheren Tumorstadium (Choi et al., 2002), der Tumorprogression (Fujiwara et al., 1993; Yaremko et al., 1994; Chang et al., 2005), einer lympahtischen, vaskulären und perineuralen Mikroinvasion (Kelemen et al., 1994, Takanishi et al., 1997) und einer schlechteren Patientenprognose (Halling et al., 1999; Chang et al., 2005) korreliert werden konnte.

\section{$2 \quad$ Aufgabenstellung und Ziel}

Ziel der vorliegenden Arbeit war die Untersuchung allelischer Verluste (LOH-"loss of heterozygosity") der chromosomalen Regionen 8p22 und 18q21.1 bei kolorektalen Karzinomen und deren Relevanz für die Patientenprognose. Dazu wurden im Rahmen der „Interdisziplinären Forschergruppe Kolonkarzinom Würzburg“ von 1999 bis 2004169 kolorektale Tumore und korrespondierende Normalschleimhaut gesammelt. Von den auswertbaren 144 Tumor-Schleimhautpaaren wurde eine Amplifikation der Mikrosatellitenmarker D8S254 (Region 8p22) und D18S474 (Region 18q21.1) mittels PCR durchgeführt. Anschließend erfolgte die Trennung und Quantifizierung der Amplifikate in einem automatischen Sequenziergerät. Durch den Vergleich der Tumor- mit der Normalschleimhautprobe konnte das Vorliegen eines allelischen Verlustes gesichtert werden. Die Ergebnisse wurden dann mit den histopathologischen Daten und den klinischen Verlaufsparametern der Patienten korreliert. 


\subsection{Untersuchtes Patientenkollektiv}

Untersucht wurde eine Serie von 144 Patienten, die im Zeitraum von 1999 bis 2004 wegen eines kolorektalen Karzinoms an der Universitätsklinik Würzburg operiert wurden. Von den 144 Patienten waren 79 männlich und 65 weiblich. Das Durchschnittsalter betrug 67,5 Jahre (Median 69 Jahre, Spannweite 29-91 Jahre).

\begin{tabular}{|c|c|c|c|c|c|c|c|c|c|}
\hline Nr. & Sex & Alter & UICC & G & Nr. & Sex & Alter & UICC & G \\
\hline $\mathbf{1}$ & W & 87 & 1 & 2 & $\mathbf{3 7}$ & W & 36 & 2 & 2 \\
\hline $\mathbf{2}$ & W & 53 & 1 & 2 & $\mathbf{3 8}$ & M & 43 & 1 & $?$ \\
\hline $\mathbf{3}$ & M & 77 & 3 & 2 & $\mathbf{3 9}$ & M & 60 & 4 & 2 \\
\hline $\mathbf{4}$ & M & 65 & 3 & 2 & $\mathbf{4 0}$ & M & 60 & 1 & 2 \\
\hline $\mathbf{5}$ & M & 72 & 1 & 1 & $\mathbf{4 1}$ & W & 59 & 2 & 2 \\
\hline $\mathbf{6}$ & W & 67 & 3 & 2 & $\mathbf{4 2}$ & W & 69 & 4 & 2 \\
\hline $\mathbf{7}$ & W & 66 & 3 & 2 & $\mathbf{4 3}$ & M & 74 & 2 & 3 \\
\hline $\mathbf{8}$ & M & 62 & 2 & 2 & $\mathbf{4 4}$ & W & 78 & 2 & 2 \\
\hline $\mathbf{9}$ & M & 59 & 2 & 2 & $\mathbf{4 5}$ & W & 86 & 2 & 3 \\
\hline $\mathbf{1 0}$ & M & 61 & 3 & 2 & $\mathbf{4 6}$ & M & 67 & 4 & 2 \\
\hline $\mathbf{1 1}$ & W & 87 & 2 & 2 & $\mathbf{4 7}$ & M & 65 & 1 & 2 \\
\hline $\mathbf{1 2}$ & W & 75 & 1 & 3 & $\mathbf{4 8}$ & W & 78 & 2 & 2 \\
\hline $\mathbf{1 3}$ & W & 66 & 1 & 2 & $\mathbf{4 9}$ & W & 70 & 2 & 2 \\
\hline $\mathbf{1 4}$ & M & 80 & 2 & $?$ & $\mathbf{5 0}$ & W & 66 & 2 & 2 \\
\hline $\mathbf{1 5}$ & W & 69 & 1 & 3 & $\mathbf{5 1}$ & M & 63 & 3 & 3 \\
\hline $\mathbf{1 6}$ & W & 79 & 4 & 2 & $\mathbf{5 2}$ & W & 69 & 1 & 2 \\
\hline $\mathbf{1 7}$ & W & 82 & 2 & 2 & $\mathbf{5 3}$ & M & 70 & 2 & 2 \\
\hline $\mathbf{1 8}$ & W & 85 & 3 & 3 & $\mathbf{5 4}$ & M & 80 & 2 & 2 \\
\hline $\mathbf{1 9}$ & W & 74 & 2 & 2 & $\mathbf{5 5}$ & W & 31 & 3 & 3 \\
\hline $\mathbf{2 0}$ & M & 68 & 4 & 3 & $\mathbf{5 6}$ & M & 73 & 1 & 2 \\
\hline $\mathbf{2 1}$ & M & 62 & 1 & 2 & $\mathbf{5 7}$ & W & 84 & 3 & 3 \\
\hline $\mathbf{2 2}$ & M & 56 & 2 & 2 & $\mathbf{5 8}$ & M & 67 & 4 & 2 \\
\hline $\mathbf{2 3}$ & M & 47 & 3 & 2 & $\mathbf{5 9}$ & M & 75 & 2 & 3 \\
\hline $\mathbf{2 4}$ & W & 76 & 3 & 3 & $\mathbf{6 0}$ & W & 89 & 2 & 2 \\
\hline $\mathbf{2 5}$ & M & 44 & 4 & 2 & $\mathbf{6 1}$ & W & 73 & 3 & 3 \\
\hline $\mathbf{2 6}$ & M & 63 & 4 & 3 & $\mathbf{6 2}$ & M & 70 & 2 & 2 \\
\hline $\mathbf{2 7}$ & M & 83 & 2 & 2 & $\mathbf{6 3}$ & W & 71 & 4 & 2 \\
\hline $\mathbf{2 8}$ & M & 57 & 4 & 3 & $\mathbf{6 4}$ & W & 78 & 2 & 2 \\
\hline $\mathbf{2 9}$ & M & 60 & 2 & 2 & $\mathbf{6 5}$ & M & 68 & 3 & 2 \\
\hline $\mathbf{3 0}$ & W & 68 & 3 & 2 & $\mathbf{6 6}$ & M & 61 & 4 & 2 \\
\hline $\mathbf{3 1}$ & M & 64 & 3 & 2 & $\mathbf{6 7}$ & W & 54 & 3 & 2 \\
\hline $\mathbf{3 2}$ & W & 47 & 2 & 2 & $\mathbf{6 8}$ & M & 63 & 2 & 2 \\
\hline $\mathbf{3 3}$ & W & 52 & 4 & 2 & $\mathbf{6 9}$ & W & 66 & 2 & 2 \\
\hline $\mathbf{3 4}$ & M & 77 & 3 & 2 & $\mathbf{7 0}$ & W & 49 & 2 & 3 \\
\hline $\mathbf{3 5}$ & W & 80 & 1 & 2 & $\mathbf{7 1}$ & M & 60 & 3 & 2 \\
\hline $\mathbf{3 6}$ & M & 67 & 4 & 2 & $\mathbf{7 2}$ & M & 80 & 2 & 2 \\
\hline & & & & & & & & & \\
\hline
\end{tabular}




\begin{tabular}{|c|c|c|c|c|c|c|c|c|c|}
\hline Nr. & Sex & Alter & UICC & $\mathbf{G}$ & Nr. & Sex & Alter & UICC & $\mathbf{G}$ \\
\hline 73 & $\mathrm{~W}$ & 30 & 2 & 2 & 109 & $\mathrm{M}$ & 52 & 2 & 2 \\
\hline 74 & $\bar{M}$ & 68 & 3 & 2 & 110 & $\bar{M}$ & 51 & 4 & 3 \\
\hline 75 & $M$ & 72 & 1 & 2 & 111 & $M$ & 73 & 1 & 3 \\
\hline 76 & W & 72 & 2 & 3 & 112 & $M$ & 78 & 4 & ? \\
\hline 77 & $M$ & 71 & 4 & 2 & 113 & $M$ & 72 & 3 & 3 \\
\hline 78 & $\bar{W}$ & 75 & 2 & 2 & 114 & $\mathrm{~W}$ & 49 & 3 & 2 \\
\hline 79 & $M$ & 74 & 2 & 2 & 115 & $M$ & 64 & 2 & 2 \\
\hline 80 & $\bar{W}$ & 83 & 4 & 3 & 116 & $\bar{W}$ & 56 & 1 & 2 \\
\hline 81 & $M$ & 77 & 4 & 2 & 117 & $W$ & 71 & 4 & 2 \\
\hline 82 & $\bar{W}$ & 64 & 4 & 2 & 118 & $\bar{M}$ & 62 & 2 & 2 \\
\hline 83 & $M$ & 64 & 3 & 2 & 119 & $M$ & 77 & 3 & 2 \\
\hline 84 & $\bar{W}$ & 70 & 2 & 3 & 120 & $\overline{\mathrm{W}}$ & 79 & 1 & 2 \\
\hline 85 & $M$ & 60 & 2 & 2 & 121 & W & 67 & 3 & 2 \\
\hline 86 & $\bar{M}$ & 69 & 2 & 2 & 122 & $M$ & 64 & 3 & 3 \\
\hline 87 & $\bar{M}$ & 40 & 2 & 2 & 123 & $\mathrm{~W}$ & 89 & 1 & 2 \\
\hline 88 & $\bar{M}$ & 72 & 1 & 2 & 124 & $\bar{M}$ & 76 & 4 & 2 \\
\hline 89 & $\bar{W}$ & 74 & 4 & 2 & 125 & $\mathrm{M}$ & 66 & 3 & 3 \\
\hline 90 & $\bar{M}$ & 55 & 3 & 3 & 126 & $\bar{W}$ & 63 & 2 & 2 \\
\hline 91 & $\bar{W}$ & 74 & 1 & 2 & 127 & $W$ & 73 & 3 & 2 \\
\hline 92 & $M$ & 67 & 4 & $?$ & 128 & $\mathrm{M}$ & 73 & 2 & 2 \\
\hline 93 & $\bar{W}$ & 81 & 2 & 2 & 129 & $\mathrm{~W}$ & 60 & 2 & 2 \\
\hline 94 & $\bar{M}$ & 62 & 1 & 2 & 130 & $\mathrm{~W}$ & 63 & 4 & 2 \\
\hline 95 & $M$ & 29 & 1 & 2 & 131 & W & 91 & 2 & 3 \\
\hline 96 & $M$ & 72 & 2 & 2 & 132 & $M$ & 65 & 4 & 2 \\
\hline 97 & $\bar{W}$ & 73 & 2 & 2 & 133 & $\mathrm{~W}$ & 66 & 4 & 3 \\
\hline 98 & $M$ & 66 & 4 & 2 & 134 & $\mathrm{~W}$ & 72 & 4 & 3 \\
\hline 99 & $\bar{W}$ & 88 & 2 & 2 & 135 & $\mathrm{~W}$ & 55 & 4 & 3 \\
\hline 100 & $\bar{W}$ & 64 & 1 & 2 & 136 & $\mathrm{M}$ & 64 & 2 & 2 \\
\hline 101 & $\bar{M}$ & 71 & 3 & 2 & 137 & $\mathrm{M}$ & 72 & 2 & 3 \\
\hline 102 & $M$ & 71 & 3 & 3 & 138 & $\mathrm{~W}$ & 63 & 4 & 2 \\
\hline 103 & $\bar{W}$ & 78 & 2 & 2 & 139 & $M$ & 68 & 2 & 2 \\
\hline 104 & $M$ & 64 & 1 & 2 & 140 & $\mathrm{M}$ & 78 & 3 & 3 \\
\hline 105 & $\mathrm{M}$ & 58 & 3 & 2 & 141 & $\mathrm{~W}$ & 82 & 4 & 3 \\
\hline 106 & $M$ & 78 & 2 & 2 & 142 & $M$ & 74 & 4 & 2 \\
\hline 107 & $\bar{M}$ & 32 & 3 & 2 & 143 & $\mathrm{M}$ & 84 & 2 & 2 \\
\hline 108 & $\mathrm{~W}$ & 86 & 1 & 2 & 144 & $M$ & 70 & 2 & 2 \\
\hline
\end{tabular}

Tabelle 1: Patientendaten (Sex=Geschlecht, $M=$ Männlich, $W=$ Weiblich; UICC=Stadium nach der UICC; G=Grading)

25 der analysierten Tumoren befanden sich im UICC-Stadium I, 54 im Stadium II, 33 im Stadium III und 32 im Stadium IV. Ein Karzinom war G1-, 107 G2 und 32 G3-differenziert. Die Angabe über das Grading fehlte bei 4 Patienten, diese wurden bei der Korrelation der Ergebnisse nicht berücksichtigt. 


\subsection{Material (Geräte und Reagenzien)}

\subsubsection{Geräte}

\begin{tabular}{|c|c|c|c|}
\hline Beschreibung & Typenbezeichnung & Hersteller & Herkunftsort \\
\hline Autoklav & & Fedegari & Albuzzano, Italien \\
\hline Elektrophoresekammer & $\begin{array}{l}\text { Mini Protein II Cell } \\
\text { Electrophoresis Power } \\
\text { Suuply EPS } 3500\end{array}$ & $\begin{array}{l}\text { BioRad } \\
\text { Pharmacia }\end{array}$ & Hercules CA, USA \\
\hline Gefrierschrank $-70^{\circ} \mathrm{C}$ & & Liebherr & Bulle, Schweiz \\
\hline Kühlschrank & & Liebherr & Bulle, Schweiz \\
\hline Magnetrührer & Ikamag RCT & IKA-Labortechnik & Staufen i.Br. \\
\hline Mikrowelle & & Philips & Hamburg \\
\hline PCR-Thermocycler & $\begin{array}{l}\text { GenAmp }{ }^{\circledR} \text { PCR- } \\
\text { System } 9700\end{array}$ & $\begin{array}{l}\text { Applied } \\
\text { BioSystems }\end{array}$ & $\begin{array}{l}\text { Foster City CA, } \\
\text { USA }\end{array}$ \\
\hline Photometer & Ultrospec 2100 pro & $\begin{array}{l}\text { Amersham } \\
\text { Biosciences }\end{array}$ & Freiburg \\
\hline Photometerküvette & Präzisionsküvette & Hellma & Müllheim \\
\hline $\begin{array}{l}\text { Pipetten }(2,5 ; 10 ; 20 ; 100 \\
200 ; 1000 \mu 1)\end{array}$ & & Eppendorf & Hamburg \\
\hline Präzisionswaage & Präzisionswaage & Sartorius & Göttingen \\
\hline Sequenzierer & $\begin{array}{l}\text { Ceq } 8000 \text { und Ceq } \\
8800 \text { Genetic Analysis } \\
\text { System }\end{array}$ & Beckman Coulter & Fullerton CA, USA \\
\hline Thermoschüttler & & GFL & Burgwedel \\
\hline UV-Illuminator & TI 3 (312nm) & Biometra & Göttingen \\
\hline Videodokumentationssystem & Biometra Biodoc & Biometria & Göttingen \\
\hline
\end{tabular}




\begin{tabular}{|l|l|l|l|}
\hline Beschreibung & Typenbezeichnung & Hersteller & Herkunftsort \\
\hline \hline Vortexer & - Vortex Genie 2 & Bender \& & Zürich, CH \\
& Hohbein AG \\
IKA Works Inc. & Wilmongton NC, \\
& - MS2 Minishaker & USA \\
\hline Zentrifugen & - Biofuge Fresco & Heraeus & Hanau \\
& - Microfuge & Sigma-Aldrich & München \\
\hline
\end{tabular}

\subsubsection{Software}

\begin{tabular}{|l|l|}
\hline Software & Hersteller \\
\hline \hline CEQ Software Version 9.0 & Beckman Coulter, Fullerton CA, USA \\
\hline
\end{tabular}

\subsubsection{Verbrauchsmaterial}

\begin{tabular}{|l|l|l|}
\hline Bezeichnung & Firma & Herkunftsort \\
\hline \hline Alufolie & Toppits & Minden \\
\hline Aqua ad iniectabilia & Delta Select & Pfullingen \\
\hline Chirurgische Einmal-Skalpelle & Braun Aesculap & Tuttlingen \\
\hline $\begin{array}{l}\text { Einmalhandschuhe } \\
\text { „ProLine Latex“ Skin PFE Powder-Free Latex } \\
\text { Exam Gloves” }\end{array}$ & Kimberly-Clark & Böblingen \\
,Examination gloves sempercare & Sempermed & Roswell GA, USA \\
\hline $\begin{array}{l}\text { Entrile” } \\
\text { Öl “Mineral Oil” }\end{array}$ & Brand & Wien, Österreich \\
& Beckman Coulter & $\begin{array}{l}\text { Fullerton CA, } \\
\text { USA }\end{array}$ \\
\hline $\begin{array}{l}\text { PCR-Reaktionsgefäße } \\
\text { MicroAmp Reaction Tube with cap“ }\end{array}$ & Applied Biosystems & $\begin{array}{l}\text { Foster City CA, } \\
\text { USA }\end{array}$ \\
\hline
\end{tabular}




\begin{tabular}{|c|c|c|}
\hline Bezeichnung & Firma & Herkunftsort \\
\hline $\begin{array}{c}\text { Pipettenspitzen ep T.I.P.S. } \\
20 \mu 1,200 \mu 1,1000 \mu 1\end{array}$ & Eppendorf Biopur & Hamburg \\
\hline Proben-Platte "Costar 6551" & Corning & $\begin{array}{l}\text { New York NY } \\
\text { USA }\end{array}$ \\
\hline Puffer-Platte „Costar 3590“ & Corning & $\begin{array}{l}\text { New York NY } \\
\text { USA }\end{array}$ \\
\hline $\begin{array}{l}\text { Reaktionsgefäße } \\
\text { - } \quad 1,7 \mathrm{ml} \text { "Safe seal Microcentrifuge } \\
\text { Tubes" } \\
\text { - } \quad 1,5 \mathrm{ml} \text { "Micro tube } 1,5 \mathrm{ml} \text { Safety Cap" }\end{array}$ & Sarstedt & $\begin{array}{l}\text { West Salt Late } \\
\text { City UT, USA } \\
\text { Nürnbrecht }\end{array}$ \\
\hline
\end{tabular}

\subsubsection{Kits}

\begin{tabular}{|l|l|l|l|}
\hline Kit & Inhalt & Firma & Herkunftsort \\
\hline \hline DNAeasy ${ }^{\circledR}$ Tissue Kit & ATL-Puffer (Gewebe-Lysis-Puffer) & Qiagen & Hilden \\
& $\begin{array}{l}\text { AE-Puffer (Elutionspuffer) } \\
\text { AW1-Puffer (Waschpuffer) } \\
\text { AW2-Puffer (Waschpuffer) } \\
\text { AL-Puffer (Präparationspuffer) } \\
\text { Proteinase K } \\
\text { Dneasy Mini spin coloumn }+2 \mathrm{ml} \\
\text { collection tubes } \\
\text { Xylen }\end{array}$ & & \\
\hline Sample Loading Solution & Sequencer-Puffer für die Probenplatte & Beckman & Fullerton CA, \\
(SLS) & Separations-Puffer pH 7,0 für die & Beckman & Fullerton CA, \\
\hline Separation Buffer & Coulter & USA \\
\hline
\end{tabular}




\begin{tabular}{|c|c|c|c|}
\hline Kit & Inhalt & Firma & Herkunftsort \\
\hline HotStar Mastermix & 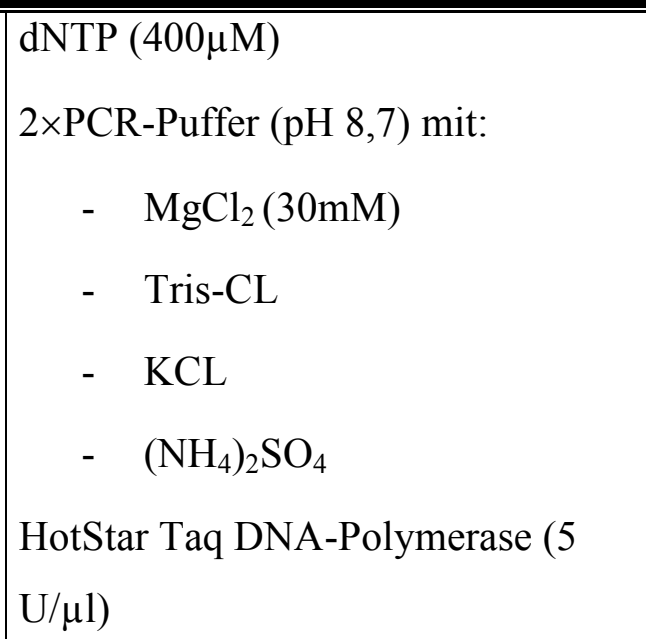 & Qiagen & Hilden \\
\hline Absolute QPCR Mix & 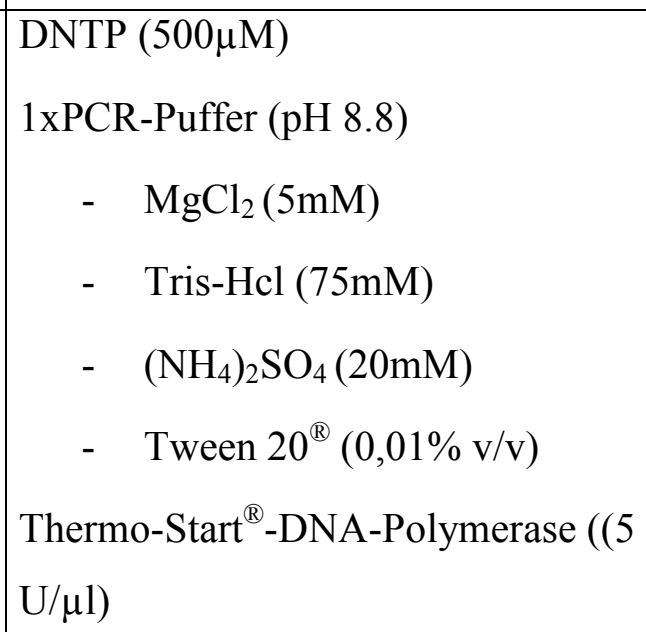 & Abgene & Epsom, UK \\
\hline
\end{tabular}

\subsubsection{Größenmarker}

\begin{tabular}{|l|l|l|l|}
\hline Beschreibung & Artikelbezeichnung & Hersteller & Herkunftsorf \\
\hline \hline $\begin{array}{l}\text { DNS-Längenstandard bis } \\
\text { 400 Bp für Sequencer }\end{array}$ & $\begin{array}{l}\text { Ceq DNA-Size Standard Kit } \\
400\end{array}$ & $\begin{array}{l}\text { Beckman } \\
\text { Coulter }\end{array}$ & $\begin{array}{l}\text { Fullerton CA, } \\
\text { USA }\end{array}$ \\
\hline $\begin{array}{l}\text { DNS-Längenstandard für } \\
\text { Gelelektrophorese }\end{array}$ & $100 \mathrm{bp}$ DNA ladder & Promega & Mannheim \\
\hline
\end{tabular}

\subsubsection{Chemikalien}

\begin{tabular}{|l|l|l|}
\hline Name & Hersteller & Herkunftsort \\
\hline \hline $\begin{array}{l}\text { Agarose ,peq GOLD Universal } \\
\text { Agarose“ }\end{array}$ & PeqLab & Erlangen \\
\hline
\end{tabular}




\begin{tabular}{|l|l|l|}
\hline Name & Hersteller & Herkunftsort \\
\hline \hline Aqua dest & & \\
\hline Borsäure & Merck & Darmstadt \\
\hline Bromphenolblau & Sigma-Aldrich & Deisenhofen \\
\hline DNTP & Promega & Mannheim \\
\hline EDTA & Sigma-Aldrich & Deisenhofen \\
\hline EDTA 0,5M pH 8.0 & Gibco BRL & Eggenstein \\
\hline Ethanol 96\% & J.T.Baker & VA Deuter, \\
& & Holland \\
\hline Ethidiumbromid & Sigma-Aldrich & Deisenhofen \\
\hline NaCl & Merck & Darmstadt \\
\hline Tris-Base (Trishydroxymethyl- & Merck & \\
\hline
\end{tabular}

\subsubsection{Puffer und Gele}

\begin{tabular}{|l|l|}
\hline Puffer/Lösung & Ingredienzien und Menge \\
\hline \hline $10 \times$ TBE (Tris-Borat-EDTA-Puffer) & $\begin{array}{l}54,45 \mathrm{~g} \text { Tris base } \\
27,5 \mathrm{~g} \text { Borsäure } \\
20 \mathrm{mM} \text { EDTA }(0,5 \mathrm{M}) \mathrm{ph} 8,0 \\
\text { ad } 500 \mathrm{ml} \text { Aqua dest. }\end{array}$ \\
\hline $1 \times$ TBE & $\begin{array}{l}100 \mathrm{ml} 10 \times \mathrm{TBE}-\mathrm{Puffer} \\
900 \mathrm{ml} \text { Aqua dest. }\end{array}$ \\
\hline $1,5 \%$ Agarose-Gel & $\begin{array}{l}1,5 \% \text { Agarose } \\
\text { in } 1 \times \mathrm{TBE}-\text { Puffer } \\
10 \mathrm{mg} / \mathrm{ml} \text { Ethidiumbromid }\end{array}$ \\
\hline
\end{tabular}




\subsubsection{PCR-Primer}

Die beiden Primer D18S254 und D18S474 wurden jeweils von der Firma Sigma Proligo auf Wunsch hergestellt und am 5'-Ende der Forward-Primer mit dem Farbstoff Dye4 markiert. Es handelt sich bei den beiden Regionen um Dinukleotid-Wiederholungen ((CA)n). Die PrimerSequenzen, Fragmentgrößen, und chromosomale Lage wurden in der Genome Database gefunden (http://www.gdb.org) (siehe Tabelle 2).

\begin{tabular}{|c|c|c|c|c|c|c|c|}
\hline Primer & Region & Verlauf & Sequenz & Repeat & $\begin{array}{l}\text { Markier- } \\
\text { ung }\end{array}$ & $\begin{array}{l}\text { Größe } \\
\text { (bp) }\end{array}$ & Firma \\
\hline$\overline{\mathrm{D} 8 \mathrm{~S} 254}$ & $8 \mathrm{p} 22$ & $\begin{array}{l}\text { Forward } \\
\text { Reverse }\end{array}$ & $\begin{array}{l}\text { 5'-TGC CGG ACA TAC ATT AGT GA } \\
\text { 5-TTG TAA ACA CCA CAA GCA GG }\end{array}$ & $\overline{(C A) n}$ & Dye 4 & $\mid 55-75$ & $\begin{array}{l}\text { Sigma } \\
\text { Proligo }\end{array}$ \\
\hline D18S474 & $18 \mathrm{q} 21.1$ & $\begin{array}{l}\text { Forward } \\
\text { Reverse }\end{array}$ & $\begin{array}{l}\text { 5'-TGG GGT GTT TAC CAG CAT C } \\
\text { 5'-TGG CTT TCA ATG TCA GAA GG }\end{array}$ & $(\mathrm{CA}) \mathrm{n}$ & Dye 4 & $\begin{array}{l}119- \\
145\end{array}$ & $\begin{array}{l}\text { Sigma } \\
\text { Proligo }\end{array}$ \\
\hline
\end{tabular}

Tabelle 2: Eigenschaften der verwendeten Mikrosatellitenprimer D8S254 und D18S474 


\subsection{Methoden}

Zur Untersuchung der Patientenproben auf den Verlust eines Allels in der Tumorprobe wurden mittels Polymerase-Kettenreaktion (PCR) hochpolymorphe Mikrosatelliten amplifiziert. Die genomische Variation in der Tumorprobe kann auf verschiedene Weisen detektiert werden, wobei die Verwendung von fluoreszenzmarkierten Produkten sensitiver ist als die Detektion durch Autoradiographie oder silbergefärbte Gele (Christensen et al., 1999). Für die Mikrosatellitenregionen 8p22 und 18q21.1 wurden Primerpaare bekannter Marker ausgewählt, welche mit dem Farbstoff Dye4 fluoreszenzmarkiert wurden (siehe Tabelle 2).

Die Verwendung von hochpolymorphen Markern ermöglicht nach Amplifizierung eine Unterscheidung beider Allele in der untersuchten chromosomalen Region. Dazu wurde zunächst die DNA aus der normalen Kolon-Schleimhaut und aus der Tumorschleimhaut isoliert und mittels PCR amplifiziert. Danach wurden die Produkte auf einem Sequencer der Firma Beckman Coulter elektrophoretisch aufgetrennt und anhand der entsprechenden Software analysiert. Lag ein heterozygoter Zustand im Normalgewebe vor, wurde der entsprechende Primer als informativ bezeichnet. Wenn im Vergleich von Normal- zu TumorDNA ein Verlust der Signalintensität in einem Allel der Tumorschleimhaut von über 30\% auftrat, lag ein Verlust der Heterozygotie (LOH) vor, entsprechend der Deletion eines Allels.

\subsubsection{Histopathologische Untersuchungen}

Im Rahmen eines interdisziplinären Projektes unter Beteiligung der Chirurgischen Universitätsklinik, der Medizinischen Klinik, des Institutes für Humangenetik und des Institutes für Pathologie (Interdisziplinäre Forschungsgruppe Kolonkarzinom Würzburg, gefördert vom IZKF Würzburg 1.5.2001-30.04.2004) wurden 169 kolorektale Karzinome (und Normalschleimhaut) in der Medizinischen Klinik asserviert und untersucht. Von jedem Paraffinblock wurden Paraffinschnitte angefertigt, die routinemäßig mit Hämatoxylin-Eosin (HE) gefärbt wurden. 
Histologisch wurden die Tumoren nach der WHO-Klassifikation (Sobin, 1977) klassifiziert. Bezüglich der Tumorstadien erfolgte eine Unterteilung nach der TNM-Klassifikation der UICC (1987).

Folgende Parameter wurden erhoben:

- Infiltrationstiefe des Tumors (pT-Kategorie)

- Lymphknotenbefall (pN-Kategorie)

- Fernmetastasen (pM-Kategorie)

- Differenzierungsgrad der Tumoren (Grading - G-Kategorie)

\subsubsection{Molekulargenetische Methoden}

\subsubsection{Gewinn des Tumormaterials}

Für die molekularpathologischen Untersuchungen wurde Gewebe von 144 Tumoren aus dem Zeitraum von 1999 bis 2002 zur DNA-Präparation gewonnen. Dazu wurden jeweils vier bis fünf ca. $5 \mathrm{~mm}^{2}$ große Proben normaler Kolonschleimhaut und Tumorgewebe entnommen und innerhalb von 30 Minuten nach der Operation mit flüssigem Stickstoff schockgefroren. Anschließend wurden die Proben bei $-80^{\circ} \mathrm{C}$ bis zur Verwendung aufbewahrt. Von jedem Tumor wurden die den für die molekularen Analysen entnommenen Gewebeproben benachbarten Tumoranteile in Paraffin eingebettet und als morphologisches Referenzmaterial archiviert.

\subsubsection{DNA-Extraktion}

Um die Mikrosatellitenuntersuchung durchführen zu können, musste zunächst die DNA aus Tumor und korrespondierender Normalschleimhaut isoliert werden. Dafür wurde das DNeasy-Extraktionsset der Firma Qiagen ${ }^{\circledR}$ verwendet, wobei nach dem beigefügten Protokoll für humanes Gewebe vorgegangen wurde. Alle Reagenzien wurden stets dicht verschlossen und örtlich getrennt von jeglicher DNA aufbewahrt. Zur Zerkleinerung der Schleimhautproben wurden sterile Skalpelle eingesetzt. 
Die Extraktion der DNA gelang wie folgt:

Von den größeren Schleimhautproben wurden 4-5 Fragmente von insgesamt weniger als 25mg (überprüft mit der Präzisionswaage) abgetrennt und in ein autoklaviertes $2 \mathrm{ml}$ Eppendorf-Gefäß verbracht, mit $1200 \mu 1$ Xylen vermischt und gründlich mit einem Vortexer vermengt. Anschließend wurde für 5 Minuten bei maximaler Geschwindigkeit (13000 Umdrehungen/ Minute (rpm)) zentrifugiert. Der Überstand wurde verworfen. Um die verbliebenen Xylenreste zu entfernen wurde 1200 $\mu 1$ 96\%iger Ethanol dazugegeben, mittels Vortexer vorsichtig durchmischt und für 5 Minuten bei maximaler Geschwindigkeit zentrifugiert. Das überschüssige Ethanol wurde vorsichtig abpipettiert. Der Waschvorgang wurde noch einmal wiederholt. Das offene Eppendorfgefäß wurde nun für 10-15 Minuten bei $37^{\circ} \mathrm{C}$ im Wasserbad (Thermoschüttler) inkubiert, bis das restliche Ethanol verdampft war.

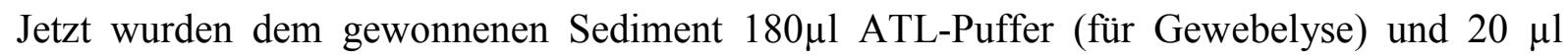
Proteinase $\mathrm{K}$ hinzugefügt, gut durchmischt und bei $55^{\circ} \mathrm{C}$ für $1-3$ Stunden im Thermoschüttler inkubiert bis das Gewebe vollständig lysiert war. Nach der Lyse wurde für $15 \mathrm{~s}$ mit dem

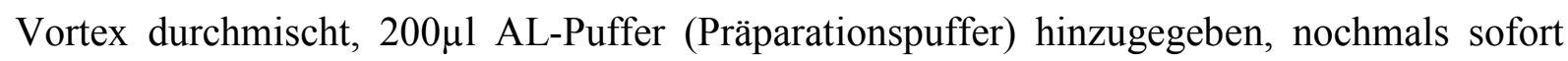
gründlich durchmischt und für 10 Minuten bei $70^{\circ} \mathrm{C}$ im Wasserbad inkubiert. Danach wurde $200 \mu 1$ Ethanol 96\% dazugegeben und gründlich durchmischt. Das Gemisch wurde jetzt komplett in eine gesonderte DNA-Säule („Dneasy Mini spin column“) überführt und in ein spezielles 2ml-Übergefäß (,„collection tube“) platziert, anschließend für 1 Minute bei 8000 rpm zentrifugiert. Das Filtrat wurde samt des Übergefäßes verworfen, die DNA-Säule in ein neues 2ml-Übergefäß platziert und mit 500 $\mu 1$ AW1-Puffer (Waschpuffer) versehen. Anschließend wurde nochmals für 1 Minute bei 8000rpm zentrifugiert. Erneut wurde das Filtrat samt des Übergefäßes verworfen, die DNA-Säule in ein neues 2ml-Übergefäß

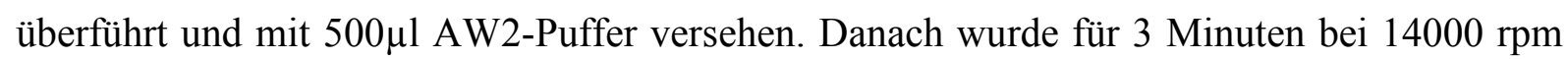
zentrifugiert, um die Membran der DNA-Säule zu trocknen. Das Übergefäß samt Puffer wurde verworfen. Die DNA-Säule wurde in ein 1,5ml Eppendorf-Gefäß gesetzt und $200 \mu 1$ AE-Puffer direkt auf die DNA-Membran pipettiert. Anschließend wurde für 1 Minute bei Raumtemperatur inkubiert und für 1 Minute bei 8000rpm zentrifugiert. In dem EppendorfGefäß befand sich nun die eluierte DNA. Die Eluierung wurde mit einem neuen Gefäß nochmals wiederholt. Das Resultat waren zwei DNA-Eluate, deren Reinheit und Konzentration mit Hilfe eines Photometers überprüft werden konnte. 


\subsubsection{Konzentrationsbestimmung von DNA}

Durch ihr charakteristisches Absorptionsmaximum bei $\lambda=260 \mathrm{~nm}$ lassen sich Nukleinsäuren photometrisch quantifizieren. Dabei entspricht eine $E_{260}$ von 1 ca. $40 \mu \mathrm{g} / \mathrm{ml}$ DNA. Verunreinigungen mit Proteinen, deren Maximum bei $\lambda=280 \mathrm{~nm}$ liegt, konnten das Ergebnis verfälschen. Das Verhältnis der Absorption bei $\lambda=260 \mathrm{zu} \lambda=280 \mathrm{~nm}$ betrug für reine DNA 1,6 .

Anschließend wurden die DNA-Lösungen mit destilliertem Wasser auf 10ng/ $\mu 1$ verdünnt und bei $-20^{\circ} \mathrm{C}$ gelagert. Zur späteren Verwendung wurde die DNA nur kurzfristig aufgetaut und anschließend sofort wieder eingefroren.

\subsubsection{Verdünnung der Primer}

Die Primer mussten mit destilliertem Wasser gelöst und auf die gewünschte Menge verdünnt werden. Dazu wurde zuerst auf $100 \mathrm{pmol} / \mu 1$ verdünnt und anschließend zu jeweils $10 \mathrm{pmol} / \mu 1$ aliquotiert. Da die mit Farbstoff-gelabelten Forward-Primer lichtempfindlich sind, mussten sie mit Alufolie vor Sonnenlicht geschützt werden.

\subsubsection{Polymerase-Ketten-Reaktion (engl. Polymerase chain reaction, PCR)}

Durch diese von Mullis erstmals 1986 (Mullis et al., 1986) beschriebene Methode lassen sich in vitro einzelne Sequenzen aus genomischer DNA mit dem Enzym TaqDNA-Polymerase exponentiell vervielfältigen, um ausreichend genetisches Material für weitere Untersuchungen, wie z.B. eine Sequenzierung oder Fragmentlängenanalyse zur Verfügung zu stellen. Anhand der Information über die gesuchte DNA-Sequenz werden zwei OlinukleotidPrimer (Amplimere) herangezogen, die im Optimalfall zwischen 18 und 25 Nukleotiden lang sind und die in ihrer Basensequenz genau den Bereichen entsprechen, die die gesuchte Sequenz flankieren.

Der Ablauf einer PCR besteht aus einer Folge von 20 bis 30 Zyklen mit jeweils drei Schritten:

- Denaturierung (Melting): Erhitzung auf $93^{\circ}$ bis $95^{\circ} \mathrm{C}$

Dadurch werden die Wasserstoffbrückenbindungen aufgebrochen und die DNA-Stränge getrennt.

- Anlagerung der Primer (Annealing): 
Diese erfolgt in Abhängigkeit von der Schmelztemperatur der zu erwarteten Doppelstrang-DNA und der Basenzusammensetzung der Primer bei ca. $50^{\circ}$ $70^{\circ} \mathrm{C}$

- DNA-Synthese (Elongation):

Diese erfolgt i.d.R. bei $70^{\circ}$ bis $75^{\circ} \mathrm{C}$. In Gegenwart einer geeigneten hitzstabilen DNA-Polymerase und der 4 Desoxynucleotidtriphosphate dATP, dCTP, dGTP und dTTP beginnt an den Primern die Synthese der neuen DNAStränge, die zum jeweils ursprünglichen DNA-Strang der Ziel-DNA komplementär sind.

Die Orientierung der Primer muss so gewählt werden, dass die Richtung der Synthese des neuen Stranges von dem einen Primer in Richtung der Bindungstelle des anderen Primers verläuft. Auf diese Weise können die neu synthetisierten Stränge ihrerseits wiederum als Matrizen für die weitere DNA-Synthese dienen, was $\mathrm{zu}$ einer Kettenreaktion mit exponentieller Produktzunahme führt.

Die PCR findet in einem Thermocycler statt, der die Reagenzien präzise auf die gewünschten Temperaturen der einzelnen Schritte erhitzt und abkühlt. Durch den beheizbaren Deckel wird eine Verdunstung verhindert.

Zur Durchführung der PCR benötigt man folgende Komponenten:

1. Die Original-DNA, die den zu amplifizierenden Abschnitt enthält.

2. Zwei Primer, Forward- und Reverseprimer, um Anfang und Ende des gesuchten Abschnitts festzulegen. Informationen zu den beiden hier verwendeten Primern unter Kapitel 3.2.8, Seite 13)

3. HotStarMastermix. Dieser enthält:

- Hitzestabile DNA-Polymerase (Taq DNA Polymerase), um den festgelegten Abschnitt zu amplifizieren. Bei der Taq-Polymerase des HotStar-Kits handelt es sich um eine sogenannte ,hot-start-Polymerase“, d.h. sie benötigt eine Aktivierungstemperatur von $95^{\circ} \mathrm{C}$ für 15 Minuten

- Nukleotide (dATP, dCTP, dGTP und dTTP) als Bausteine für den neusynthetisierten DNA-Strang

- PCR-Puffer für eine für die Tag-Polymerase geeignete chemische Umgebung.

4. Aqua dest. 
5. PCR Reaktionsgefäße

6. Pipetten

7. Pipettenspitzen

8. Halterung für die Reaktionsgefäße

9. Thermocycler

Ansatz für die PCR:

\begin{tabular}{|c|c|c|c|}
\hline Reagenzien & Konzentration & Menge & Endkonzentration \\
\hline DNA & $10 \mathrm{ng} / \mu \mathrm{l}$ & $1 \mu 1$ & $1 / 25(1 / 50)$ \\
\hline „Hotstar“-Mastermix & Siehe Kapitel 3.2.4 & $12,5 \mu \mathrm{l}(25 \mu \mathrm{l})$ & $\begin{array}{l}2,5 \mathrm{U} \text { HotStar Taq DNA- } \\
\text { Polymerase } \\
1 \times \text { PCR-Puffer mit } 15 \mathrm{mM} \\
\mathrm{MgCl}_{2} \\
\text { jew. } 200 \mu \mathrm{M} \text { dNTP }\end{array}$ \\
\hline Forward Primer & $10 \mathrm{pmol} / \mu \mathrm{l}$ & $1 \mu 1$ & 0,2 pmol oder $0,1 \mathrm{pmol}$ \\
\hline Reverse Primer & $10 \mathrm{pmol} / \mu \mathrm{l}$ & $1 \mu 1$ & 0,2 pmol oder $0,1 \mathrm{pmol}$ \\
\hline Aqua dest. & - & ad $25 \mu 1($ ad $50 \mu 1)$ & - \\
\hline
\end{tabular}

Anfangs wurde eine Endmenge von $50 \mu 1$ verwendet; die dafür benötigten Mengen und die jeweiligen Endkonzentrationen stehen in Klammern. Als die Methode besser etabliert war, wurde aus Kostengründen nur noch die Halbe Menge des HotStar-Mastermix verwendet. Zur Negativkontrolle wurde als Leerwert stets ein Ansatz ohne DNA mit amplifiziert um eine mögliche Kontamination der Reagenzien zu erkennen.

\section{PCR-Bedingungen:}

Um sicherzustellen, dass sich Ausgangs-DNA und Primer vollständig voneinander getrennt haben und zur Aktivierung der Taq-Polymerase wird im ersten Zyklus 15 Minuten denaturiert.

Am Ende der Zyklen wird noch einmal 15 Minuten elongiert. 
Der Ablauf sah daher wie folgt aus:

Für D8S254:

1. $95^{\circ} \mathrm{C}$ für $15 \mathrm{~min}$

2. $95^{\circ} \mathrm{C}$ für $30 \mathrm{~s}$

3. $54^{\circ} \mathrm{C}$ für $30 \mathrm{~s}$

4. $72^{\circ} \mathrm{C}$ für $30 \mathrm{~s}$

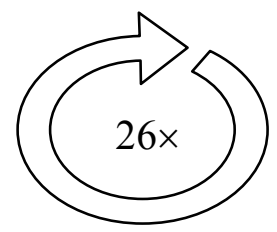

5. $72^{\circ} \mathrm{C}$ für $15 \mathrm{~min}$

Für D18S474:

1. $95^{\circ} \mathrm{C}$ für $15 \mathrm{~min}$

10. $95^{\circ} \mathrm{C}$ für $30 \mathrm{~s}$

2. $54^{\circ} \mathrm{C}$ für $30 \mathrm{~s}$

3. $72^{\circ} \mathrm{C}$ für $30 \mathrm{~s}$

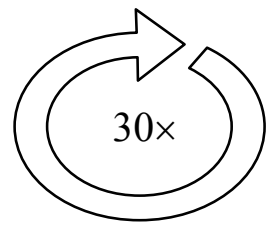

4. $72^{\circ} \mathrm{C}$ für $15 \mathrm{~min}$

Den Erfolg der PCR kann man anschließend anhand einer Gelelektrophorese feststellen.

\subsubsection{Nachbearbeitung der amplifizierten DNA}

Da die DNA während der Elektrophorese nicht sichtbar ist, musste die amplifizierte DNA, auch template genannt, mit einem Farbstoff markiert werden. Dieser trennt sich während des Laufes in drei Farbfronten auf und erleichtert somit das Erkennen des Fortschritts der Gelelektrophorese. Außerdem beschwert er die DNA und ermöglicht so ein leichteres „Laden“ der Taschen (siehe Kapitel 3.3.2.7, Seite 21). Als Farbstoff diente Bromphenolblau. Hierzu wurden $10 \mu 1$ der amplifizierten DNA mit $5 \mu 1$ Farbstoff (Bromphenolblau) in ein gesondertes Gefäß zusammenpipettiert. Bei dem Längenstandard wurde auf die gleiche Weise verfahren.

Die restlichen 15 bzw. anfänglich $35 \mu \mathrm{l}$ des PCR-Produktes wurden für die Längenfragmentanalyse (siehe Kapitel 3.3.2.8, Seite 23) auf $200 \mu 1$ mit Aqua ad iniectabilia verdünnt. 


\subsubsection{Agarose-Gelelektrophorese}

Agarose-Gel ist die Bezeichnung für ein Gel, das in der Gelelektrophorese zur Trennung von Substanzen, hier DNA, eingesetzt wird. Es wird durch Zugabe von Agarose zu einem Puffer (TBE-Puffer) hergestellt.

Bei der Agarose-Gelelektrophorese handelt es sich um eine molekularbiologische Methode, um DNA-Stränge nach ihrer Größe zu trennen und ihre Größe anhand eines Vergleichs mit Strängen bekannter Größe (DNA-Längenstandard) zu bestimmen. Mit Hilfe eines elektrischen Feldes werden die aufgrund der Phosphatreste negativ geladenen DNA-Moleküle durch die Gelmatrix in Richtung Anode gezogen, wobei kleinere DNA-Moleküle schneller durch das Gel wandern, wodurch eine Auftrennung der Stränge der Größe nach ermöglicht wird. Der DNA-Längenstandard, auch DNA-Leiter genannt, besteht aus einem Gemisch von DNASträngen bekannter, unterschiedlicher Länge. Er dient als vergleichender Marker zur Größenund Mengenbestimmung der zu bestimmenden DNA.

Für die Agarose-Gelelektrophorese werden benötigt:

- DNA-template (isolierte, amplifizierte DNA)

- DNA-Längenstandard

- $\quad$ TBE-Puffer

- Agarose

- Aqua dest.

- Ethidiumbromid

- Farbmarker (hier: Bromphenolblau) (zum Beladen der DNA und zum leichteren Erkennen des Fortschritts der Elektrophorese)

- Schlitten

- Kamm (zur Taschenbildung für die Auftragung der DNA)

- Gelkammer

- Elektroden 
Ethidiumbromid wird zum Anfärben der Nukleinsäuren bei der Gelelektrophorese angewandt. Einzelne Ethidiumbromidmoleküle interkalieren dabei zwischen die Basen der DNA, wodurch sich das Anregungsspektrum von Ethidiumbromid verändert. Die Fluoreszenz der Substanz wird dadurch bei Anregung durch ultraviolettes Licht stark erhöht. Auf diese Weise leuchten im Agarosegel die Stellen hell auf, an denen sich Nukleinsäuren befinden, während Stellen ohne DNA dunkel bleiben. Die Lichtintensität ist dabei proportional zur vorhandenen DNA-Menge

\section{Durchführung der Agarose-Gelelektrophorese:}

Zur Herstellung einer 1,4\% Agaroselösung in TBE-Puffer wurde 0,6mg Agarose in 40ml TBE Puffer vermischt und anschließend in der Mikrowelle drei- bis viermal kurz aufgekocht bis sich die Agarose vollständig aufgelöst hat. Jetzt wurde $1 \mu 1$ Ethidiumbromid zu dem Gel dazupipettiert, gut vermischt und anschließend auf ca. $60^{\circ} \mathrm{C}$ abgekühlt. Der Kamm wurde an die dazu vorgesehene Halterung des Schlittens angebracht. Der Schlitten wurde in der Gelkammer so befestigt, dass die Gummienden des Schlittens diesen luftdicht abschließen konnten. Das Gel konnte jetzt langsam und ohne Luftblasen in die Kammer gegossen werden. Durch das Luftdichte Abschließen konnte ein Austreten des Gels verhindert werden. Nach weiterem Abkühlen und Festwerden des Gels, nach ca. 10 Minuten, wurde der Kamm entfernt - Die Aussparungen, die im Gel zurückbleiben, werden Taschen genannt - und der Schlitten um $90^{\circ}$ in der Gelkammer gedreht, so dass die Taschen am Kathodenende zum Liegen kamen. Die Gelkammer wurde mit $1 \times$ TBE-Puffer so weit aufgefüllt, dass der Schlitten mit dem Gel komplett mit dem Puffer bedeckt war. Jetzt konnten jeweils 5-10 $\mu 1$ der mit Bromphenolblau markierten DNA in die Taschen aufgetragen werden. Die letzte Tasche wurde mit dem Längenstandard befüllt. Nach dem Auftragen wurden die Elektroden an der Gelkammer befestigt und das elektrische Feld auf 100 Volt eingestellt. Die DNA wandert aufgrund der negativen Ladung Richtung Anode und wird anhand ihrer Größe aufgetrennt. Die durch den Farbstoff erzeugten Farbbanden zeigen den Fortschritt der Gelelektrophorese an. Nach üblicherweise 45 Minuten, wenn die schnellste Farbfront das Ende des Gels erreicht hat, wurde die Spannung unterbrochen und die Elektrophorese beendet.

Zur Bewertung der Elektrophorese wurde der Schlitten vorsichtig aus der Gelkammer entnommen und unter einem UV-Illuminator betrachtet. Durch das Ethidiumbromid fluoresziert die DNA im ultravioletten Licht.

Wenn die Gelelektrophorese positiv ausfiel, konnte die Fragmentlängenanalyse zur LOHAnalyse am Sequencer stattfinden. 


\subsubsection{Fragmentlängenanalyse}

Die Fragmentlängenanalyse erfolgt nach dem Prinzip der Glaskapillar-Elektrophorese:

Wenn eine Spannung an eine offene Kapillare (hier mit einem inneren Durchmesser von $75 \mu \mathrm{m}$ ) angelegt wird, die mit einer einheitlichen Lösung (hier das jeweils zu analysierende DNA-Fragment) gefüllt ist, erfolgt die Separation anhand der Kombination des elektrophoretischen und des elektroosmotischen Flusses. Der elektrophoretische Fluss ist die Bewegung von geladenen Molekülen in einer Lösung in Richtung der entgegengesetzt geladenen Elektrode. Der elektroosmotische Fluss kommt durch den gesamten Elektrolytfluss zustande, der durch die Ladung der inneren Kapillare durch das angelegte Potential bedingt wird. Wenn die Kapillare mit einer Elektrolytlösung mit einem pH Wert größer als 1,5 in Verbindung kommt, wird die innere Kapillarwand negativ geladen (bedingt durch eine Silanol-Gruppe). In Folge dessen bleibt eine geringe positive Restladung in der Elektrolytlösung, die einen Fluss zu Kathode bedingt, den sog elektroosmotischen Fluss. Kationen haften also an der Kapillarwand und bilden eine elektrische Doppelschicht. Wird nun eine Spannung angelegt, kommt es zu einem Fluss der Elektrolytlösung in Richtung Kathode. Anhand der Tatsache, dass der elektroosmotische Fluss stets von größerer Wirkung ist als der elektrophoretische, wandern sowohl positiv geladene Kationen als auch negativ geladene Anionen in Richtung Kathode. Kationen erreichen die Kathode zuerst, da sowohl der elektrophoretische als auch der elektroosmotische Fluss direkt in deren Richtung führen. Die Zeit, die für den Kapillardurchfluss eines jeden Moleküls benötigt wird, ist von vielen Faktoren, wie der Kapillarlänge und -durchmesser, den Moleküleigenschaften, dem pH-Wert und der angelegten Spannung, abhängig. Aus diesem Grund werden Moleküle unterschiedlicher Eigenschaften auch zu unterschiedlichen Zeiten detektiert werden.

Bei der DNA bedingt nun die Phosphatgruppe der Nukleotide eine sehr starke negative Ladung. Anhand der unterschiedlichen Größe der Fragmente kommt es zu unterschiedlichen Durchlaufzeiten und zu unterschiedlicher Detektion mittels eines Lasers am Ende der Kapillare.

Für die Fragmentlängenanalyse standen mehrere 8 Kanal Capillar Elektrophorese Sequenzautomaten (CEQ 8000 und CEQ 8800) der Firma Beckman Coulter zur Verfügung. 
Zur Analyse am Sequencer wurden folgende Materialien benötigt:

- Amplifizierte DNA-Fragmente

- $\quad$ SLS-Puffer

- Separationspuffer

- Längenstandard „Ceq DNA size standard kit 400“

- Ö1 ( „Mineral Oil“)

- Puffer-Platte

- Probenplatte

- $\quad$ Sequencer CEQ 8000 oder 8800

- Aqua ad iniectabilia

Für die Fragmentlängenanalyse wurde die amplifizierte DNA beider Regionen nochmals mit Aqua ad iniectibila auf $200 \mu 1$ verdünnt. Die Puffer-Platte wurde mit jeweils $40 \mu 1$ des Separationspuffers beladen.

Für die Probenplatte galten für die jeweiligen Regionen unterschiedliche Ansätze.

Ansatz für D8S254:

\begin{tabular}{|l|l|}
\hline Reagenz & Menge \\
\hline Amplifizierte DNA & $0,3 \mu 1$ von $200 \mu 1$ \\
\hline DNS-Längenstandard & $0,3 \mu 1$ \\
\hline SLS-Puffer & Ad $40 \mu 1$ \\
\hline Öl & 1 Tropfen \\
\hline
\end{tabular}

Ansatz für D18S474:

\begin{tabular}{|l|l|}
\hline Reagenz & Menge \\
\hline Amplifizierte DNA & $1 \mu 1$ von $200 \mu 1$ \\
\hline DNS-Längenstandard & $0,3 \mu 1$ \\
\hline SLS-Puffer & Ad $40 \mu 1$ \\
\hline Öl & 1 Tropfen \\
\hline
\end{tabular}


Die Gelpräparation, Denaturierung, Datenerhebung und Datenauswertung erfolgten dann vollautomatisch.

Die Bedingungen der Sequenzierung waren folgende (Programm „Frag 50/50“):

- Denaturierung für 120 Sekunden bei $90^{\circ} \mathrm{C}$

- Injektion für 30 Sekunden bei 2000V

- Separation für 50 Minuten bei $6000 \mathrm{~V}$

- Kapillartemperatur $50^{\circ} \mathrm{C}$

\subsubsection{Auswertung}

Die Auswertung der Daten erfolgte mit der Version 9.0 der „CEQ 8800“-Software der Firma Beckman Coulter.

\subsection{Heterozygotendiagnostik}

Durch die verschiedene Anzahl von Wiederholungseinheiten innerhalb der Mikrosatellitensequenzen ergaben sich zwei in der Größe verschiedene DNA-Fragmente, die sich analog zu den Dinukleotid-Wiederholungen der beiden Primer D8S254 und D18S474 um mindestens 2 Nukleotide unterschieden. Die Bandenlage und Allelsignalstärke der Tumorund Normalschleimhaut-DNA wurden miteinander verglichen, wobei jeweils das Verhältnis der beiden Allele einer DNA zueinander entscheidend war, nicht deren absolute Höhe. Es wurde also jeweils das Verhältnis des Allel $1 \mathrm{zu}$ dem Allel 2 berechnet und die beiden Verhältnisse der Normal- und Tumorschleimhaut in Relation zueinander gestellt. (siehe Gleichung 1).

\begin{tabular}{|c|}
\hline Allel N-1 \\
\cline { 2 - 2 } Allel N-2 \\
Allel T-1 \\
Allel T-2
\end{tabular}

Gleichung 1: $N=$ Normalschleimhaut-DNA, $T=$ Tumorschleimhaut-DNA

Allel N-1 und Allel T-1 sind die Peak-Höhen des Allel 1 der Normal- bzw. des korrespondierenden Allel 1 der Tumorschleimhaut

Allel N-2 und Allel T-2 sind die Peak-Höhen des Allel 2 der Normal- bzw. des korrespondierenden Allel 2 der Tumorschleimhaut 
Anhand des Quotienten der Verhältnisse der beiden Allele konnte man einen chromosomalen Verlust feststellen. Lag der Quotient über 1,3 wurde dies als LOH im Allel 1 gewertet. Analog dazu wurde beim zweiten Allel ab einem Quotienten unter 0,7 verfahren. Alle Ergebnisse wurden rechnerisch bestimmt und nicht per Augenmaß (siehe Abbildung 2).

Ein Verlust der Heterozygotie lag also dann vor, wenn ein Allelsignal auf weniger als $30 \%$ reduziert oder vollständig verloren gegangen war. Der cut-off-Wert lag demnach bei $30 \%$.

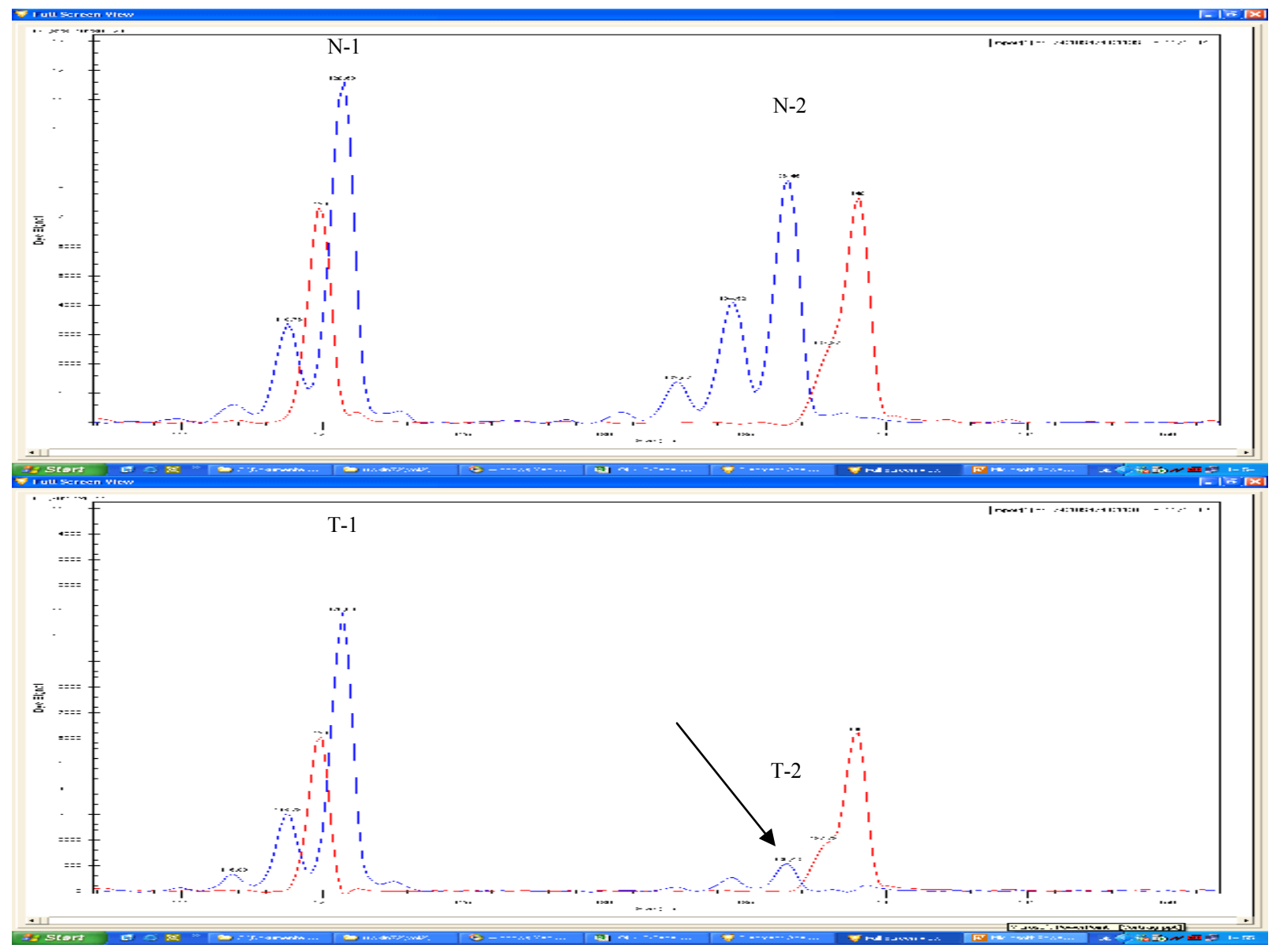

Abbildung 2: Beispiel eines LOH im Allel T-2. Sowohl in der Normal-schleimhaut-Probe (oben) als auch im Tumorgewebe (unten) sind zwei Allele (N-1 bzw. N-2 für die beiden Allele des normalen Schleimhautgewebes und T-1 bzw. T-2 für die beiden Allele des Tumorgewebes) zu erkennen. Im Tumorgewebe (unten) ist das zweite Allel (T-2) deutlich reduziert (Pfeil). Sobald dieser Verlust mehr als $30 \%$ betrug, wurde er als LOH gewertet, wie in diesem Beispiel.

Die kleineren Signale vor den Hauptpeaks sind sog. Stotterbanden, ohne Auswirkungen. Die roten Peaks kennzeichnen den Längenstandard 


\subsection{Homozygote Fälle}

Homozygote Proben, in denen beide Allele den selben Haplotyp besaßen, also übereinander dargestellt wurden, mussten für die Analysen ausgeschlossen werden, sie waren nichtinformativ (siehe Abbildung 3).

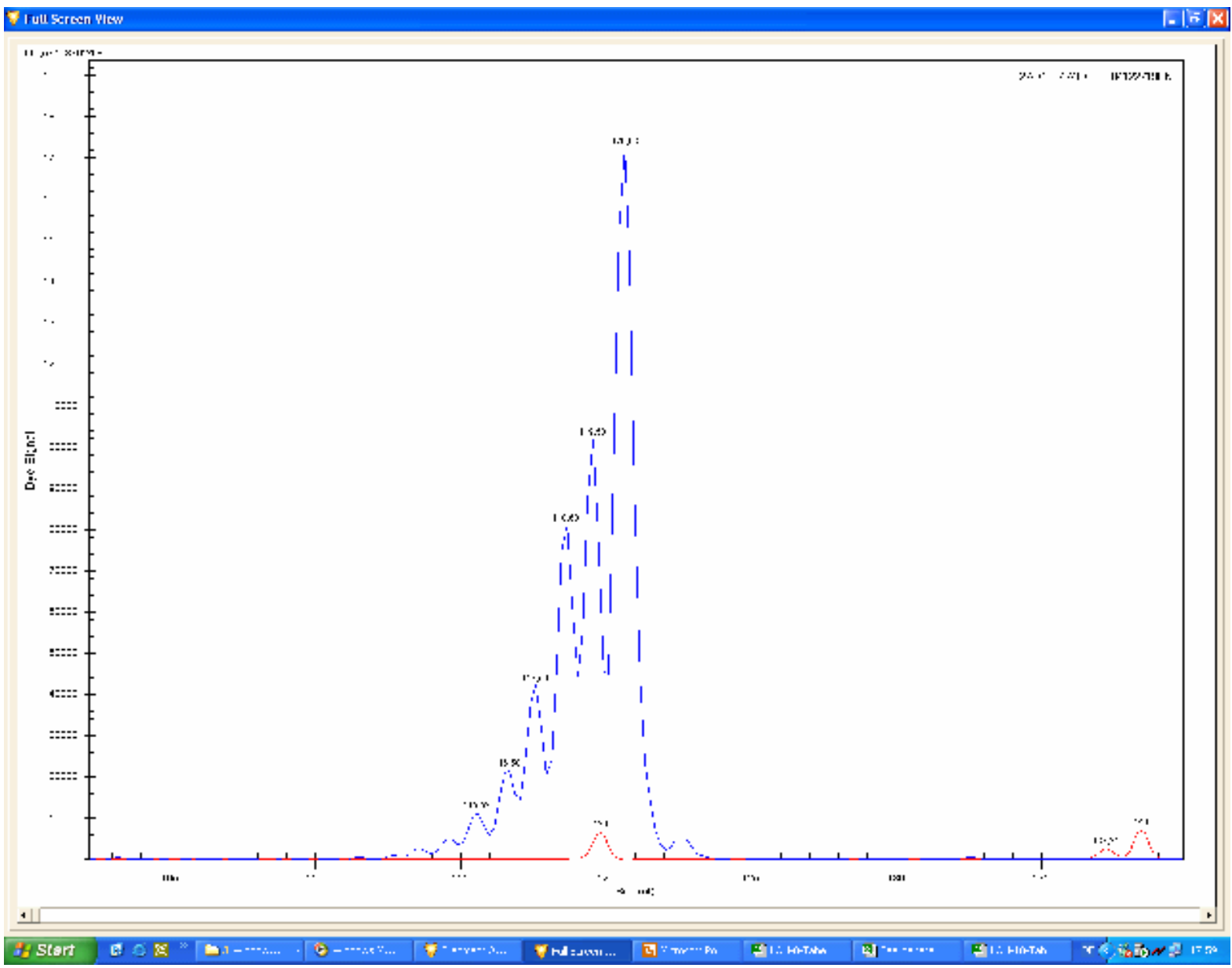

Abbildung 3: Homozygoter, nicht-informativer Fall. Beide Allel stellen sich hintereinander dar und somit kann nicht beurteilt werden, ob ein Allel deletiert ist oder nicht. Die roten Peaks kennzeichnen den Längenstandard 


\subsection{Mikrosatelliteninstabilität}

Eine Mikrosatelliteninstabilität (MSI) lag vor, wenn eine zusätzliche Bande bzw. Banden im Bereich der spezifischen Allele auftraten oder wenn ein Verschieben (shift) eines Allelsignals nachweisbar war (siehe Abbildung 4).
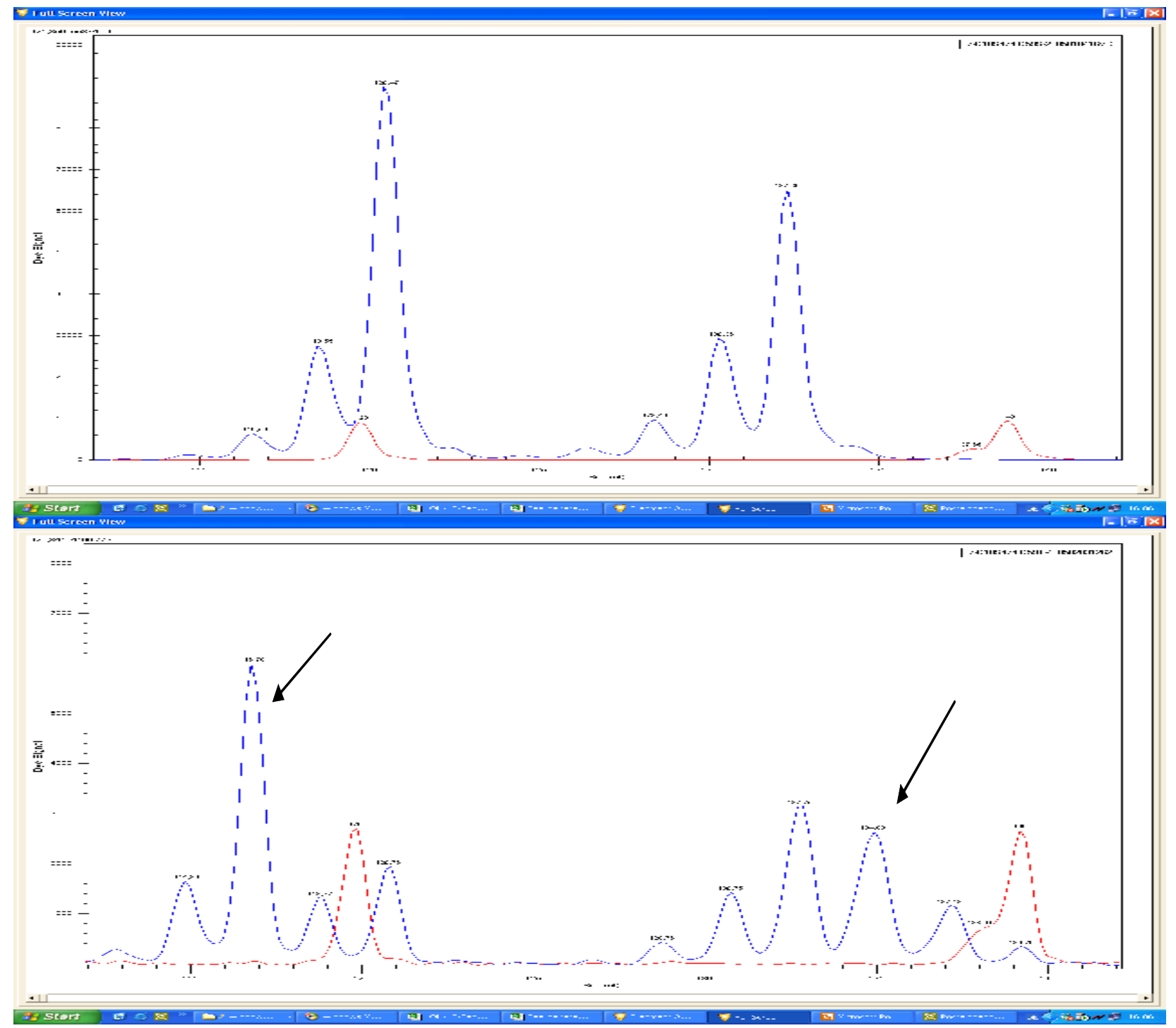

Abbildung 4: Beispiel einer Mikrosatelliteninstabilität: Hier sind DNA aus der normalen Dickdarmschleimhaut (oben) und DNA aus Tumorschleimhaut (unten) dargestellt. In der Normalschleimhaut-DNA erkennt man deutlich zwei Peaks, während in der Tumor-DNA zusätzliche Peaks unterschiedlicher Größe zu sehen sind (Pfeile). Dieses Auftreten zusätzlicher Allele wird als Mikrosatelliteninstabilität bezeichnet. Die roten Peaks kennzeichnen den Längenstandard. 


\subsubsection{Korrelation mit den histopathologischen Daten}

Die Korrelation der allelischen Verluste mit den klinischen und histopathologischen Daten erfolgte anhand des Chi-Quadrat-Test für zwei alternative Merkmale und wurde angewendet, um voneinander abhängige Variablen zu erkennen. Ein $p$-Wert von $<0,05$ wurde als statistisch signifikant angesehen.

\subsubsection{Kaplan-Meier-Analyse}

Überlebenszeitanalysen wurden mittels der Kaplan-Meier-Methode durchgeführt. Mit dieser Methode wird der geschätzte Verlauf der Überlebenszeitkurve durch eine fallende Treppenfunktion dargestellt. Durch die Teststatistik wird die Nullhypothese: „die Überlebenszeitkurven der Gruppen haben den gleichen Verlauf“" gegen die Alternativhypothese: „die Verläufe unterscheiden sich“ geprüft. Als zeitlicher Nullpunkt wurde der Zeitpunkt der primären Tumoroperation festgelegt. Als Überlebenszeit wurde die Zeit bis zum tumorbedingten Tod festgelegt. Das Kollektiv wurde zur Analyse der klinischen Verläufe in Abhängigkeit der Betrachtung eines Verlustes der Heterozygotie in 2 Gruppen, unterteilt. Eine Gruppe ohne LOH, die andere Gruppe mit LOH. Die Signifikanztestung zwischen den einzelnen Gruppen wurde mit dem Log-rank-Test (zweiseitige Fragestellung) durchgeführt. Die Auswertung erfolgte als univariate Analyse.

Die graphische Darstellung dieser Ergebnisse erfolgte mittels Kaplan-Meier-Kurven, die das Überleben bestimmter Subgruppen innerhalb eines Beobachtungszeitraumes von 60 Monaten graphisch darstellen. Als vergleichender Graph wurde immer die zu erwartende Sterberate einer gleich alten Vergleichspopulation gegenübergestellt. 


\section{Ergebnisse}

\subsection{Etablierung der PCR-Methode}

144 Patienten mit kolorektalen Karzinomen wurden mit den beiden Primern D8S254 und D18S474 auf einen Verlust der Heterozygotie für die Mikrosatellitenloci 8p22 und 18q21.1 untersucht. Um für diese Analyse spezifische, saubere und ausreichende Mengen an amplifizierter DNA zu erhalten, mussten die PCR-Bedingungen optimiert werden. Dies geschah zum einen durch Veränderung der Annealingtemperatur, der Anzahl der Zyklen in einem Bereich von 26 - 36, und durch Variieren der DNA-Konzentration. Es wurden zwei Kits (von Abgene (Absolute QPCR Mix) und von Qiagen (HotStar Mastermix)) getestet. Dabei ergaben sich die in Kapitel 3.3.2.5, (Seite 17) angegebenen optimierten Bedingungen. Zusätze wie DMSO oder Fomamid ergaben keine weiteren Verbesserungen.

\subsection{Informationsgehalt der Primer}

Um eine Aussage über einen Verlust der Heterozygotie treffen zu können, mussten die beiden Allele in heterozygotem Zustand vorliegen. Homozygote Fälle sind nicht nicht informativ, da sich beide Allele überlagern und somit nicht entschieden werden kann, ob ein allelischer Verlust vorliegt oder nicht. In über 87\% aller Untersuchungen (126 von 144) war mindestens einer der beiden Mikrosatellitenmarker informativ. In 73 Fällen (=51\%) konnten beide Primer ausgewertet werden. 18 Patienten mussten für beide Primer ausgeschlossen werden, weil sie sich für beide Regionen als homozygot erwiesen. Für den Primer D8S254 waren 89 von 144 Fällen $(=61,8 \%)$ informativ, also heterozygot im Bezug auf die beiden Allele. 55 Fälle $(=38,2 \%)$ waren homozygot, also nicht auswertbar. Für den Primer D18S474 waren 110 von 144 Fällen $(=76,4 \%)$ informativ. $34(=23,6 \%)$ waren homozygot, also nicht informativ. 


\subsection{Analyse des Patientenkollektiv}

In allen analysierten Kolonkarzinom-Fällen konnten in 73 Fällen $(=50,7 \%)$ in mindestens einer der beiden chromosomalen Regionen 8p22 und 18q21.1 ein LOH nachgewiesen werden. In 16 Fällen $(=11,1 \%)$ konnte in beiden Regionen ein $\mathrm{LOH}$, in 71 Fällen $(=49,3 \%)$ in keiner Region ein LOH gefunden werden. Ein allelischer Verlust zeigte sich etwas häufiger in der Region 18q21.1 (49,1\%) als in der Region 8p22 (39,3\%). (siehe Tabelle 3) In der Region 8 p22 konnte demnach bei dem Informationsgehalt von $61,8 \%$ bei 35 Patienten ein LOH in dieser Region nachgewiesen werden (siehe Abbildung 5, Seite 33). In der Region 18q21.1 lag die LOH-Frequenz mit 49,1\% etwas höher als in der Region 8p22. Bei insgesamt 76,4\% informativen Fällen wiesen demnach 54 Patienten einen LOH in diesem Lokus auf (siehe Abbildung 6, Seite 33). Sechs Tumore waren mikrosatelliteninstabil. Jedoch zeigte sich diese Instabilität eher bei dem Primer D18S474. Dieselben Proben waren bei dem Primer D8S254 lediglich in 2 Fällen instabil, die restlichen 4 waren allerdings homozygot und somit ebenfalls auszuschließen. Diese 6 Patienten wurden für die weiteren Korrelationen der Patientendaten mit dem Verlust der Heterozygotie nicht mitberücksichtigt (siehe Tabelle 4, Seite 32). Das Tumormaterial wurde im pathologischen Institut der Universität Würzburg vorher ebenfalls auf Mikrosatelliteninstabilität mit den fünf Mikrosatellitenprimern untersucht, in einer internationalen Zusammenkunft festgelegt wurden (Boland, 1998). Das Ergebnis bestätigte die Analysen der vorliegenden Arbeit.

\begin{tabular}{|l|l|l|l|}
\hline Locus & Informativ & LOH & MSI \\
\hline D8S254 & $89 / 144(61,8 \%)$ & $35(39,3 \%)$ & $2 / 144(1,4 \%)$ \\
\hline D18S474 & $110 / 144(76,4 \%)$ & $54(49,1 \%)$ & $6 / 144(4,2 \%)$ \\
\hline
\end{tabular}

Tabelle 3: Zusammenfassung der Ergebnisse der Mikrosatellitenanalyse 


\begin{tabular}{|c|c|c|c|c|c|c|c|c|c|c|c|c|c|c|}
\hline Nr. & D8 & D18 & Nr. & D8 & D18 & Nr. & D8 & D18 & Nr. & D8 & D18 & Nr. & D8 & D18 \\
\hline 1 & 2 & 2 & 30 & $\mathrm{LOH}$ & 1 & 59 & 2 & $\mathrm{LOH}$ & 88 & 1 & 2 & 117 & $\mathrm{LOH}$ & 2 \\
\hline 2 & $\mathrm{LOH}$ & 2 & 31 & 1 & $\mathrm{LOH}$ & 60 & 2 & $\mathrm{LOH}$ & 89 & 1 & $\mathrm{LOH}$ & 118 & 1 & $\mathrm{LOH}$ \\
\hline 3 & 2 & 2 & 32 & 2 & 2 & 61 & 2 & 2 & 90 & 2 & $\mathrm{LOH}$ & 119 & 2 & 2 \\
\hline 4 & 2 & 2 & 33 & 1 & 2 & 62 & $\mathrm{LOH}$ & 1 & 91 & 2 & 2 & 120 & 2 & 2 \\
\hline 5 & 1 & 1 & 34 & $\mathrm{LOH}$ & $\mathrm{LOH}$ & 63 & $\mathrm{LOH}$ & 1 & 92 & 2 & $\mathrm{LOH}$ & 121 & 2 & 1 \\
\hline 6 & 2 & 2 & 35 & 1 & 2 & 64 & 2 & $\mathrm{LOH}$ & 93 & 2 & $\mathrm{LOH}$ & 122 & 1 & $\mathrm{LOH}$ \\
\hline 7 & $\mathrm{LOH}$ & 2 & 36 & 1 & 2 & 65 & 2 & $\mathrm{LOH}$ & 94 & 2 & 2 & 123 & $\mathrm{LOH}$ & 2 \\
\hline 8 & $\mathrm{LOH}$ & 2 & 37 & 1 & $\mathrm{LOH}$ & 66 & 2 & 1 & 95 & 1 & 2 & 124 & 2 & 1 \\
\hline 9 & 1 & 2 & 38 & 2 & 2 & 67 & $\mathrm{LOH}$ & 2 & 96 & $\mathrm{LOH}$ & $\mathrm{LOH}$ & 125 & 2 & $\mathrm{LOH}$ \\
\hline 10 & 1 & LOH & 39 & $\mathrm{LOH}$ & $\mathrm{LOH}$ & 68 & 1 & 1 & 97 & 1 & 2 & 126 & 1 & 1 \\
\hline 11 & 2 & 2 & 40 & MSI & MSI & 69 & 2 & $\mathrm{LOH}$ & 98 & 2 & 2 & 127 & 2 & 2 \\
\hline 12 & 2 & 2 & 41 & $\mathrm{LOH}$ & 1 & 70 & 1 & 2 & 99 & 2 & $\mathrm{LOH}$ & 128 & $\mathrm{LOH}$ & $\mathrm{LOH}$ \\
\hline 13 & MSI & MSI & 42 & $\mathrm{LOH}$ & $\mathrm{LOH}$ & 71 & $\mathrm{LOH}$ & 2 & 100 & 1 & MSI & 129 & 1 & 1 \\
\hline 14 & 2 & 1 & 43 & 2 & $\mathrm{LOH}$ & 72 & 1 & 2 & 101 & 1 & 2 & 130 & 2 & $\mathrm{LOH}$ \\
\hline 15 & 1 & 1 & 44 & $\mathrm{LOH}$ & 1 & 73 & 2 & 2 & 102 & 1 & $\mathrm{LOH}$ & 131 & 1 & 2 \\
\hline 16 & $\mathrm{LOH}$ & $\mathrm{LOH}$ & 45 & 2 & 2 & 74 & LOH & LOH & 103 & 1 & $\mathrm{LOH}$ & 132 & $\mathrm{LOH}$ & 2 \\
\hline 17 & 1 & $\mathrm{LOH}$ & 46 & 2 & 2 & 75 & 2 & 2 & 104 & 1 & $\mathrm{LOH}$ & 133 & $\mathrm{LOH}$ & $\mathrm{LOH}$ \\
\hline 18 & 1 & 1 & 47 & 1 & $\mathrm{LOH}$ & 76 & 2 & 2 & 105 & 2 & 2 & 134 & $\mathrm{LOH}$ & 1 \\
\hline 19 & 1 & 2 & 48 & $\mathrm{LOH}$ & $\mathrm{LOH}$ & 77 & 1 & $\mathrm{LOH}$ & 106 & $\mathrm{LOH}$ & $\mathrm{LOH}$ & 135 & 1 & $\mathrm{LOH}$ \\
\hline 20 & 2 & 2 & 49 & 1 & $\mathrm{LOH}$ & 78 & 1 & $\mathrm{LOH}$ & 107 & $\mathrm{LOH}$ & 1 & 136 & $\mathrm{LOH}$ & $\mathrm{LOH}$ \\
\hline 21 & 2 & $\mathrm{LOH}$ & 50 & 1 & 1 & 79 & $\mathrm{LOH}$ & $\mathrm{LOH}$ & 108 & 1 & $\mathrm{LOH}$ & 137 & 1 & $\mathrm{LOH}$ \\
\hline 22 & $\mathrm{LOH}$ & $\mathrm{LOH}$ & 51 & 2 & 2 & 80 & 1 & MSI & 109 & 2 & 1 & 138 & $\mathrm{LOH}$ & $\mathrm{LOH}$ \\
\hline 23 & $\mathrm{LOH}$ & 2 & 52 & 1 & $\mathrm{LOH}$ & 81 & 1 & 1 & 110 & 1 & 1 & 139 & 1 & 1 \\
\hline 24 & 1 & MSI & 53 & 1 & $\mathrm{LOH}$ & 82 & 2 & 2 & 111 & $\mathrm{LOH}$ & 1 & 140 & 2 & $\overline{\mathrm{LOH}}$ \\
\hline 25 & 2 & $\mathrm{LOH}$ & 54 & 2 & 2 & 83 & 2 & $\mathrm{LOH}$ & 112 & 1 & 2 & 141 & 2 & 2 \\
\hline 26 & $\mathrm{LOH}$ & 1 & 55 & 2 & 2 & 84 & 1 & $\mathrm{LOH}$ & 113 & 2 & 1 & 142 & 2 & 2 \\
\hline 27 & $\mathrm{LOH}$ & 2 & 56 & $\mathrm{LOH}$ & $\mathrm{LOH}$ & 85 & 1 & $\mathrm{LOH}$ & 114 & 1 & 2 & 143 & 1 & 2 \\
\hline 28 & 1 & MSI & 57 & 2 & 2 & 86 & 1 & $\mathrm{LOH}$ & 115 & 1 & 1 & 144 & 2 & 2 \\
\hline 29 & $\mathrm{LOH}$ & $\mathrm{LOH}$ & 58 & 2 & 1 & 87 & 1 & 1 & 116 & 2 & 2 & & & \\
\hline
\end{tabular}

Tabelle 4: Ergebnisse der Mikrosatellitenanalyse 'D8 = D8S254, D18 = D18S474 $1=$ homozygot

\section{$2=$ heterozygot $\mathbf{L O H}=$ Loss of heterozygosity $\quad$ MSI $=$ Mikrosatelliteninstabilität}




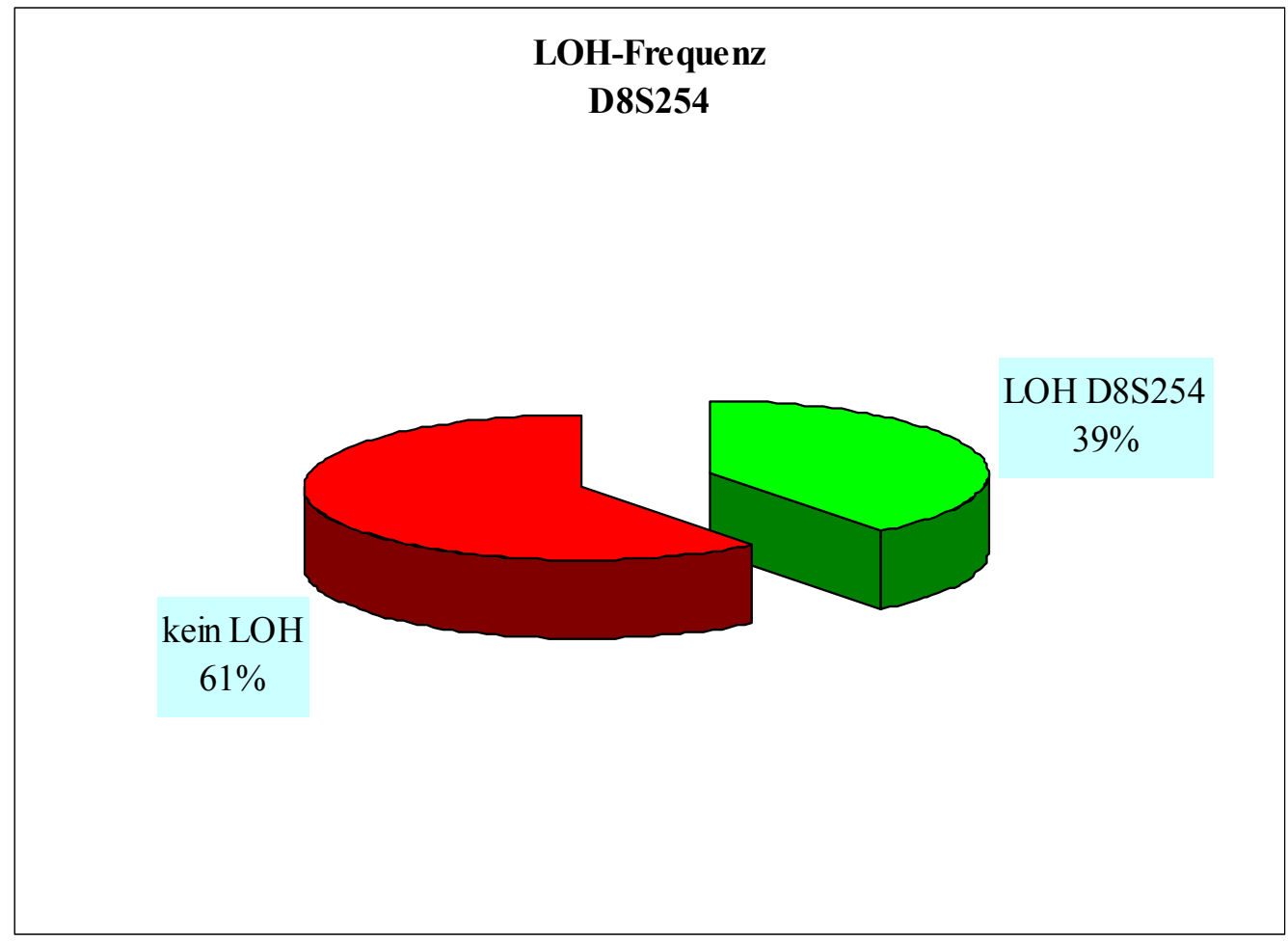

Abbildung 5: LOH-Frequenz im Bereich 8p22 um den Primer D8S254

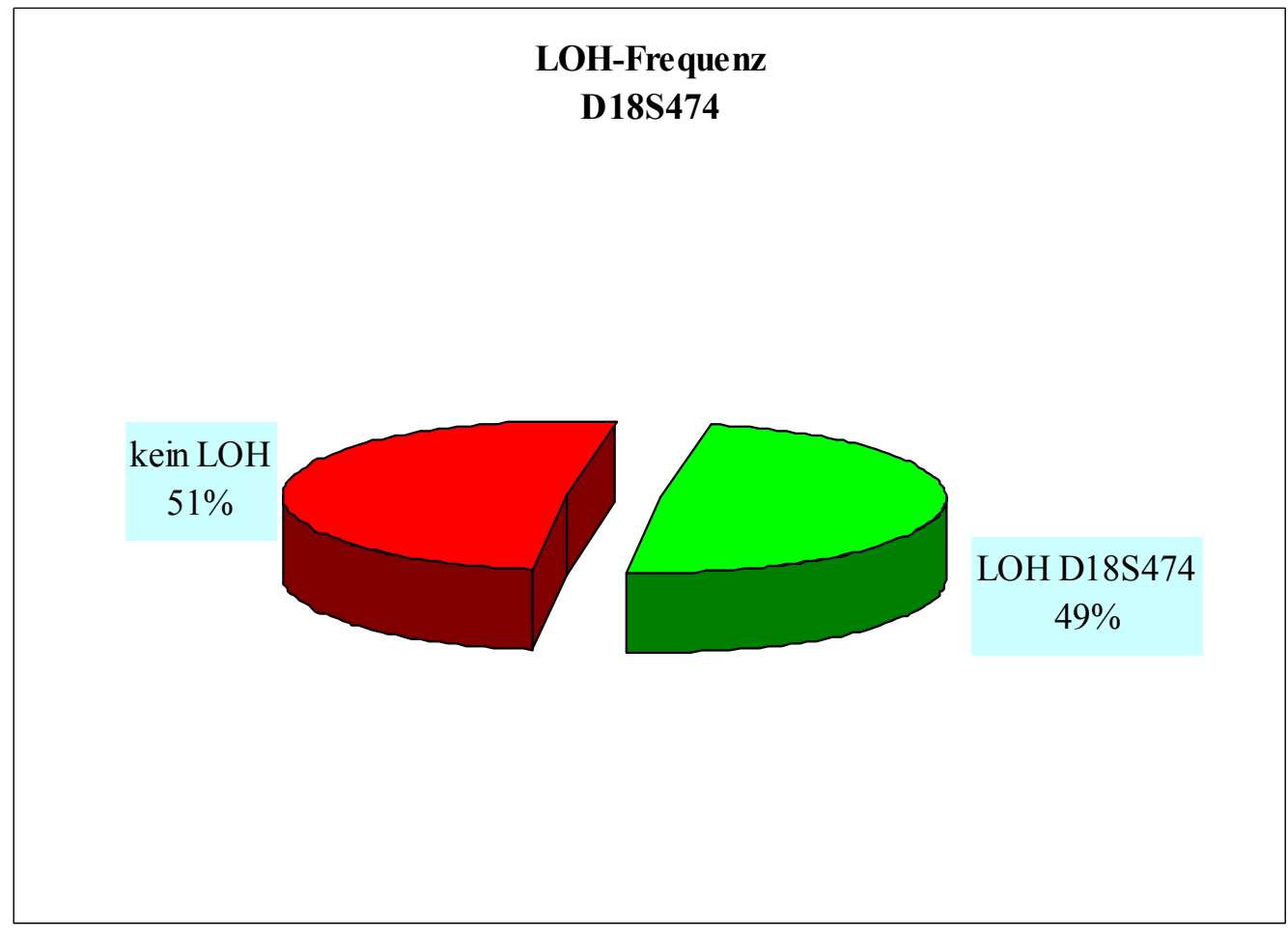

Abbildung 6: LOH-Frequenz im Bereich 18q21.1 um den Primer D18S474 


\subsection{Korrelation eines chromosomalen Verlustes mit klinischen und histopathologischen Parametern}

Die Daten für den allelischen Verlust beider Regionen wurden mit den klinischen und histopathologischen Daten der Patienten verglichen und anhand des Chi-Quadrat-Test korrelliert.

\subsubsection{Die chromosomale Region $8 \mathrm{p} 22$}

\subsubsection{Geschlecht und LOH 8p22}

Für einen Verlust der Heterozygotie der Region 8p22 gibt es keine Bevorzugung eines Geschlechts. Zwar entwickeln etwas mehr Männer als Frauen einen LOH in dieser Region, aber ein Unterschied zur Kontrollgruppe der Patienten ohne LOH besteht nicht.

\begin{tabular}{|c|c|c|c|c|c|c|c|}
\hline \multirow[t]{2}{*}{ D8S254 } & \multicolumn{2}{|c|}{$\begin{array}{c}\text { Anzahl } \\
n=89\end{array}$} & \multicolumn{2}{|c|}{$\begin{array}{l}\mathrm{LOH} \\
n=35\end{array}$} & \multicolumn{2}{|c|}{$\begin{array}{c}\text { kein LOH } \\
n=54\end{array}$} & \multirow[t]{2}{*}{$\mathrm{p}$} \\
\hline & (n) & $(\%)$ & (n) & $(\%)$ & (n) & $(\%)$ & \\
\hline \multicolumn{8}{|l|}{ Geschlecht } \\
\hline Männlich & 50 & $56,2 \%$ & 20 & $57,1 \%$ & 30 & $55,6 \%$ & 0,8828 \\
\hline Weiblich & 39 & $43,8 \%$ & 15 & $42,9 \%$ & 24 & $44,4 \%$ & \\
\hline
\end{tabular}

Tabelle 5: LOH der Region 8p22 in Abhängigkeit vom Geschlecht 


\subsubsection{Alter und LOH 8p22}

Auch bezogen auf das Alter zeigen sich keine wesentlichen, signifikanten Unterschiede zwischen Patienten mit und ohne LOH.

\begin{tabular}{|c|c|c|c|c|c|c|c|}
\hline \multirow[t]{2}{*}{ D8S254 } & \multicolumn{2}{|c|}{$\begin{array}{c}\text { Anzahl } \\
n=89\end{array}$} & \multicolumn{2}{|c|}{$\begin{array}{l}\mathrm{LOH} \\
n=35\end{array}$} & \multicolumn{2}{|c|}{$\begin{array}{c}\text { kein } \mathrm{LOH} \\
n=54\end{array}$} & \multirow[t]{2}{*}{$\mathrm{p}$} \\
\hline & (n) & $(\%)$ & (n) & $(\%)$ & (n) & $(\%)$ & \\
\hline Alter (in Jahren) & \multicolumn{2}{|c|}{$\varnothing 68,0$} & \multicolumn{2}{|c|}{$\varnothing 67,0$} & \multicolumn{2}{|c|}{$\varnothing 68,8$} & \multirow{5}{*}{0,3741} \\
\hline $29-59$ & 15 & $16,9 \%$ & 6 & $17,1 \%$ & 9 & $16,7 \%$ & \\
\hline $60-69$ & 31 & $34,8 \%$ & 13 & $37,1 \%$ & 18 & $33,3 \%$ & \\
\hline $70-79$ & 31 & $34,8 \%$ & 14 & $40,0 \%$ & 17 & $31,5 \%$ & \\
\hline$>80$ & 12 & $13,5 \%$ & 2 & $5,8 \%$ & 10 & $18,5 \%$ & \\
\hline
\end{tabular}

Tabelle 6: LOH der Region 8p22 in Abhängigkeit vom Alter

\subsubsection{UICC-Stadium und LOH 8p22}

Bei dem Primer D8S254 befanden sich von den 35 LOH-positiven Tumoren $4(=11,4 \%)$ im UICC-Stadium I, 13 (=37,1\%) im Stadium II, 8 (=22,9\%) im Stadium III und 10 (=28,6\%) im Stadium IV. Eine statistisch signifikante Korrelation zwischen UICC-Stadium und LOH besteht nicht.

\begin{tabular}{|c|c|c|c|c|c|c|c|}
\hline \multirow[t]{2}{*}{ D8S254 } & \multicolumn{2}{|c|}{$\begin{array}{l}\text { Anzahl } \\
n=89\end{array}$} & \multicolumn{2}{|c|}{$\begin{array}{l}\mathrm{LOH} \\
n=35\end{array}$} & \multicolumn{2}{|c|}{$\begin{array}{c}\text { kein } \mathrm{LOH} \\
n=54\end{array}$} & \multirow[t]{2}{*}{$\mathrm{p}$} \\
\hline & (n) & $(\%)$ & (n) & $(\%)$ & (n) & $(\%)$ & \\
\hline \multicolumn{8}{|l|}{ UICC } \\
\hline Stadium I & 14 & $15,7 \%$ & 4 & $11,4 \%$ & 10 & $18,5 \%$ & \multirow{4}{*}{0,4236} \\
\hline Stadium II & 29 & $32,6 \%$ & 13 & $37,1 \%$ & 16 & $29,7 \%$ & \\
\hline Stadium III & 26 & $29,2 \%$ & 8 & $22,9 \%$ & 18 & $33,3 \%$ & \\
\hline Stadium IV & 20 & $22,5 \%$ & 10 & $28,6 \%$ & 10 & $18,5 \%$ & \\
\hline
\end{tabular}

Tabelle 7: LOH der Region 8p22 in Abhängigkeit vom UICC-Stadium 


\subsubsection{4 pT-, pN-, pM-Kategorie und LOH 8 p22}

Bei der Infiltrationstiefe (pT-Kategorie) zeigte sich bei dem Primer D8S254 kein signifikanter Unterschied zwischen LOH-positiven und LOH-negativen Tumoren. Bei der Lymphknotenmetastasierung ( $\mathrm{pN}$-Kategorie) zeigte sich allerdings ein nicht signifikanter Trend $\mathrm{zu}$ überregionalen Lymphknotenmetastasen bei Tumoren mit einem LOH $(\mathrm{p}=0,0697)$.Während sich $28,6 \%$ der Patienten mit einem Verlust der Heterozygotie im Bereich 8 p22 bereits im Stadium pN2 befanden, war dies bei der Kontrollgruppe in lediglich $13,8 \%$ der Fall.

Auch in der pM-Kategorie ist ein leichter, aber ebenfalls nicht signifikanter Trend zu Fernmetastasen bei Tumoren mit einem LOH zu erkennen.

\begin{tabular}{|c|c|c|c|c|c|c|c|}
\hline \multirow[t]{2}{*}{ D8S254 } & \multicolumn{2}{|c|}{$\begin{array}{c}\text { Anzahl } \\
n=89\end{array}$} & \multicolumn{2}{|c|}{$\begin{array}{l}\mathrm{LOH} \\
n=35\end{array}$} & \multicolumn{2}{|c|}{$\begin{array}{c}\text { kein } \mathrm{LOH} \\
n=54\end{array}$} & \multirow[t]{2}{*}{$\mathrm{p}$} \\
\hline & (n) & $(\%)$ & (n) & $(\%)$ & (n) & $(\%)$ & \\
\hline \multicolumn{8}{|l|}{ pT-Kategorie $^{1}$} \\
\hline pT1 & 1 & $1,2 \%$ & 0 & $0 \%$ & 1 & $2,0 \%$ & \multirow{4}{*}{0,8609} \\
\hline $\mathrm{pT} 2$ & 18 & $20,9 \%$ & 7 & $20,0 \%$ & 11 & $21,6 \%$ & \\
\hline pT3 & 53 & $61,6 \%$ & 22 & $62,9 \%$ & 31 & $60,7 \%$ & \\
\hline $\mathrm{pT} 4$ & 14 & $16,3 \%$ & 6 & $17,1 \%$ & 8 & $15,7 \%$ & \\
\hline \multicolumn{8}{|l|}{ pN-Kategorie $^{1}$} \\
\hline pNo & 47 & $54,6 \%$ & 20 & $57,1 \%$ & 27 & $52,9 \%$ & \multirow{3}{*}{0,0697} \\
\hline $\mathrm{pN} 1$ & 22 & $25,6 \%$ & 5 & $14,3 \%$ & 17 & $33,3 \%$ & \\
\hline $\mathrm{pN} 2$ & 17 & $19,8 \%$ & 10 & $28,6 \%$ & 7 & $13,8 \%$ & \\
\hline \multicolumn{8}{|l|}{ pM-Kategorie } \\
\hline pM0 & 69 & $77,5 \%$ & 25 & $71,4 \%$ & 44 & $81,5 \%$ & \multirow[t]{2}{*}{0,2671} \\
\hline pM1 & 20 & $22,5 \%$ & 10 & $28,6 \%$ & 10 & $18,5 \%$ & \\
\hline
\end{tabular}

Tabelle 8: LOH der Region 8p22 in Abhängigkeit von der pT-, pN-, pM-Kategorie

${ }^{1}$ Bei einigen Patienten waren die Angaben bezüglich der pT- und der pN-Kategorie unvollständig; diese wurden nicht in die Auswertung aufgenommen 


\subsubsection{Differenzierungsgrad (Grading) und LOH 8p22}

Je schlechter ein Tumor differenziert bzw. je höher das Grading ist, desto seltener haben die Patienten chromosomale Verluste der Region 8p22. Hier herrscht also ein signifikanter, inverser Zusammenhang ( $\mathrm{p}=0,0482)$. Bei dem Primer D8S254 waren 31 Fälle $(=88,6 \%)$ mit LOH mäßig differenziert (G2), lediglich 4 Fälle (=11,4\%) schlecht (G3)-differenziert, verglichen mit dem Kontrollkollektiv der Patienten ohne LOH, bei denen 70,6\% mäßig und $29,4 \%$ schlecht differenziert waren

\begin{tabular}{|c|c|c|c|c|c|c|c|}
\hline \multirow[t]{2}{*}{ D8S254 } & \multicolumn{2}{|c|}{$\begin{array}{l}\text { Anzahl } \\
n=86^{1}\end{array}$} & \multicolumn{2}{|c|}{$\begin{array}{l}\mathrm{LOH} \\
n=35\end{array}$} & \multicolumn{2}{|c|}{$\begin{array}{c}\text { kein } \mathrm{LOH} \\
n=51\end{array}$} & \multirow[t]{2}{*}{$\mathrm{p}$} \\
\hline & (n) & $(\%)$ & (n) & $(\%)$ & (n) & $(\%)$ & \\
\hline \multirow{2}{*}{\multicolumn{8}{|c|}{$\begin{array}{l}\text { Differenzierungs- } \\
\operatorname{grad}^{1}\end{array}$}} \\
\hline & & & & & & & \\
\hline G2 & 67 & $77,9 \%$ & 31 & $\underline{88,6} \%$ * & 36 & $70,6 \%$ & \\
\hline G3 & 19 & $22,1 \%$ & 4 & $11,4 \%$ & 15 & $29,4 \%$ & \\
\hline
\end{tabular}

Tabelle 9: LOH der Region 8p22 in Abhängigkeit vom histologischen Differenzierungsgrad

${ }^{1}$ Bei einigen Patienten waren die Angaben bezüglich des Differenzierungsgrades unvollständig; diese wurden nicht in die Auswertung aufgenommen 


\subsubsection{Rezidivrate und LOH 8p22}

Etwas mehr Patienten mit einem chromosomalen Verlust der Region 8p22 (22,9\%) entwickelten ein Rezidiv ihres kolorektalen Karzinoms im Vergleich mit den Patienten ohne LOH (13,0\%), für einen Zusammenhang zwischen Rezidivrate $\mathrm{LOH}$ besteht aber kein signifikanter Hinweis.

\begin{tabular}{|c|c|c|c|c|c|c|c|}
\hline \multirow[t]{2}{*}{ D8S2544 } & \multicolumn{2}{|c|}{$\begin{array}{c}\text { Anzahl } \\
n=89\end{array}$} & \multicolumn{2}{|c|}{$\begin{array}{l}\mathrm{LOH} \\
n=35\end{array}$} & \multicolumn{2}{|c|}{$\begin{array}{c}\text { kein LOH } \\
n=54\end{array}$} & \multirow[t]{2}{*}{$\mathrm{p}$} \\
\hline & (n) & $(\%)$ & (n) & $(\%)$ & (n) & $(\%)$ & \\
\hline \multicolumn{8}{|l|}{ Rezidiv } \\
\hline positiv & 15 & $16,9 \%$ & 8 & $22,9 \%$ & 7 & $13,0 \%$ & 0,2232 \\
\hline negativ & 74 & $83,1 \%$ & 27 & $77,1 \%$ & 47 & $87,0 \%$ & \\
\hline
\end{tabular}

Tabelle 10: Rezidivrate in Abhängigkeit eines LOH der Region 8p22

\subsubsection{Unterscheidung des Patientenkollektivs nach dem Geschlecht}

\subsection{UICC-Stadium und LOH 8p22 bei Frauen}

Unterscheidet man die beiden Patientenkollektive der LOH-postiven und LOH-negativen Fälle nochmals nach dem Geschlecht, zeigte sich, dass bei Frauen signifikant häufiger LOH's bei Stadium IV Tumoren auftreten, im Vergleich mit den restlichen Stadien $(p=0,0174)$. So fanden sich 46,7\% Stadium IV-Tumoren bei Patientinnen mit einem LOH der Region 8p22 im Vergleich zu 12,5\% bei Patientinnen ohne diesen Verlust (siehe Tabelle 11, Seite 39). 


\begin{tabular}{|c|c|c|c|c|c|c|c|}
\hline \multirow[t]{2}{*}{ D8S254 } & \multicolumn{2}{|c|}{$\begin{array}{l}\text { Anzahl } \\
n=39\end{array}$} & \multicolumn{2}{|c|}{$\begin{array}{l}\mathrm{LOH} \\
n=15\end{array}$} & \multicolumn{2}{|c|}{$\begin{array}{c}\text { kein } \mathrm{LOH} \\
n=24\end{array}$} & \multirow[t]{2}{*}{$\mathrm{p}$} \\
\hline & (n) & $(\%)$ & (n) & $(\%)$ & (n) & $(\%)$ & \\
\hline \multicolumn{8}{|l|}{$\overline{\text { UICC }}$} \\
\hline Stadium I & 7 & $17,9 \%$ & 2 & $13,3 \%$ & 5 & $20,8 \%$ & \multirow{4}{*}{$\begin{array}{r}0,1170 \\
* 0,0174^{1}\end{array}$} \\
\hline Stadium II & 13 & $33,3 \%$ & 3 & $20,0 \%$ & 10 & $41,7 \%$ & \\
\hline Stadium III & 9 & $23,2 \%$ & 3 & $20,0 \%$ & 6 & $25,0 \%$ & \\
\hline Stadium IV & 10 & $25,6 \%$ & 7 & $\underline{46,7} \% * 1$ & 3 & $12,5 \%$ & \\
\hline
\end{tabular}

Tabelle 11: LOH der Region 8p22 in Abhängigkeit vom UICC-Stadium bei Frauen

${ }^{1}$ Für den Primer D8S254 zeigte sich eine signifikante Häufung von UICC IV-Tumoren bei Frauen im Vergleich gegen die restlichen Stadien

\subsection{UICC-Stadium und LOH 8p22 bei Männern}

Bei Männern zeigte sich eine signifikante Häufung von UICC-Stadium II Tumoren mit einem LOH im Vergleich mit den restlichen Stadien ( $p=0,0259)$. 50\% der Männer im Stadium II besaßen einen LOH 8p22, während sich lediglich 20\% der Patienten ohne LOH im Stadium II befanden.

\begin{tabular}{|c|c|c|c|c|c|c|c|}
\hline \multirow[t]{2}{*}{ D8S254 } & \multicolumn{2}{|c|}{$\begin{array}{l}\text { Anzahl } \\
n=50\end{array}$} & \multicolumn{2}{|c|}{$\begin{array}{l}\mathrm{LOH} \\
n=20\end{array}$} & \multicolumn{2}{|c|}{$\begin{array}{c}\text { kein } \mathrm{LOH} \\
\quad n=30\end{array}$} & \multirow[t]{2}{*}{$\mathrm{P}$} \\
\hline & (n) & $(\%)$ & (n) & $(\%)$ & (n) & $(\%)$ & \\
\hline \multicolumn{8}{|l|}{ UICC } \\
\hline Stadium I & 7 & $14,0 \%$ & 2 & $10,0 \%$ & 5 & $16,7 \%$ & \multirow{4}{*}{$\begin{array}{c}0,1742 \\
* 0,0259^{1}\end{array}$} \\
\hline Stadium II & 16 & $32,0 \%$ & 10 & $\underline{50,0} \% * 1$ & 6 & $20,0 \%$ & \\
\hline Stadium III & 17 & $34,0 \%$ & 5 & $25,0 \%$ & 12 & $40,0 \%$ & \\
\hline Stadium IV & 10 & $20,0 \%$ & 3 & $15,0 \% *$ & 7 & $23,3 \%$ & \\
\hline
\end{tabular}

Tabelle 12: LOH der Region 8p22 in Abhängigkeit vom UICC-Stadium bei Männern

${ }^{1}$ Für den Primer D8S254 zeigte sich eine signifikante Häufung von UICC II-Tumoren bei Männern im Vergleich gegen die restlichen Stadien 


\subsubsection{Die chromosomale Region $18 \mathrm{q} 21.1$}

\subsubsection{Geschlecht und LOH 18q21.1}

Auch bei einem allelischen Verlust der Region 18q21.1 zeigte sich kein bevorzugtes Geschlecht. Zwar waren Männer mit 61,1\% häufiger von einem LOH betroffen als Frauen (38,9\%), jedoch nicht signifikant.

\begin{tabular}{|l||cr|rr|rr|c|}
\hline \multicolumn{1}{|c|}{ D18S474 } & \multicolumn{2}{|c|}{ Anzahl } & \multicolumn{2}{|c|}{ LOH } & \multicolumn{2}{|c|}{ kein LOH } & \\
& \multicolumn{2}{|c|}{$n=110$} & \multicolumn{2}{|c|}{$n=54$} & \multicolumn{2}{|c|}{$n=56$} & $\mathrm{p}$ \\
& $(\mathrm{n})$ & $(\%)$ & $(\mathrm{n})$ & $(\%)$ & $(\mathrm{n})$ & $(\%)$ & \\
\hline \hline Geschlecht & & & & & & \\
Männlich & 60 & $54,5 \%$ & 33 & $61,1 \%$ & 27 & $48,2 \%$ & 0,1745 \\
Weiblich & 50 & $45,5 \%$ & 21 & $38,9 \%$ & 29 & $51,8 \%$ & \\
\hline
\end{tabular}

Tabelle 13: LOH der Region 18q21.1 in Abhängigkeit vom Geschlecht

\subsubsection{Alter und LOH 18q21.1}

Beim Alter allerdings besteht bei einem LOH der Region 18q21.1 ein signifikanter Unterschied. So waren 81,5\% der Patienten mit einem LOH zwischen 60 und 79 Jahren alt, während dies bei Patienten ohne LOH lediglich zu 53,6\% vorkam ( $\mathrm{p}=0,0018)$. Das Risiko für Patienten unter 60 bzw. über 80 Jahren ist demnach geringer, diese genetische Aberration auf dem Chromosom 18 zu tragen, als für Patienten zwischen 60 und 79 Jahren. 


\begin{tabular}{|c|c|c|c|c|c|c|c|}
\hline \multirow[t]{2}{*}{ D18S474 } & \multicolumn{2}{|c|}{$\begin{array}{l}\text { Anzahl } \\
n=110\end{array}$} & \multicolumn{2}{|c|}{$\begin{array}{l}\mathrm{LOH} \\
n=54\end{array}$} & \multicolumn{2}{|c|}{$\begin{array}{c}\text { kein LOH } \\
n=56\end{array}$} & \multirow[t]{2}{*}{$\mathrm{p}$} \\
\hline & (n) & $(\%)$ & (n) & $(\%)$ & (n) & $(\%)$ & \\
\hline Alter (in Jahren) & \multicolumn{2}{|c|}{$\varnothing 68,0$} & \multicolumn{2}{|c|}{$\varnothing 67,0$} & \multicolumn{2}{|c|}{$\varnothing 68,8$} & \multirow{5}{*}{$\begin{array}{l}* 0,0160 \\
* 0,0018^{1}\end{array}$} \\
\hline $29-59$ & 19 & $17,3 \%$ & 5 & $9,3 \%$ & 14 & $25,0 \%$ & \\
\hline $60-69$ & 36 & $32,7 \%$ & 23 & $42,6 \% *^{1}$ & 13 & $23,2 \%$ & \\
\hline $70-79$ & 38 & $34,5 \%$ & 21 & $38,8^{* 1}$ & 17 & $30,4 \%$ & \\
\hline$>80$ & 17 & $15,5 \%$ & 5 & $9,3 \%$ & 12 & $21,4 \%$ & \\
\hline
\end{tabular}

Tabelle 14: LOH der Region 18q21.1 in Abhängigkeit vom Alter. ${ }^{1}$ Der Zusammenhang im Alter zwischen 60 und 79 Jahren und LOH war hochsignifikant

\subsubsection{UICC-Stadium und LOH 18q21.1}

Bei dem Primer D18S474 befanden sich von den 54 Fällen mit einem allelischen Verlust 6 $(=11,1 \%)$ im UICC-Stadium I, $26(48,1 \%)$ im Stadium II und jeweils $11(=20,4 \%)$ im Stadium III und IV. In der Kontrollgruppe befanden sich 25,0\% im Stadium I, 28,6\% im Stadium II, 30,4\% im Stadium III und 16,1\% im Stadium IV. Hier besteht eine signifikante Häufung der LOH-Frequenz bei UICC II-Tumoren im Vergleich zu den Tumoren der Stadien I, III und IV ( $\mathrm{p}=0$,0346). Die Wahrscheinlichkeit, einen LOH der Region 18q21.1 in einem Stadium II-Tumor zu entdecken ist demnach signifikant erhöht.

\begin{tabular}{|c|c|c|c|c|c|c|c|}
\hline \multirow[t]{2}{*}{ D18S474 } & \multicolumn{2}{|c|}{$\begin{array}{l}\text { Anzahl } \\
n=110\end{array}$} & \multicolumn{2}{|c|}{$\begin{array}{l}\mathrm{LOH} \\
n=54\end{array}$} & \multicolumn{2}{|c|}{$\begin{array}{c}\text { kein LOH } \\
n=56\end{array}$} & \multirow[t]{2}{*}{$\mathrm{p}$} \\
\hline & (n) & $(\%)$ & (n) & $(\%)$ & (n) & $(\%)$ & \\
\hline \multicolumn{8}{|l|}{ UICC } \\
\hline Stadium I & 20 & $18,2 \%$ & 6 & $11,1 \%$ & 14 & $25,0 \%$ & \multirow{4}{*}{$\begin{array}{c}0,0708, \\
* 0,0346^{1}\end{array}$} \\
\hline Stadium II & 42 & $38,2 \%$ & 26 & $\underline{48,1} \% *^{1}$ & 16 & $28,5 \%$ & \\
\hline Stadium III & 28 & $25,4 \%$ & 11 & $20,4 \%$ & 17 & $30,4 \%$ & \\
\hline Stadium IV & 20 & $18,2 \%$ & 11 & $20,4 \%$ & 9 & $16,1 \%$ & \\
\hline
\end{tabular}

Tabelle 15: LOH der Region 18q21.1 in Abhängigkeit vom UICC-Stadium

${ }^{1}$ Es zeigte sich eine signifikante Häufung von UICC II-Tumoren im Vergleich gegen die restlichen Stadien 


\subsubsection{4 pT-, pN-, pM-Kategorie und LOH 18q21.1}

Es zeigte sich bezogen auf die Infiltrationstiefe, dass LOH-positive Tumoren der Region 18q21.1 signifikant häufiger bereits die Tunica muscularis durchbrochen haben und eventuell bereits in benachbarte Regionen infiltrierten, sich also im Stadium pT3 oder pT4 befanden ( $p=0,0286$ ). 67,9\% bzw.17,0\% der Tumoren mit einem LOH in dieser Region befanden sich im Stadium pT3 bzw. pT4 verglichen mit 51,9\% bzw. 14,8\% der Kontrollgruppe ohne LOH. Ein LOH prädestiniert demnach für eine höhere Invasivität der kolorektalen Karzinome.

Ein Zusammenhang zwischen Lymphknoten- bzw. Fernmetastasen zeigte sich jedoch nicht.

\begin{tabular}{|c|c|c|c|c|c|c|c|}
\hline \multirow[t]{2}{*}{ D18S474 } & \multicolumn{2}{|c|}{$\begin{array}{l}\text { Anzahl } \\
n=110\end{array}$} & \multicolumn{2}{|c|}{$\begin{array}{l}\mathrm{LOH} \\
n=54\end{array}$} & \multicolumn{2}{|c|}{$\begin{array}{c}\text { kein } \mathrm{LOH} \\
n=56\end{array}$} & \multirow[t]{2}{*}{$\mathrm{P}$} \\
\hline & (n) & $(\%)$ & (n) & $(\%)$ & (n) & $(\%)$ & \\
\hline \multicolumn{8}{|l|}{ pT-Kategorie $^{1}$} \\
\hline pT1 & 2 & $1,9 \%$ & 2 & $3,8 \%$ & 0 & $0,0 \%$ & \multirow{4}{*}{$* 0,0286$} \\
\hline pT2 & 24 & $22,4 \%$ & 6 & $11,3 \%$ & 18 & $\underline{33,3} \%$ & \\
\hline pT3 & 64 & $59,8 \%$ & 36 & $\underline{67,9} \% *$ & 28 & $51,9 \%$ & \\
\hline pT4 & 17 & $15,9 \%$ & 9 & $\underline{17,0} \% *$ & 8 & $14,8 \%$ & \\
\hline \multicolumn{8}{|l|}{ pN-Kategorie $^{1}$} \\
\hline pNo & 65 & $60,7 \%$ & 33 & $62,2 \%$ & 32 & $59,2 \%$ & \multirow{3}{*}{0,4640} \\
\hline $\mathrm{pN} 1$ & 25 & $23,4 \%$ & 10 & $18,9 \%$ & 15 & $27,8 \%$ & \\
\hline $\mathrm{pN} 2$ & 17 & $15,9 \%$ & 10 & $18,9 \%$ & 7 & $13,0 \%$ & \\
\hline \multicolumn{8}{|l|}{ pM-Kategorie } \\
\hline pM0 & 90 & $81,8 \%$ & 43 & $79,6 \%$ & 47 & $83,9 \%$ & \multirow[t]{2}{*}{0,5589} \\
\hline pM1 & 20 & $18,2 \%$ & 11 & $20,4 \%$ & 9 & $19,1 \%$ & \\
\hline
\end{tabular}

Tabelle 16: LOH der Region 18q21.1 in Abhängigkeit der pT-, pN-, und pM-Kategorie

${ }^{1}$ Bei einigen Patienten waren die Angaben bezüglich pT- und der pN-Kategoerie unvollständig; diese wurden nicht in die Auswertung aufgenommen 


\subsubsection{Differenzierungsgrad (Grading) und LOH 18q21.1}

Für den D18S474-Primer zeigte sich signifikant kein Unterschied zwischen dem Grading bei LOH-positiven und LOH-negativen Tumoren ( $p=0,9607)$. 79,2\% der LOH-positiven bzw. 79,6\% der LOH-negativen Tumore waren G2- und 20,8\% bzw. 20,4\% G3-differenziert.

\begin{tabular}{|c|c|c|c|c|c|c|c|}
\hline \multirow[t]{2}{*}{ D18S474 } & \multicolumn{2}{|c|}{$\begin{array}{l}\text { Anzahl } \\
n=107^{1}\end{array}$} & \multicolumn{2}{|c|}{$\begin{array}{l}\mathrm{LOH} \\
n=53\end{array}$} & \multicolumn{2}{|c|}{$\begin{array}{l}\text { kein LOH } \\
\qquad n=54\end{array}$} & \multirow[t]{2}{*}{$P$} \\
\hline & (n) & $(\%)$ & (n) & $(\%)$ & (n) & $(\%)$ & \\
\hline $\begin{array}{l}\text { Differenzierungs- } \\
\operatorname{grad}^{1}\end{array}$ & & & & & & & \\
\hline $\mathrm{G} 2$ & 85 & $79,4 \%$ & 42 & $\underline{79,2} \%$ & 43 & $79,6 \%$ & \\
\hline G3 & 22 & $20,6 \%$ & 11 & $20,8 \%$ & 11 & $20,4 \%$ & \\
\hline
\end{tabular}

Tabelle 17: LOH der Region 18q21.1 in Abhängigkeit vom histologischen Differenzierungsgrad

${ }^{1}$ Bei einigen Patienten waren die Angaben bezüglich des Differenzierungsgrades, der pT- und der pN-Kategoerie unvollständig; diese wurden nicht in die Auswertung aufgenommen

\subsubsection{Rezidivrate und LOH 18q21.1}

Wie bei einem LOH der Region 8p22 findet sich auch hier kein Zusammenhang zwischen einem chromosomalen Verlust und eines Rezidivs des kolorektalen Karznoms.

\begin{tabular}{|c|c|c|c|c|c|c|c|}
\hline \multirow[t]{2}{*}{ D18S474 } & \multicolumn{2}{|c|}{$\begin{array}{l}\text { Anzahl } \\
n=110\end{array}$} & \multicolumn{2}{|c|}{$\begin{array}{l}\mathrm{LOH} \\
n=54\end{array}$} & \multicolumn{2}{|c|}{$\begin{array}{c}\text { kein } \mathrm{LOH} \\
n=56\end{array}$} & \multirow[t]{2}{*}{$\mathrm{P}$} \\
\hline & (n) & $(\%)$ & (n) & $(\%)$ & (n) & $(\%)$ & \\
\hline \multicolumn{8}{|l|}{ Rezidiv } \\
\hline positiv & 19 & $17,3 \%$ & 10 & $18,5 \%$ & 9 & $16,1 \%$ & 0,7343 \\
\hline negativ & 91 & $82,7 \%$ & 44 & $81,5 \%$ & 47 & $83,9 \%$ & \\
\hline
\end{tabular}

Tabelle 18: Rezidivrate in Abhängigkeit eines LOH der Region 18q21.1 


\subsubsection{Unterscheidung des Patientenkollektivs nach dem Geschlecht}

\subsection{UICC-Stadium und LOH 18q21.1 bei Frauen}

Auch bei dem Primer D18S474 zeigen sich intersexuelle Unterschiede. So weisen bei Frauen signifikant weniger UICC-I-Tumoren, aber signifikant häufiger UICC-IV-Tumoren einen LOH auf $(p=0,0078)$. Lediglich 9,5\% der Patientinnen im Stadium I besaßen einen LOH 18q21.1 im Vergleich zu 27,6\% der Kontrollgruppe. Im Gegensatz dazu befanden sich 33,3\% der LOH-positiven Fälle im Stadium IV, verglichen mit 13,8\% der LOH-negativen.

\begin{tabular}{|c|c|c|c|c|c|c|c|}
\hline \multirow[t]{2}{*}{ D18S474 } & \multicolumn{2}{|c|}{$\begin{array}{l}\text { Anzahl } \\
n=50\end{array}$} & \multicolumn{2}{|c|}{$\begin{array}{l}\mathrm{LOH} \\
n=21\end{array}$} & \multicolumn{2}{|c|}{$\begin{array}{c}\text { kein } \mathrm{LOH} \\
n=29\end{array}$} & \multirow[t]{2}{*}{$\mathrm{p}$} \\
\hline & (n) & $(\%)$ & (n) & $(\%)$ & (n) & $(\%)$ & \\
\hline \multicolumn{8}{|l|}{$\overline{\text { UICC }}$} \\
\hline Stadium I & 10 & $20,0 \%$ & 2 & $9,5 \%$ & 8 & $\underline{27,6} \%$ & \multirow{4}{*}{$* 0,0078$} \\
\hline Stadium II & 21 & $42,0 \%$ & 12 & $57,2 \%$ & 9 & $31,0 \%$ & \\
\hline Stadium III & 8 & $16,0 \%$ & 0 & $0,0 \%$ & 8 & $27,6 \%$ & \\
\hline Stadium IV & 11 & $22,0 \%$ & 7 & $\underline{33,3} \%$ * & 4 & $13,8 \%$ & \\
\hline
\end{tabular}

Tabelle 19: LOH der Region 8p22 in Abhängigkeit vom UICC-Stadium bei Frauen 


\subsection{UICC-Stadium und LOH 18q21.1 bei Männern}

Bei den männlichen Patienten hingegen zeigen sich keine signifikanten Unterschiede zwischen dem Auftreten eines allelischen Verlustes der Region 18q21.1 und dem UICCStadium

\begin{tabular}{|c|c|c|c|c|c|c|c|}
\hline \multirow[t]{2}{*}{ D18S474 } & \multicolumn{2}{|c|}{$\begin{array}{l}\text { Anzahl } \\
n=60\end{array}$} & \multicolumn{2}{|c|}{$\begin{array}{l}\mathrm{LOH} \\
n=33\end{array}$} & \multicolumn{2}{|c|}{$\begin{array}{c}\text { kein LOH } \\
\quad n=27\end{array}$} & \multirow[t]{2}{*}{$\mathrm{p}$} \\
\hline & (n) & $(\%)$ & (n) & $(\%)$ & (n) & $(\%)$ & \\
\hline \multicolumn{8}{|l|}{ UICC } \\
\hline Stadium I & 10 & $16,7 \%$ & 4 & $12,1 \%$ & 6 & $22,3 \%$ & \multirow{4}{*}{0,4809} \\
\hline Stadium II & 21 & $35,0 \%$ & 14 & $42,5 \%$ & 7 & $25,9 \%$ & \\
\hline Stadium III & 20 & $33,3 \%$ & 11 & $33,3 \%$ & 9 & $33,3 \%$ & \\
\hline Stadium IV & 9 & $15,0 \%$ & 4 & $12,1 \% * 1$ & 5 & $18,5 \%$ & \\
\hline
\end{tabular}

Tabelle 20: LOH der Region 8p22 in Abhängigkeit vom UICC-Stadium bei Männern

\subsubsection{Die chromosomalen Regionen 8p22 und 18q21.1}

Einige der Patienten wiesen auch einen doppelten LOH in beiden Regionen auf. Für die nachfolgenden Korrelationen sowie für die Kaplan-Meier-Analysen wurden alle nichtinformativen Patienten, also alle sowohl für den Primer D8S254 als auch für D18S474 homozygoten Fälle ausgeschlossen. Ebenso nicht mit in die Berechnungen einbezogen wurden alle Patienten, die jeweils nur einen LOH einer der beiden Regionen aufwiesen. Von den restlichen 47 informativen Fällen wiesen 16 (=34,0\%) einen doppelten LOH auf.

Es konnten zwischen einem solchen doppelten chromosomalen Verlust und dem UICCStadium sowie dem Alter der Patienten ein signifikanter Zusammenhang festgestellt werden. So befinden sich wesentlich weniger Patienten der LOH-positiven Gruppe im Stadium I $(6,2 \%)$ und deutlich mehr im Stadium IV (31,3\%) als in der LOH-negativen Kontrollgruppe $(p=0,0302)$.

Analog zu einem chromosomalen Verlust der Region 18q21.1 findet sich auch bei einem zusätzlichen Verlust der Region 8p22 eine signifikante Häufung der Patienten zwischen 60 und 79 Jahren $(93,8 \%$ gegenüber $61,3 \%)(p=0,0184)$. 
Weitere signifikante Zusammenhänge mit dem Geschlecht, der Infiltrationstiefe, der Metastasierung, dem Differenzierungsgrad oder der Rezidivrate zeigten sich nicht.

\begin{tabular}{|c|c|c|c|c|c|c|c|}
\hline \multirow{2}{*}{$\begin{array}{l}\text { D8S254+ } \\
\text { D18S474 }\end{array}$} & \multicolumn{2}{|c|}{$\begin{array}{l}\text { Anzahl } \\
n=47\end{array}$} & \multicolumn{2}{|c|}{$\begin{array}{l}\mathrm{LOH} \\
n=16\end{array}$} & \multicolumn{2}{|c|}{$\begin{array}{c}\text { kein LOH } \\
n=31\end{array}$} & \multirow[t]{2}{*}{$\mathrm{p}$} \\
\hline & (n) & $(\%)$ & (n) & $(\%)$ & (n) & $(\%)$ & \\
\hline \multicolumn{8}{|l|}{ UICC } \\
\hline Stadium I & 10 & $21,3 \%$ & 1 & $\underline{6,2} \%$ & 9 & $29,0 \%$ & \multirow{4}{*}{$* 0,0302$} \\
\hline Stadium II & 15 & $31,9 \%$ & 8 & $50,0 \%$ & 7 & $22,6 \%$ & \\
\hline Stadium III & 13 & $27,7 \%$ & 2 & $12,5 \%$ & 11 & $35,5 \%$ & \\
\hline Stadium IV & 9 & $19,1 \%$ & 5 & $\underline{31,3} \%$ & 4 & $12,9 \%$ & \\
\hline Alter (in Jahren) & \multicolumn{2}{|c|}{$\varnothing 68,5$} & \multicolumn{2}{|c|}{$\varnothing 69,4$} & \multicolumn{2}{|c|}{$\varnothing 68,0$} & \multirow{3}{*}{$* 0,0184$} \\
\hline $60-79$ & 34 & $72,3 \%$ & 15 & $\underline{93,8} \% *$ & 19 & $61,3 \%$ & \\
\hline$<60+>80$ & 13 & $27,7 \%$ & 1 & $6,2 \%$ & 12 & $38,7 \%$ & \\
\hline
\end{tabular}

Tabelle 21: Doppelter LOH der Region 8p22 und 18q21.1 in Abhängigkeit vom UICC-Stadium und des Alters

\subsubsection{UICC-Stadium und LOH 8p22 und 18q21.1 bei Frauen}

Betrachtet man nun wieder Frauen und Männer getrennt, zeigen sich ebenfalls beträchtliche Unterschiede. So befinden sich Tumore von Patientinnen mit einem doppelten LOH signifikant häufiger ( $80 \%$ gegenüber $11,8 \%)$ im Stadium IV $(p=0,0217)$.

\begin{tabular}{|c|c|c|c|c|c|c|c|}
\hline \multirow{2}{*}{$\begin{array}{l}\text { D8S254+ } \\
\text { D18S474 }\end{array}$} & \multicolumn{2}{|c|}{$\begin{array}{l}\text { Anzahl } \\
n=22\end{array}$} & \multicolumn{2}{|c|}{$\begin{array}{c}\mathrm{LOH} \\
n=5\end{array}$} & \multicolumn{2}{|c|}{$\begin{array}{c}\text { kein } \mathrm{LOH} \\
n=17\end{array}$} & \multirow[t]{2}{*}{$\mathrm{p}$} \\
\hline & (n) & $(\%)$ & (n) & $(\%)$ & (n) & $(\%)$ & \\
\hline \multicolumn{8}{|l|}{$\overline{\text { UICC }}$} \\
\hline Stadium I & 5 & $22,7 \%$ & 0 & $0,0 \%$ & 5 & $29,4 \%$ & \multirow{4}{*}{$* 0,0217$} \\
\hline Stadium II & 6 & $27,3 \%$ & 1 & $20,0 \%$ & 5 & $29,4 \%$ & \\
\hline Stadium III & 5 & $22,7 \%$ & 0 & $0,0 \%$ & 5 & $29,4 \%$ & \\
\hline Stadium IV & 6 & $27,3 \%$ & 4 & $\underline{80,0} \%$ & 2 & $11,8 \%$ & \\
\hline
\end{tabular}

Tabelle 22: Doppelter LOH der Region 8p22 und 18q21.1 in Abhängigkeit vom UICC-Stadium bei Frauen 


\subsubsection{UICC-Stadium und LOH 8p22 und 18q21.1 bei Männern}

Im Gegensatz dazu besteht bei Männern ein Trend zu niedrigeren Stadien, vor allem Stadium II, in dem sich 63,6\% aller Männer mit einem doppelten LOH befanden. Allerdings ist dieser Trend nicht signifikant.

\begin{tabular}{|c|c|c|c|c|c|c|c|}
\hline \multirow{2}{*}{$\begin{array}{l}\text { D8S254t } \\
\text { D18S474 }\end{array}$} & \multicolumn{2}{|c|}{$\begin{array}{l}\text { Anzahl } \\
n=25\end{array}$} & \multicolumn{2}{|c|}{$\begin{array}{l}\mathrm{LOH} \\
n=11\end{array}$} & \multicolumn{2}{|c|}{$\begin{array}{c}\text { kein } \mathrm{LOH} \\
n=14\end{array}$} & \multirow[t]{2}{*}{$\mathrm{p}$} \\
\hline & & & (n) & $(\%)$ & (n) & $(\%)$ & \\
\hline \multicolumn{8}{|l|}{ UICC } \\
\hline Stadium I & 5 & $20,0 \%$ & 1 & $9,1 \%$ & 4 & $28,6 \%$ & \multirow{4}{*}{0,0840} \\
\hline Stadium II & 9 & $36,0 \%$ & 7 & $63,6 \%$ & 2 & $14,3 \%$ & \\
\hline Stadium III & 8 & $32,0 \%$ & 2 & $18,2 \%$ & 6 & $42,8 \%$ & \\
\hline Stadium IV & 3 & $12,0 \%$ & 1 & $9,1 \%$ & 2 & $14,3 \%$ & \\
\hline
\end{tabular}

Tabelle 23: Doppelter LOH der Region 8p22 und 18q21.1 in Abhängigkeit vom UICC-Stadium bei $\underline{\text { Männern }}$ 


\subsubsection{Korrelation mit den klinischen Verlaufsparametern}

\subsubsection{Verlust der Heterozygotie der Region 8p22 und Patientenprognose}

Ein chromosomaler Verlust dieser Region scheint einen geringen Einfluss auf die Patientenprognose zu haben. Allerdings ist dieser Trend nicht signifikant. Die 5-JahresÜberlebensrate (5-JÜR) bei Patienten mit einem LOH beträgt ca. 55\% im Vergleich zu 70\% für Patienten ohne $\mathrm{LOH}(\mathrm{p}=0,3255)$. Die Prognose der einzelnen Stadien im getrennten Vergleich ergaben keine signifikanten Ergebnisse.

\section{D8S254}

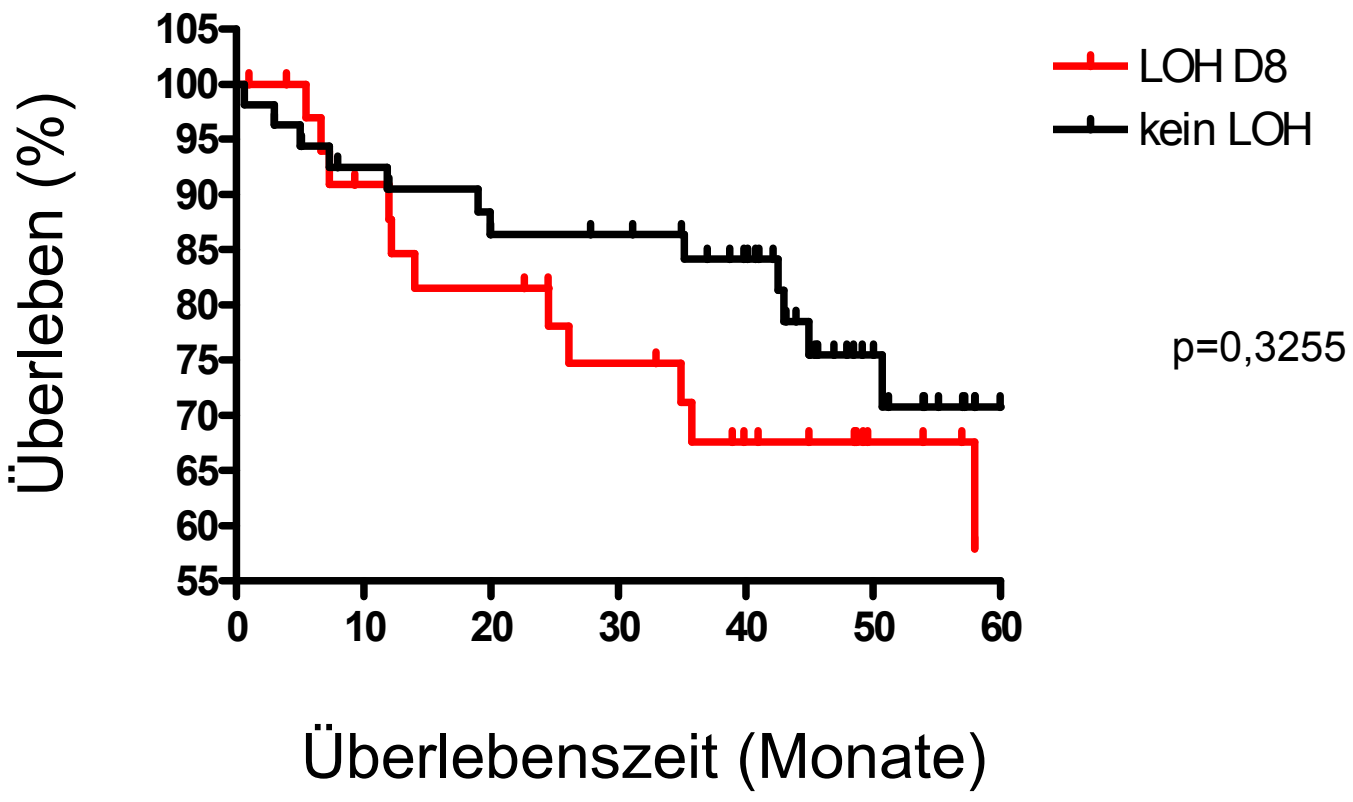

Abbildung 7: Kaplan-Meier-Überlebenskurve in Abhängigkeit eines LOH im Bereich 8p22 
Unterscheidet man nun aber zwischen Männern und Frauen zeigen sich Unterschiede. So sieht man bei Frauen eine signifikant schlechtere Prognose (5-JÜR von 30\% (p=0,0239)) bei Patientinnen mit einem Verlust der Heterozygotie der Region 8p22. Die 5-JÜR von Patientinnen ohne LOH in dieser Region beträgt ca. $80 \%$.

\section{D8S254}

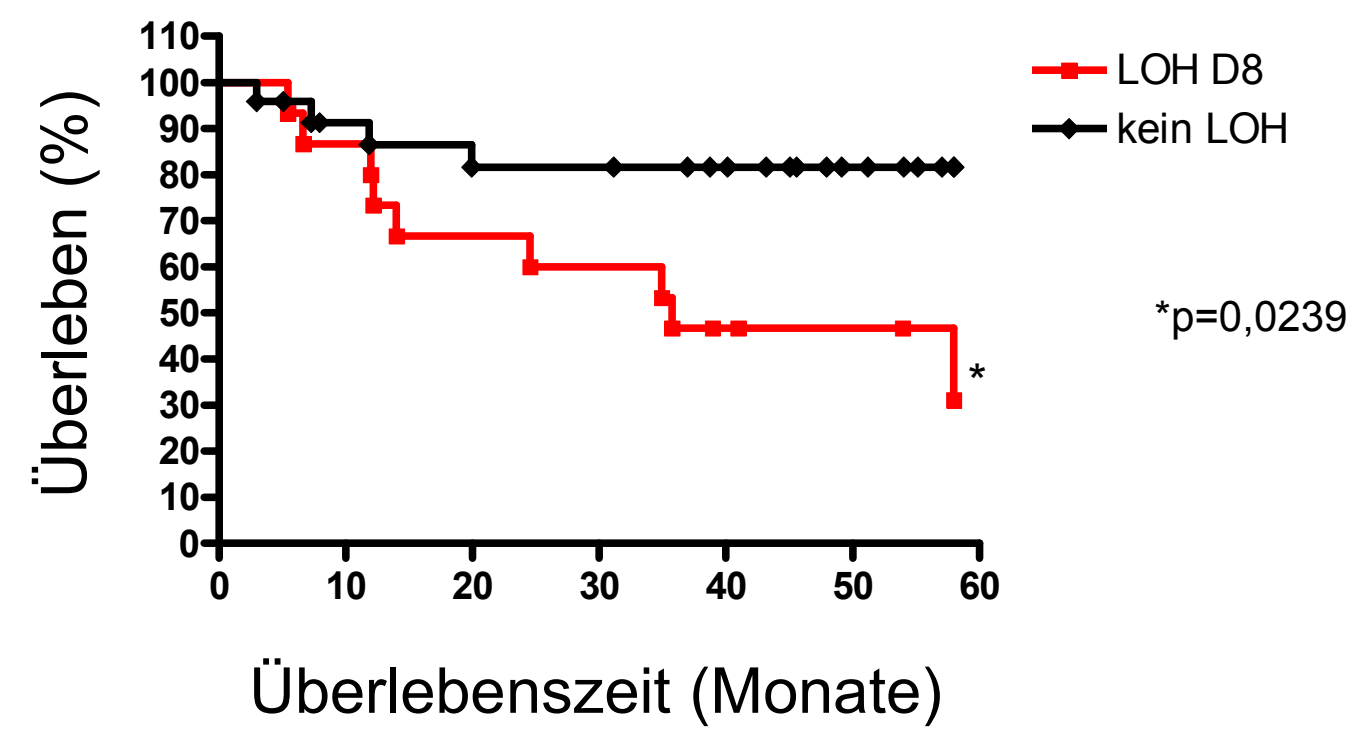

Abbildung 8: Kaplan-Meier-Überlebenskurve in Abhängigkeit eines LOH im Bereich 8p22 bei Frauen 
Bei Männern verhält es sich genau umgekehrt. Ein LOH 8p22 scheint für Männer prognostisch günstiger zu sein. So beträgt die 5-JÜR für Patienten mit LOH 85\%, während lediglich $60 \%$ der Patienten ohne LOH im Durchschnitt 5 Jahre überleben. Allerdings erwies sich dieser Trend mit einem p-Wert von 0,2172 als nicht signifikant.

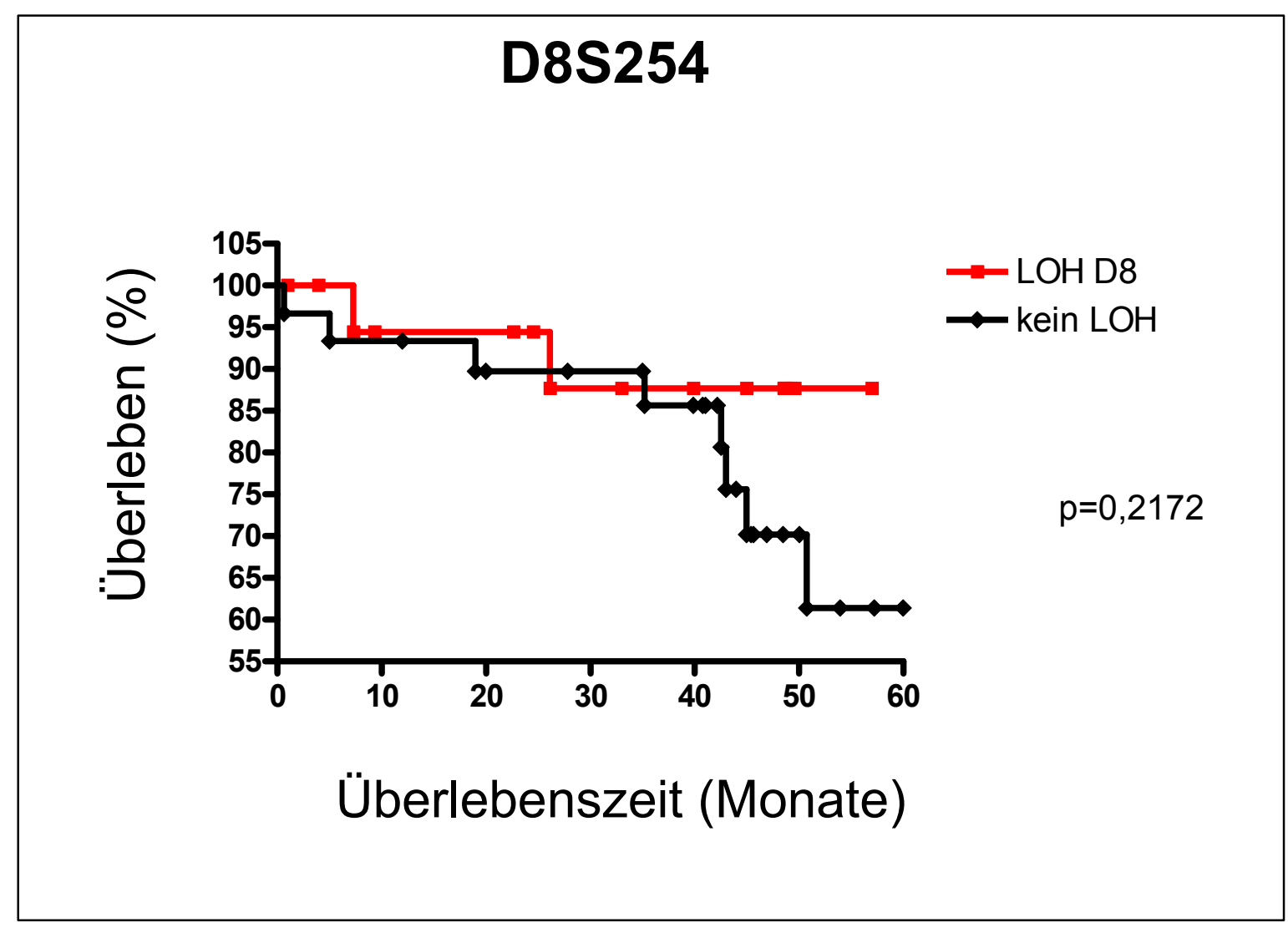

Abbildung 9: Kaplan-Meier-Überlebenskurve in Abhängigkeit eines LOH im Bereich 8p22 bei Männern

Es zeigten sich keine signifikanten Unterschiede bei Korrelationen nach dem Alter der Patienten. 


\subsubsection{Verlust der Heterozygotie der Region 18q21.1 und Patientenprognose}

Bei einem LOH der Region 18q21.1 zeigte sich für Patienten mit LOH ohne Unterscheidung des Geschlechtes eine signifikant schlechtere Prognose im Vergleich mit Patienten ohne einen LOH in dieser Region, was man an der deutlichen Diskriminierung der roten Kaplan-MeierKurve in Abbildung 10 erkennen kann. Die 5-JÜR für Patienten mit LOH beträgt ca. 60\%, bzw. 75\% für Patienten der Kontrollgruppe. ( $\mathrm{p}=0,0304)$. Auch bei einem LOH 18q21.1 ergaben sich keine Unterschiede in der Prognose im getrennten Vergleich der einzelnen Stadien.

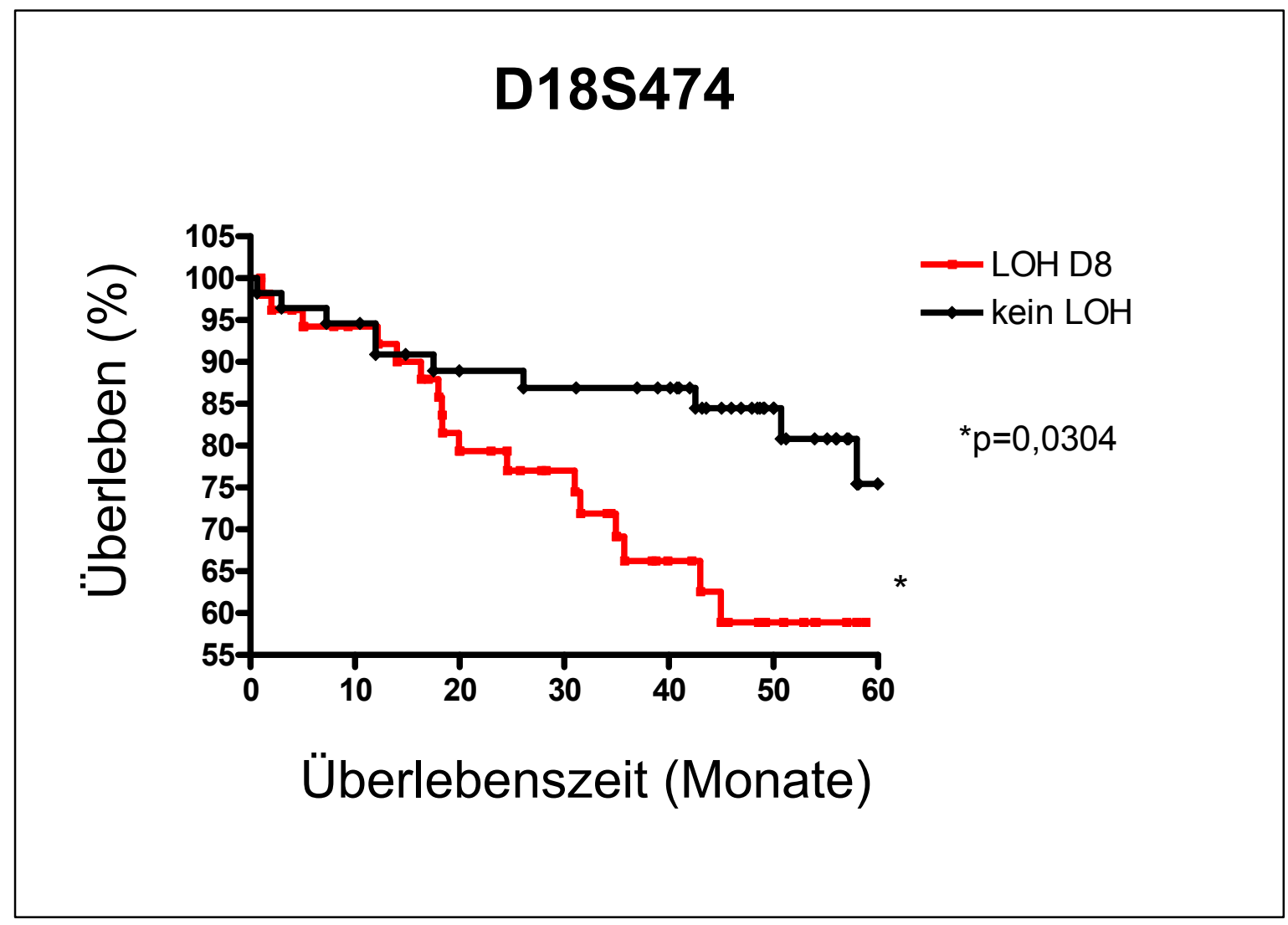

Abbildung 10: Kaplan-Meier-Überlebenskurve in Abhängigkeit eines LOH im Bereich 18q21.1 ohne Unterscheidung nach Geschlecht

Auch hier wurden nach der Trennung nach dem Geschlecht Bei einem Verlust der Heterozygotie der Region 18q21.1 Unterschiede in der Patientenprognose zwischen Männern und Frauen deutlich. 
Obwohl ein Verlust der Heterozygotie in dieser Region etwas häufiger bei Männern vorkommt, zeigt sich trotzdem eine signifikant schlechtere Prognose für Frauen. Analog zu einem LOH der Region 8p22 weisen Patientinnen mit einem LOH 18q21.1 eine deutliche, signifikante Diskrepanz in der 5-JÜR von ca. 45\% im Vergleich zu 70\% der Kontrollgruppe ohne LOH auf $(p=0,0255)$.

\section{D18S474}

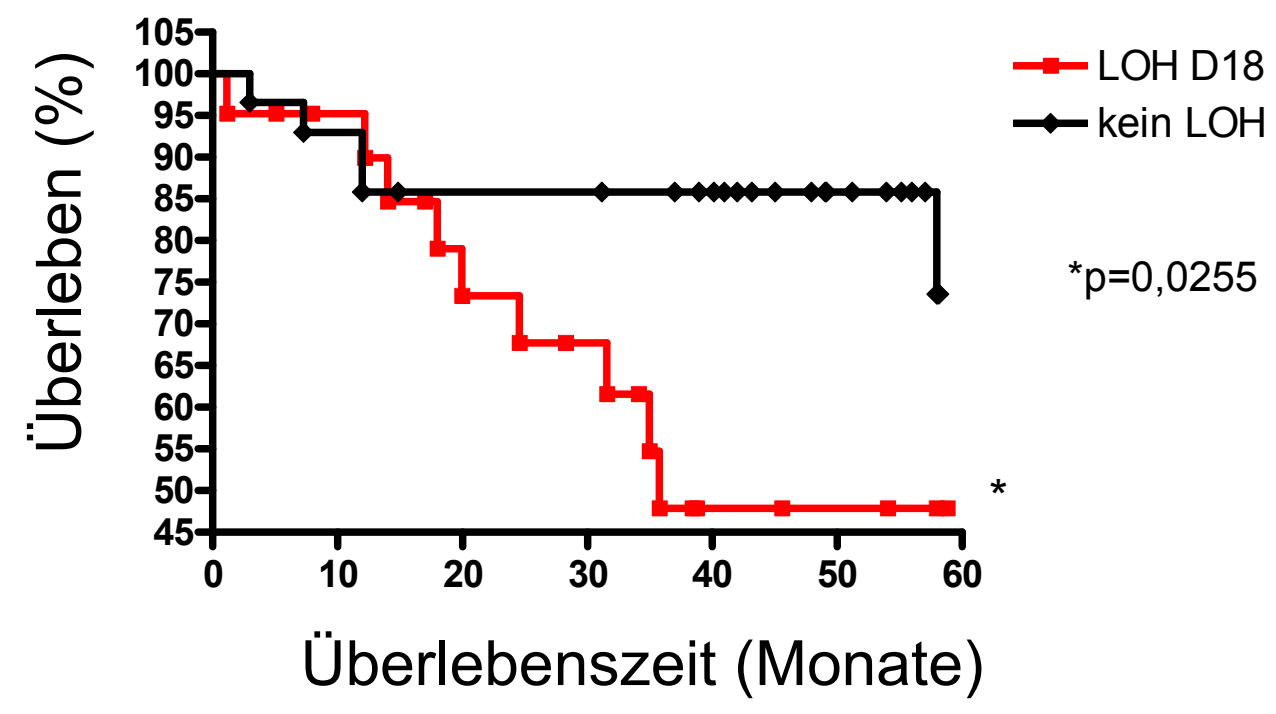

Abbildung 11: Kaplan-Meier-Überlebenskurve in Abhängigkeit eines LOH im Bereich 18q21.1 bei Frauen 
Bei Männern zeigt sich kein eindeutiger Trend für eine prognostische Unterscheidung. Zwar erkennt man einen minimalen Trend zur schlechteren Patientenprognose bei einem LOH (5JÜR 65\% gegenüber 75\% bei Männern ohne LOH), der sich aber deutlich nicht signifikant zeigt $(\mathrm{p}=0,3509)$.

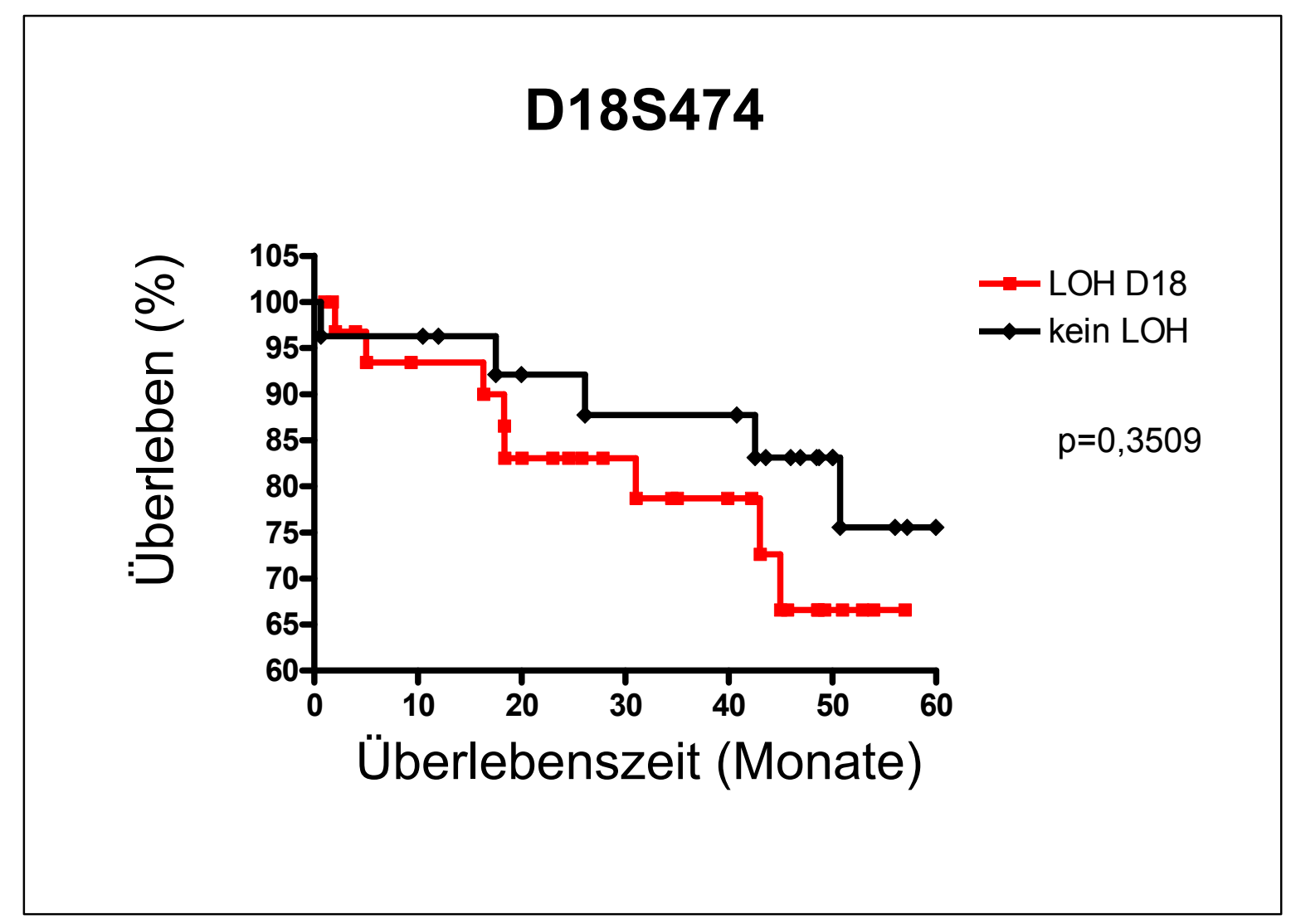

Abbildung 12: Kaplan-Meier-Überlebenskurve in Abhängigkeit eines LOH im Bereich 18q21.1 bei Männern 
Hier zeigt sich jetzt im Gegensatz zu der Region 8p22 ein signifikanter Unterschied zwischen den verschiedenen Altersstufen. So hat ein LOH 18q21.1 bei Patienten, die älter als 70 Jahre sind eine signifikant schlechtere Prognose mit einer 5-JÜR von 55\% (gegenüber $80 \%$ des Kontrollkollektivs) $(\mathrm{p}=0,0440)$. Bei Patienten unter 70 Jahren besteht lediglich ein minimaler, nicht signifikanter Trend zum schlechteren Überleben.

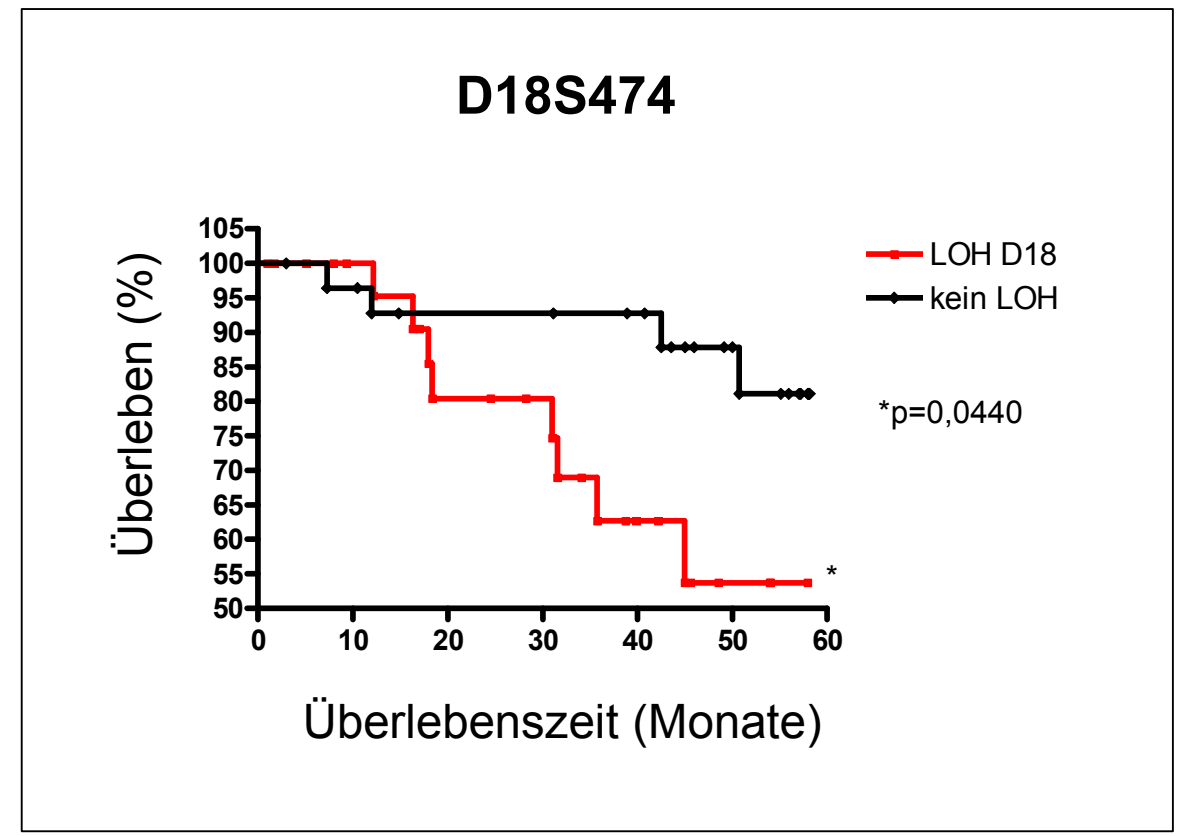

Abbildung 13: Kaplan-Meier-Überlebenskurve in Abhängigkeit eines LOH im Bereich 18q21.1 bei über 70jährigen Patienten

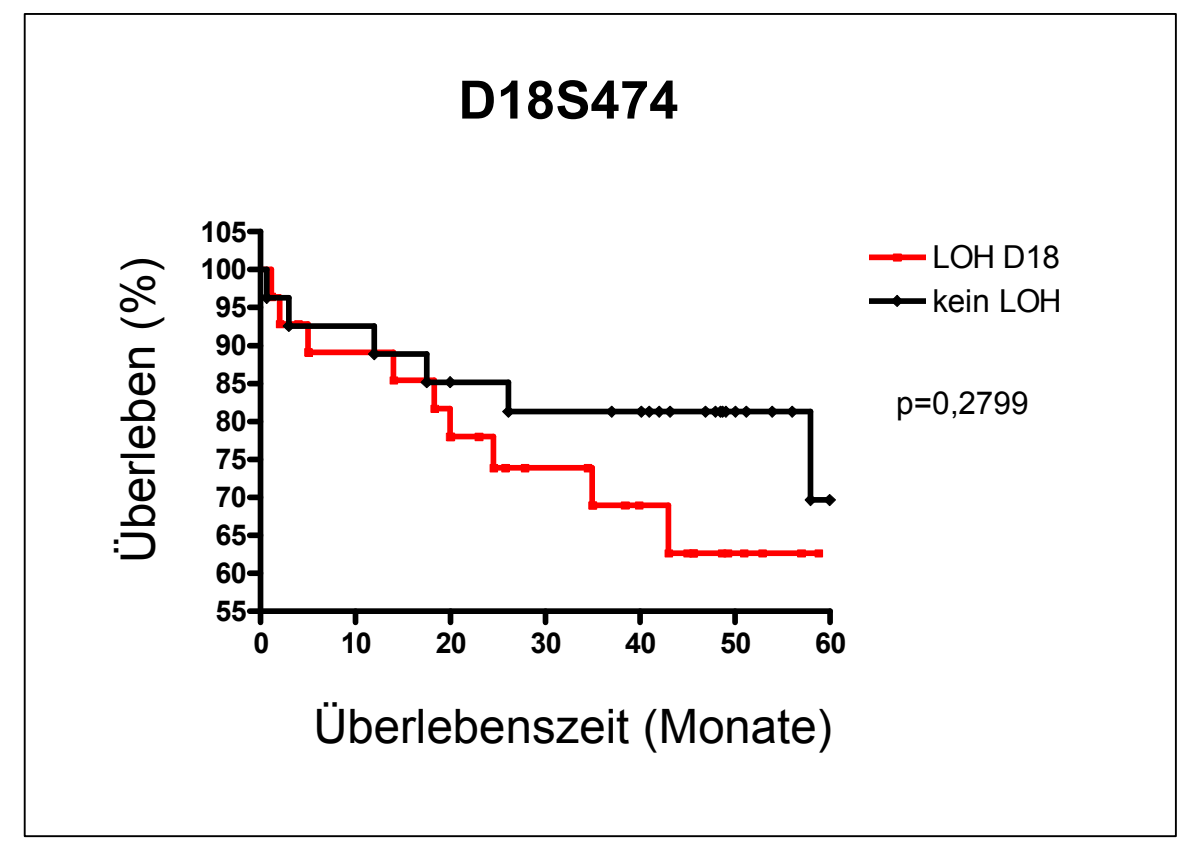

Abbildung 14: Kaplan-Meier-Überlebenskurve in Abhängigkeit eines LOH im Bereich 18q21.1 bei unter 70jährigen Patienten 


\subsubsection{Verlust der Heterozygotie der Regionen 8p22 und 18q21.1 und Patientenprognose}

Für Patienten, die einen $\mathrm{LOH}$ in beiden untersuchten chromosomalen Regionen aufweisen zeigt sich ebenfalls ein Trend zum schlechteren Überleben, allerdings ist dieser nicht signifikant $(\mathrm{p}=0,3255)$. Die 5-JÜR beträgt $60 \%$ bzw. $70 \%$ für Patienten mit einem LOH in beiden Regionen gegenüber Patienten ohne einen LOH. Aufgrund zu geringer Fallzahlen ist eine geschlechtsspezifische Unterscheidung nicht aussagekräftig.

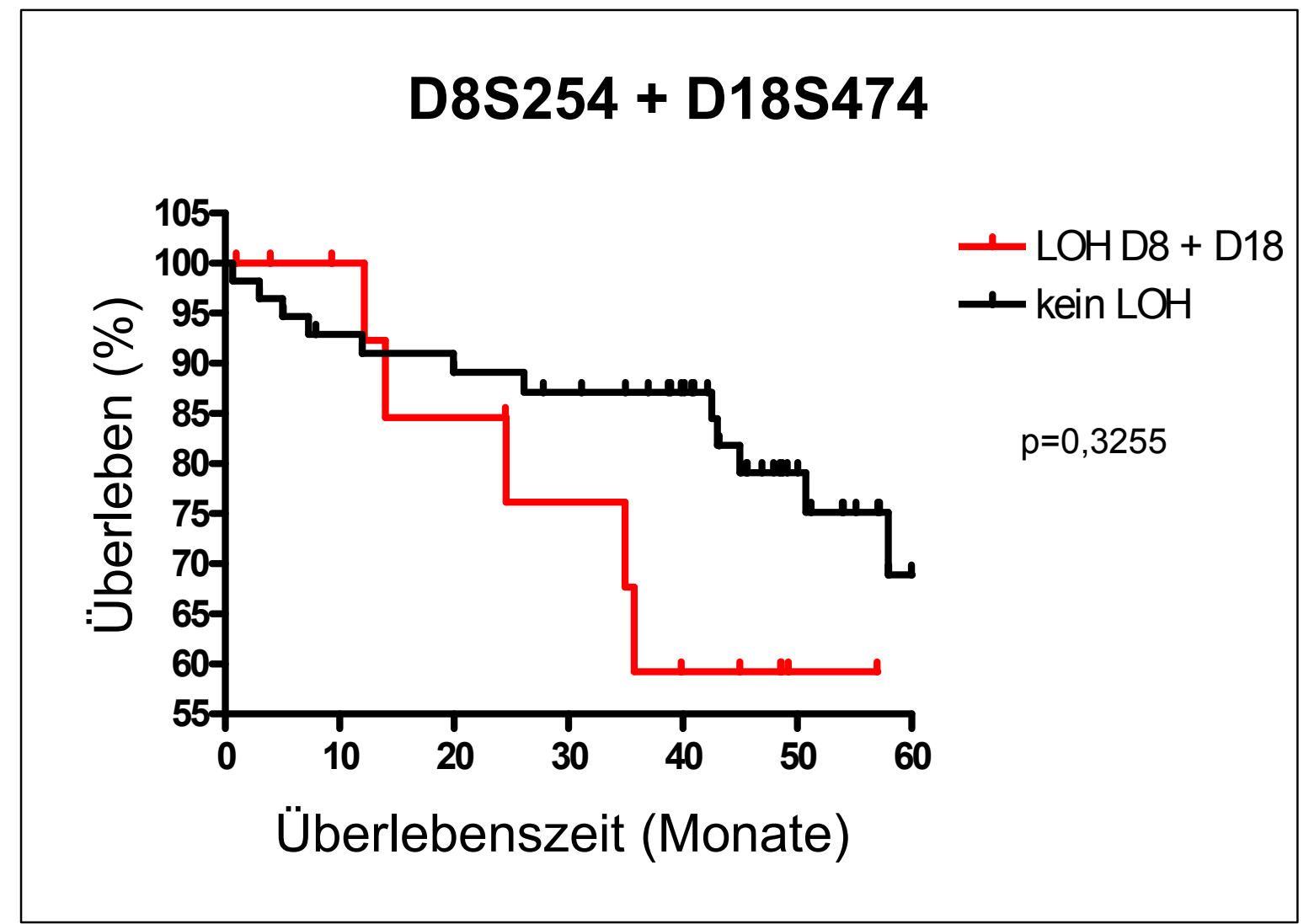

Abbildung 15: Kaplan-Meier-Überlebenskurve in Abhängigkeit eines doppelten LOH in den Bereichen 8p22 und 18q21.1 


\subsection{Prognostische Relevanz eines allelischen Verlustes des Markers D8S254}

In der vorliegenden Arbeit konnte kein signifikanter Zusammenhang zwischen einem LOH der Region 8p22 um den Mikrosatellitenmarker D8S254 und einer schlechteren Patientenprognose im gesamten Patientenkollektiv festgestellt werden. Es fand sich allerdings eine signifikante inverse Korrelation mit dem Tumor-Grading, so dass ein LOH eher in besser differenzierten Tumoren nachweisbar zu seien scheint. Interessanterweise fanden sich einige geschlechtsspezifische Besonderheiten. So konnte eine signifikante Häufung eines LOH der Region 8p22 bei Frauen mit einem Stadium IV und bei Männern mit Stadium II-Tumor gefunden werden. Die 5-JÜR bei Frauen mit LOH lag bei ca. 30\%, verglichen mit ca. 85\% der Frauen ohne LOH ( $\mathrm{n}=10, \mathrm{p}<0,05)$. Bei Männern lag die 5-JÜR mit über $85 \%$ bei den Patienten mit einem chromosomalen Verlust der Region 8p22 etwa 25\% höher als in der Kontrollgruppe ohne LOH $(n=42, p<0,05)$. Da die Anzahl der untersuchten Patienten in den Untergruppen sehr niedrig war, müssen die Ergebnisse allerdings mit Vorsicht gewertet und an größeren Patientenkollektiven bestätigt werden. Außer von der Gruppe um Tsai et al. (2002), die eine Häufung eines LOH der Region um den Marker D8S254 bei Männern feststellten, die in der vorliegenden Arbeit nicht bestätigt werden konnte, gibt es bisher keine weiteren Beobachtungen zu geschlechtsspezifischen Unterschieden.

Über eine prognostische Aussagekraft eines Verlustes der Region um den Primer D8S254 wurde als erstes von Halling et al. (1999) berichtet. Die Gruppe fand heraus, dass sowohl die Überlebenszeit als auch die Zeit bis zu einem erneuten Rezidiv bei Patienten mit einem LOH signifikant verkürzt war. Choi et al. zeigten 2002 hingegen, dass ein Verlust der Region 8p22 zwar im Zusammenhang multipler chromosomaler Verluste steht, aber für sich gesehen kein unabhängiger prognostischer Faktor ist. Lin konnte mit seiner Arbeitsgruppe zwar keinen direkten Zusammenhang zwischen einem LOH der Region D8S254 und einer schlechteren Patientenprognose feststellen, allerdings mit einer Aneuploidie (Lin et al., 2003). Kelemen et al. (1994) und Takanishi et al. (1997) fanden eine signifikante Korrelation mit Lymphknotenmetastasen. In kolorektalen Adenomen findet sich im Gegensatz zu den Karzinomen sehr selten ein LOH auf 8p (Cunningham et al., 1994; Gustafson et al., 1996). 
Dem zu Folge ist ein allelischer Verlust von $8 \mathrm{p}$ anscheinend ein spätes Ereignis in der Tumorgenese (Cunningham et al., 1994; Takanishi et al., 1997).

In Tabelle 24 sind die bisherigen Arbeiten und deren Aussagen zu Heterozygotieverlusten in der Region 8p22 zusammengefasst.

\begin{tabular}{|c|c|c|c|c|c|}
\hline $\begin{array}{l}\text { 8p22 und } \\
\text { D8S254 }\end{array}$ & Karzinom & $\begin{array}{l}\text { Informati- } \\
\text { vität }\end{array}$ & $\begin{array}{l}\text { Cut- } \\
\text { off }\end{array}$ & $\begin{array}{c}\text { LOH- } \\
\text { Frequenz }\end{array}$ & Aussage \\
\hline Rosler & Kolon & $61,8 \%$ & $30 \%$ & $39,3 \%$ & $\begin{array}{c}\text { Schlechtere Prognose für } \\
\text { Frauen }\end{array}$ \\
\hline $\begin{array}{l}\text { Halling et al. } \\
\text { (1999) }\end{array}$ & Kolon & $44,5 \%$ & $50 \%$ & $54,4 \%$ & $\begin{array}{l}\text { Schlechtere Prognose und } \\
\text { frühere Rezidive }\end{array}$ \\
\hline $\begin{array}{l}\text { Tsai et al } \\
(2002)\end{array}$ & Kolon & $56,4 \%$ & $?$ & $27,3 \%$ & Häufung bei Männern \\
\hline $\begin{array}{l}\text { Lin et al. } \\
(2003)\end{array}$ & Kolon & $47,3 \%$ & $\begin{array}{l}33 \% / \\
50 \%\end{array}$ & $49,1 \%$ & $\begin{array}{l}\text { Assoziation mit DNA- } \\
\text { Aneuploidie und mit } \\
\text { Fernmetastasen }\end{array}$ \\
\hline $\begin{array}{l}\text { Chang et al } \\
\qquad(2005)\end{array}$ & Kolon & $43,0 \%$ & $\begin{array}{l}33 \% / \\
50 \%\end{array}$ & $51,7 \%$ & $\begin{array}{l}\text { Schlechtere 3-JÜR bei } \\
\text { Stadium I, II und III- } \\
\text { Tumoren }\end{array}$ \\
\hline $\begin{array}{l}\text { Yaremko et al. } \\
\qquad(1996)\end{array}$ & Mamma & $66,7 \%$ & $?$ & $30,8 \%$ & $\begin{array}{c}\text { Assoziation mit } \\
\text { Tumorprogression }\end{array}$ \\
\hline
\end{tabular}

Tabelle 24: Zusammenfassung bisheriger Arbeiten mit dem Mikrosattelitenprimer D8S254. Informativität - Heterozygotenfrequenz. LOH-Frequenz - Anzahl der LOH's unter den informativen Fällen. Cut-off - Prozentualer Verlust des deletierten Allels 


\subsubsection{Potentielle Tumorsuppressorgene auf 8 p22}

Es gibt etliche Arbeiten, die zeigen, dass der Verlust der chromosomalen Region $8 \mathrm{p}$ in mehreren Tumorarten eine Rolle spielt und dass ein oder sogar mehrere Tumorsuppressorgene auf 8p lokalisiert zu sein scheinen (Kagan et al., 1995; Wright et al., 1998; Pineau et al., 1999; Miller et al., 2003; Wilson et al., 2003). Studien anhand eines Verlustes der Heterozygotie sowie mittels komparativer genomischer Hybridisierung haben bewiesen, dass ein Verlust der Region 8p nicht nur beim kolorektalen Karzinom (Vogelstein et al., 1989, Fujiwara et al., 1993 \& 1994; Farrington et al., 1996; Yaremko et al., 1994; Cunningham et al., 1993 \& 1994; Emi et al., 1992; Kelemen et al., 1994; Gustafson et al., 1996; Halling et al., 1999), sondern auch beim Magenkarzinom (French et al., 2004), Mamma-Karzinom (Bieche et al., 1995; Pykett et al., 1994), hepatozellulären Karzinom (Emi et al., 1992 \& 1993), Prostata-Karzinom (Macoska et al. 1995; Matsuyama et al., 1994; Trapman et al., 1994; Cher et al., 1994, Suzuki et al., 1995; Cunningham et al., 1996), Bronchial-Karzinom (Emi et al., 1992, Ohata et al., 1993, Lerebours et al., 1999, Wistuba et al., 1999), Pankreas-Karzinom (Wasylyshyn et al., 1991; Johansson et al., 1992), Harnblasen-Karzinom (Knowles et al., 1993; Ohgaki et al., 1999), Ovarial-Karzinom (Emi et al., 1992) und bei Kopf- und NackenKarzinomen (Naggar et al., 1995) auftreten kann.

Der funktionelle Beweis für ein Tumorsuppressorgen in dieser Region wurde durch experimentellen Transfer der Region 8p22 in Tumorzellen erbracht. Eine Amplifikation des kurzen Armes des Chromosom 8 und speziell der Region um den Marker D8S254 reduziert dabei die Tumoraktivität in verschiedenen Zelllinien (Gustafson et al., 1996; Tanaka et al., 1996; Seibold et al., 2003). Im Gegensatz dazu resultiert eine Deletion der Region um D8S254 in einer Tumorprogression (Ishii et al., 1999; Ohgaki et al., 1999; Sasiadek et al., 2001; Tsai et al., 2002; Vocke et al., 1996; Yaremko et al., 1995; Chuaqui et al., 1995; El Naggar et al., 2001). Diese Beobachtungen legen den Verdacht auf ein oder mehrere Tumorsuppressorgens auf diesem Arm nahe.

Im Jahr 2003 beschrieben Seibold und seine Arbeitsgruppe ein potentielles Tumorsuppressorgen (MTUS1), das weniger als 0,9 Megabasen von dem Marker D8S254 entfernt liegt. Das Genprodukt, ein Precursor-Protein von 436 Aminosäuren wird in die Mitochondrien eingeschleust und entwickelt seine tumorunterdrückende Aktivität durch Regulation zellulärer Proliferation mittels der Beeinflussung verschiedener mitochondrialer Prozesse. Bisher konnten allerdings noch keine Mutationen in MTUS1 nachgewiesen werden, 
Flanagan et al. grenzten 2004 in dem chromsomalen Bereich 8p23.1 eine 898 kBp umfassende Region ein, in der die Gene FLJ23749 und KIAA1456 lokalisiert sind. Über die Funktion dieser Gene ist nur wenig bekannt und es konnten ebenfalls bisher keine Mutationen gefunden werden. In der Region $8 \mathrm{p} 22$ wurden noch weitere mutmaßliche Tumorsuppressorgene postuliert, allerdings noch nicht endgültig bestätigt. 1998 wurde z.B. das DLC1-Gen (deleted in liver cancer) auf 8p22 als ein mögliches Tumorsuppressorgen gefordert (Yuan et al., 1998). Zwei Jahre später wurde von Wilson und seiner Arbeitsgruppe allerdings nachgewiesen, dass DLC1 weder in der Pathogenese des kolorektalen noch des ovariellen Karzinoms eine Rolle spielt (Wilson et al., 2000). Weitere Beispiele zeigt die Tabelle 25.

\begin{tabular}{|c|c|c|c|}
\hline Locus & Putatives Ts-Gen & Tumore & Literatur \\
\hline $8 \mathrm{p} 22$ & PRLTS & "HCC, CRC, NSCLC & Fujiwara et al. (1995) \\
\hline $8 \mathrm{p} 22$ & N33 & $\begin{array}{l}\text { CRC, HCC, Bronchial-, } \\
\text { Prostata-Karzinom, }\end{array}$ & $\begin{array}{l}\text { MacGrogan et al., (1996), } \\
\text { Bookstein et al. (1997) }\end{array}$ \\
\hline $8 \mathrm{p} 22$ & DLC1 & $\mathrm{HCC}$ & Yuan et al. (1998) \\
\hline $8 p 11-21$ & FRP1/FRZB & Mamma-Karzinom & Ugolini et al. (1999) \\
\hline $8 \mathrm{p} 12$ & NRG1 & $\begin{array}{l}\text { Mamma-Karzinom, } \\
\text { Pankreas-Karzinom }\end{array}$ & $\begin{array}{l}\text { Wang et al. (1999), Liu et al. } \\
\text { (1999), Adélaïde et al. } \\
(2003)\end{array}$ \\
\hline $8 \mathrm{p} 22$ & FEZ1 (LZTS1) & $\begin{array}{l}\text { Ösophagus-Karzinom, } \\
\text { Prostata-Karzinom, } \\
\text { Mamma-Karzinom, } \\
\text { Magen-Karzinom }\end{array}$ & $\begin{array}{l}\text { Ishii et al. (1999), Cabeza- } \\
\text { Arvelaiz et al. (2001), } \\
\text { Vecchione et al. (2001) }\end{array}$ \\
\hline $8 \mathrm{p} 23$ & LPTS & $\mathrm{HCC}$ & Liao et al. (2000) \\
\hline $8 \mathrm{p} 12$ & TACC1 & Mamma-Karzinom & Conte et al. (2002) \\
\hline 8p22 (D8S254) & MTUS1 & Zellkultur & Seibold et al. (2003) \\
\hline $8 \mathrm{p} 22$ & KIAA1456 & CRC & Flanagan et al. (2004) \\
\hline
\end{tabular}

Tabelle 25: Auflistung möglicher Tumorsuppressorgene auf 8p HCC - Hepatozelluläres

Karzinom CRC - Kolorektales Karzinom NSCLC - Nicht-kleinzelliges Bronchial-Karzinom 


\subsection{Prognostische Relevanz eines allelischen Verlustes des Markers D18S474}

In der vorliegenden Arbeit konnte ein signifikanter Zusammenhang zwischen einem LOH der Region 18q21.1 um den Mikrosatellitenmarker D18S474 und einer schlechteren Patientenprognose im gesamten Patientenkollektiv festgestellt werden $(p=0,0304)$. Des weiteren zeigte sich eine deutliche Häufung von LOH's bei Tumoren im UICC-Stadium II $(\mathrm{p}=0,0286)$. Auch bei den allelischen Verlusten des Markers D18S474 zeigten sich geschlechtsspezifische Unterschiede, indem bei Frauen eine hochsignifkante Korrelation mit schlechteren Tumorstadien gezeigt werden konnte. Weiterhin konnte festgestellt werden, dass ein LOH D18S474 hochsignifikant häufiger im Alter zwischen 60 und 79 Jahren auftritt. Bezüglich des Differenzierungsgerades zeigt sich signifikant, dass zwischen LOH-positiven und LOH-negativen Tumoren kein Unterschied besteht $(p>0,95)$. Da die Anzahl der untersuchten Patienten in den Untergruppen sehr niedrig war, müssen die Ergebnisse allerdings mit Vorsicht gewertet und an größeren Patientenkollektiven bestätigt werden.

In zahlreichen Arbeiten zuvor wurde bereits die Region $18 \mathrm{q}$ auf einen Verlust der Heterozygotie und eine prognostische Aussagekraft dieses Verlustes untersucht. Allerdings zeigten sich oftmals widersprüchliche Ergebnisse. So stellten einige Autoren die Hypothese auf, ein LOH 18q führe zu einer schlechteren Prognose für die Patienten (Kern et al., 1989; Lanza et al., 1998; Martinez-Lopez et al., 1998; Ogunbiyi et al., 1998; Jen et al., 1994; Font et al., 2001; Watanabe et al., 2001; Choi et al., 2002; Diep et al., 2003; Sarli et al., 2004, Bardi et al., 2004), während andere Forschungsgruppen diese Hypothese nicht bestätigen konnten (Cohn et al., 1997; Carethers et al., 1998; Halling et al., 1999; Zauber et al., 2004; Hadzija et al., 2004).

Die Gründe für diese Diskrepanz könnten zum einen darin liegen, dass verschiedene Mikrosatellitenloci auf 18q und somit jeweils spezifische Regionen untersucht wurden, dass die cut-off-Werte für einen $\mathrm{LOH}$ unterschiedlich angesetzt worden sind oder dass die unterschiedlichen Patientenkollektive bezüglich Alter, Geschlecht, wie z.B. bei Cohn und seiner Arbeitsgruppe 1997, Tumorstadium, Nachsorge, Beobachtungszeitraum und Einschlusskriterien stark divergieren und somit $\mathrm{zu}$ unterschiedlichen Ergebnissen führen können. Bei einigen Studien (Watanabe et al., 2001; Jen et al., 1994) wurden MSI-highTumore in die Kategorie ohne chromosomale Verluste eingestuft, weil sie diese in der Regel nur selten zeigen (Lengauer et al., 1998). Durch Southern-Blot-Analysen wurden aber geringe 
Frequenzen an allelischen Verlusten bei MSI-high-Tumoren festgestellt (Thibodeau et al., 1993). Somit kann dieser Einschluss der MSI-high-Tumore starken Einfluss auf die, womöglich falsche, prognostische Aussagekraft haben. Halling et al. beobachteten 1999, dass es keine signifikanten Unterschiede in der Patientenprognose bezüglich eines Verlustes von 18q gab. Sie zeigten aber eine signifikant schlechtere Prognose und frühere Rezidive bei Patienten mit LOH 18q als sie die MSI-high-Tumore in das Kontrollkollektiv der Patienten ohne allelische Verluste mit einbezogen. Sie zeigten somit auf, wie der Einschluss der MSIhigh-Patienten zu den Patienten ohne chromosomale Verluste die prognostische Aussagekraft chromosomaler Verluste eventuell fälschlicherweise verändern kann.

Vergleicht man die Publikationen in denen der Primer D18S474 für die Mikrosatellitenanalyse verwendet wurde, sieht man kaum noch eine Diskrepanz in den Ergebnissen. So ist bei allen in Tabelle 26 angegebenen Arbeiten entweder eine signifikante Korrelation zwischen einem LOH D18S474 und einer schlechteren Patientenprognose gefunden worden, oder es wurde nicht näher darauf eingegangen.

\begin{tabular}{|c||c|c|c|}
\hline $\begin{array}{c}\text { D18S474 und } \\
18 q 21.1\end{array}$ & Informativität & $\begin{array}{c}\text { LOH- } \\
\text { Frequenz }\end{array}$ & Aussage \\
\hline \hline Rosler & $76,4 \%$ & $49,1 \%$ & Schlechtere Prognose \\
\hline $\begin{array}{c}\text { Martinez-Lopez } \\
\text { et al. (1998) }\end{array}$ & $55,2 \%$ & $27,1 \%$ & $\begin{array}{c}\text { Schlechtere Prognose im Stadium II; besseres } \\
\text { Ansprechen von Chemotherapie bei LOH (!) }\end{array}$ \\
\hline $\begin{array}{c}\text { Font et al. } \\
(2001)\end{array}$ & $55,3 \%$ & $39,7 \%$ & $\begin{array}{c}\text { Schlechtere Prognose bei Stadium II- } \\
\text { Patienten }\end{array}$ \\
\hline $\begin{array}{c}\text { Choi et al. } \\
(2002)\end{array}$ & $59,0 \%$ & $74,8 \%$ & $\begin{array}{c}\text { Schlechtere Prognose, vor allem bei mehreren } \\
\text { LOH's }\end{array}$ \\
\cline { 2 - 5 } $\begin{array}{c}\text { Hadzija et al. } \\
(2004)\end{array}$ & $66,7 \%$ & $47,5 \%$ & $\begin{array}{c}\text { LOH häufiger in kleinen Tumoren, nicht nach } \\
\text { Prognose untersucht }\end{array}$ \\
\hline $\begin{array}{c}\text { Kim et al. } \\
(2005)\end{array}$ & n.a & n.a. & $\begin{array}{c}\text { Assoziation mit lymphovaskulärer Invasion } \\
\text { und schlechterem Differenzierungsgrad }\end{array}$ \\
\cline { 2 - 4 }
\end{tabular}

Tabelle 26: Zusammenfassung bisheriger Arbeiten mit dem Mikrosatellitenprimer D18S474. Informativität - Heterozygotenfrequenz. LOH-Frequenz - Anzahl der LOH's unter den informativen Fällen 


\subsubsection{Potentielle Tumorsuppressorgene auf 18q21.1}

Obwohl ein 18q-LOH in mehr als 70\% der Fälle das DCC-Gen (deleted in colon cancer) beinhaltet, ist dessen Bedeutung in der kolorektalen Tumorgenese nicht gesichert (Fazeli et al., 1997). Es finden sich noch mehrere Gene in der Nähe der Region 18q21.1, wie z.B. das bcl-2 (gastrin releasing peptide gene) und das yes-1, aber keines von diesen Genen konnte bei kolorektalen Karzinomen als verändert nachgewiesen werden. Die letzten beiden Kandidatengene DPC4/SMAD4 und MADH2/SMAD2, die beide zentromerisch zum DCCGen liegen, wurden neuerdings als die gesuchten Ts-Gene dieser Region für das kolorektale Karzinom angenommen (Hahn et al., 1996; Eppert et al., 1996; Riggins et al., 1996, White, 1998). SMAD 4 scheint das Hauptziel der chromosomalen Deletionen auf 18q zu sein. Es ist in ca. 50\% aller Pankreas-Karzinome (Hahn et al., 1996) und 20-30\% aller kolorektaler Karzinome (Thiagalingam et al., 1996; Woodford-Richens et al., 2001) inaktiviert. Allerdings ist es sehr unwahrscheinlich, dass alle chromosomalen Verluste auf 18q nur SMAD4 betreffen. Lediglich 30\% aller kolorektaler Tumore mit einer großen Deletion auf 18q weisen eine Mutation von SMAD4 auf (Thiagalingam et al., 1996). Bei etlichen Tumoren ohne SMAD4-Mutation sind SMAD2 oder DCC inaktiviert, ohne dass allerdings dadurch alle chromosomalen Verluste erfasst werden können (Thiagalingam et al., 1996, Riggins et al., 1996). Die Smad-Proteine sind die entscheidende Komponente des TGF $\beta$-Signalwegs, der das Wachstum epithelialer Zellen negativ reguliert. Takaku konnte dies im Tierversuch bestätigen. So entwickelten SMAD4/APC-compound heterozygote knock-out-Mäuse invasive Adenokarzinome, während bei SMAD2/APC-compound heterozygoten knock-out-Mäusen keine Unterschiede in der Anzahl, Größe und Form der Polypen von APC-heterozygoten knock-out-Mäusen auszumachen waren. Seine Resultate bestätigen, dass auf Chromosom 18q21 ein SMAD4-LOH eine signifikantere Rolle in der Kolonkarzinogenese spielt als SMAD2 (Takaku et al.,1998 \& 2002). SMAD3 ist in kolorektalen Karzinomen nicht signifikant mutiert (Arai et al., 1998b), Interessanterweise liegt auch SMAD7 auf 18q21, als negativer Regulator des TGF $\beta$-Signalwegs. SMAD7 unterdrückt diesen und ist somit ein mutmaßliches Onkogen. Es wurden bereits Arbeiten veröffentlicht, in denen ein Verlust des SMAD7-Gens mit einer besseren Patientenprognose korreliert ist (Boulay et al., 2003). Dem gegenüber stehen in vitro-Studien, die dem SMAD7 eine induzierende Wirkung auf die Apoptose und ihm somit zusätzlich eine Rolle als Ts-Gen zusprechen (Lallemand et al., 2001; Mazars et al., 2001). 
SMAD2 und SMAD7 liegen ebenfalls in oder nahe der minimalen Verlustregion auf 18q beim kolorektalen Karzinom (Miyaki et al., 2003). Trotzdem gibt es nur wenige Hinweise darauf, dass ein 18q-Verlust zu einer Inaktivierung von SMAD2 und SMAD7 führt (Boulay et al., 2003; Mehlen und Fearon, 2004; Fukushima et al., 2003). In einer Arbeit aus dem Jahr 2003 wurden 100 Patienten mit einem kolorektalen Karzinom auf Mutationen in SMAD2, SMAD3, SMAD4, SMAD6 und SMAD7 untersucht. Zusätzlich wurde auf ein Verlust der Region 18q21, der bekanntlich die beiden Gene SMAD2 und SMAD4 enthält, geachtet. Insgesamt konnten keine Veränderungen in den Genen SMAD2, SMAD3, SMAD6 und SMAD7 gefunden werden. Allerdings wurden in SMAD4 zu 5\% Punktmutationen entdeckt. Dies bestätigt einerseits die wichtige Rolle von SMAD4 und die fragliche Rolle von SMAD2 in der Tumorgenese, andererseits zeigt diese Studie auch, dass SMAD4-Inaktivierungen nicht nur durch chromosomale Verluste der Region 18q21 erfolgen können (Fukushima et al., 2003). Die wichtigsten Gene auf 18q sind nochmals in Tabelle 16 zusammengefasst.

\begin{tabular}{|c|c|c|c|}
\hline Lokus & Verändertes Gen & $\begin{array}{l}\text { Funktion des Wild-Typ Gen- } \\
\text { Produktes }\end{array}$ & $\begin{array}{c}\text { Prognostische } \\
\text { Aussagekraft eines } \\
\text { LOH beim CRC }\end{array}$ \\
\hline $18 \mathrm{q} 21.1$ & $\mathrm{DCC}$ & $\begin{array}{l}\text { Zell-Adhäsionsmolekül, mögliches } \\
\text { Tumorsuppressorgen }\end{array}$ & $\begin{array}{c}\text { Schlechtere } \\
\text { Patientenprognose }\end{array}$ \\
\hline $18 \mathrm{q} 21.1$ & $\begin{array}{l}\text { SMAD4 (DPC4, } \\
\text { MADH4) }\end{array}$ & $\begin{array}{l}\text { Nuklearer Transkriptionsfaktor in } \\
\text { TGF- } \beta 1 \text { Signalwegen, , Downstream- } \\
\text { mediator von Smad2, mögliches } \\
\text { Tumorsuppressorgen }\end{array}$ & $\begin{array}{c}\text { Schlechtere } \\
\text { Patientenprognose }\end{array}$ \\
\hline $18 \mathrm{q} 21.1$ & $\begin{array}{c}\text { SMAD2 } \\
(\mathrm{MADH} 2, \mathrm{JVI})\end{array}$ & Mögliches Tumorsuppressorgen & keine \\
\hline $18 \mathrm{q} 21.1$ & SMAD7 & $\begin{array}{l}\text { Mögliches Onkogen mit eventueller } \\
\text { tumor-unterdrückender Eigenschaft }\end{array}$ & $\begin{array}{c}\text { Bessere } \\
\text { Patientenprognose }\end{array}$ \\
\hline
\end{tabular}

Tabelle 27: mögliche Kandidaten-Ts-Gene auf 18q, deren Funktion und prognostische Aussagekraft

${ }^{1}$ CRC - kolorektales Karzinom 


\subsubsection{LOH D18S474 und Chemotherapie}

Neben der prognostischen Bedeutung könnte ein LOH 18q21.1 auch einen Einfluß auf die Therapie der Patienten haben. So konnten Barratt et al. (2002) zeigen, dass die Therapie mit 5-FU bei Patienten ohne Verlust der Heterozygotie der Region 18q signifikant besser wirkt als bei Patienten mit diesem LOH. Womöglich kann in Zukunft anhand des 18q-Status die Indikation für eine Chemotherapie leichter gestellt werden. Jen zeigte, dass Stadium IITumore mit einem LOH 18q21.1 sich klinisch wie Stadium III-Tumore mit dementsprechend schlechterer Prognose verhalten und forderte ebenfalls, dass diese Patienten einer Chemotherapie unterzogen werden (Jen et al., 1994). In einer Studie wurde gezeigt, dass zwar die Prognose bei Patienten mit einem Stadium II-Kolonkarzinom und einem LOH um den Marker D18S474 signifikant schlechter, allerdings das Ansprechen der Chemotherapie signifikant besser ist. Die Autoren stellten die Hypothese auf, dass dieser paradoxe Effekt durch ein besseres Ansprechen der zytotoxischen Chemotherapeutika bei Patienten erklärt werden kann, bei denen ein 18q LOH eine höhere Aggressivität bedingt hat, verglichen mit den anscheinend weniger ansprechenden Tumoren, bei denen noch beide 18q-Allele erhalten sind (Martinez-Lopez et al., 1998).

\subsection{Die chromosomalen Regionen 8p22 und 18q21.1}

Wie schon eine Arbeitsgruppe des Vogelstein-Labors um Zhou feststellte, gibt es auch unterschiedliche Folgen für die Patienten, wenn beide chromosomale Regionen 8p22 und 18q21.1 deletiert sind. Zhou stellte fest, dass 100\% der Patienten, die noch beide Allele hatten, nach fünf Jahren noch lebten. Die 5-JÜR bei Patienten mit einem Verlust einer der beiden Regionen lag bei $74 \%$ oder sogar bei $58 \%$ bei den Patienten mit einem LOH beider Regionen (Zhou, 2002). Auch in der hier vorliegenden Studie konnten Unterschiede festgestellt werden. Ein doppelter chromosomaler Verlust beider Regionen kommt demnach signifikant häufiger in Stadium IV und wesentlich seltener in Stadium I Tumoren vor, unabhängig vom Geschlecht. Jedoch kann über eine Prognose keine Aussage getroffen werden, lediglich ein Trend zum schlechteren Patientenüberleben ist zu erkennen.

Aber wie schon bei den beiden Regionen getrennt betrachtet, spiegeln sich auch bei einem kombinierten Verlust Unterschiede zwischen Frauen und Männern wieder. So kommt auch hier ein kombinierter LOH bei Frauen mit 80\% signifikant häufiger im Stadium IV vor. Da schon der chromosomale Verlust jeweils einer Region für Frauen wesentlich schlechter war, ist auch nicht verwunderlich, dass ein kombinierter Verlust beider Regionen eine infauste 
Prognose für Frauen hat. Keine dieser Patientinnen überlebte länger als 36 Monate während ca. 90\% der Patientinnen mit beiden erhaltenen Allelen über 5 Jahre lebten $(\mathrm{p}=0,0004)$. Dieser hochsignifikante Unterschied in der Prognose unterstützt die Behauptung von Choi, der 2002 berichtete, dass ein isolierter Verlust der Region $8 \mathrm{p}$ allein kein unabhängiger prognostischer Faktor ist, wohl aber in Kombination mit anderen chromosomalen Verlusten. Paradoxer Weise verhält es sich bei Männern allerdings exakt umgekehrt. Während keine der weiblichen Patienten fünf Jahre überlebte, ist kein einziger der elf männlicher Patienten mit einem Verlust beider Regionen gestorben. Die 5-JÜR der Patienten mit beiden erhaltenen Allelen lag nicht signifikant bei ca. $65 \%(\mathrm{p}>0,05)$ Allerdings ist $\mathrm{zu}$ beachten, dass ein kombinierter LOH bei diesen Männern wesentlich häufiger in Stadium I- bzw. II-Tumoren zu finden war $(p=0,0840)$. Nur einer dieser Patienten hatte ein Stadium IV-Karzinom. Wie schon bei den isolierten chromosomalen Verlusten müssen die Ergebnisse allerdings mit Vorsicht gewertet und an größeren Patientenkollektiven bestätigt werden.

\subsection{Problematik der LOH-Analyse}

Auch wenn ein Verlust der Heterozygotie oft signifikant mit einer schlechteren Patientenprognose (Martinez-Lopez et al., 1999) der Tumorprogressivität (Chang et al., 2005) oder dem Vorhandensein von Metastasen (Iino et al., 1994) korreliert wurde, ist trotzdem aufgrund der Koexistenz verschiedenster chromosomaler Verluste in individuellen kolorektalen Karzinomen Vorsicht geboten. Ein Verlust der Heterozygotie kann sich aufgrund verschiedener Ereignisse darstellen. Er kann durch mitotische Fehlverteilung (nondisjunction), Verlust eines Chromosomenabschnittes infolge einer Deletion, mitotische Rekombination zweier homologer Chromosomen, Rekombination zweier nicht-homologer Chromosomen (Translokation) oder durch Genkonversion enstehen (Cavenee et al., 1983 \& 1985; Stanbridge, 1990; Haber, 1999). Einzelne chromosomale Veränderungen sind demnach eventuell nur indirekte Marker einer Vielzahl chromosomaler Veränderungen, die z.B. für die Aggressivität eines Tumors verantwortlich sind (Vogelstein et al., 1989; Kern et al., 1989). Alternativ dazu kann das große Netz aus chromosomalen Verlusten, das durch GenomAnalysen angenommen wird, einige LOH's enthalten, die keinen biologischen Effekt auf das Tumor-Wachstum haben, aber im Zusammenhang mit der Tumorprogression auftreten und so eine Anhäufung genetischer Veränderungen in fortgeschrittenen Tumor-Stadien widerspiegeln können (Vogelstein et al., 1989; Kern et al., 1989). Aus dieser Perspektive aus gesehen, ist zu beachten, dass bei Magen-Karzinomen ein hoher und ein niedriger Level an chromosomalen Verlusten (z.B. der Regionen 5q, 9p, 13q, 17p und 18q) mit einem hohen 
bzw. niedrigen Risiko eines Tumor-bedingten Todes korreliert ist (Choi et al., 2000) und auch beim kolorektalen Karzinom hat die Anzahl der chromosomalen Verluste nachweislich einen Einfluss auf das Patientenüberleben (Zhou et al., 2002, Choi et al., 2002), wie auch in der vorliegenden Arbeit bestätigt wurde. Diese Erkenntnis, dass die Anzahl der chromosomalen Verluste einen Einfluss auf die Patientenprognose hat, fordert, dass eine große Auswahl an Mikrosatellitenmarkern verschiedener Regionen plausibel die Effekte spezifischer chromosomaler Verluste bei verschiedenen Tumoren erklären könnte.

Eine weitere Fehlerquelle hat Lindforss mit seinen Kollegen 2000 festgestellt. Sie analysierten ebenfalls Biopsien von kolorektalen Karzinomen auf allelische Verluste, nur achteten sie dabei besonders auf den Entnahmeort der Biopsie. So stellten sie fest, dass der LOH-Status in Tumorzellen je nach Lokalisierung sehr heterogen sein kann und, dass immer multiple Biopsien von Tumoren zur Mikrosatellitenanalyse entnommen werden müssen, um eine exakte Aussage treffen zu können (Lindforss, 2000).

Insgesamt sind wiederholt genetische Veränderungen, wie ein Verlust der Heterozygotie beim kolorektalen Karzinom nachgewiesen worden. Nach der Knudson'schen Zwei-Hit-Hypothese aus dem Jahr 1971 ist solch ein Verlust für die Inaktivierung von Tumorsuppressorgenen verantwortlich. Dennoch finden sich doch zahlreiche Tumore, in denen keine chromosomalen Deletionen festgestellt werden konnten. Demnach muss es noch weitere Wege für eine Inaktivierung von Tumorsuppressogenen geben, die ohne chromosomale Verluste einhergehen. Diese sog. epigenetischen Mechanismen sind z.B. die Hypermethylierung der Promotor-Region eines Ts-Gens (Garinis et al., 2002, Grady et al., 2000; Esteller et al., 2000 \& 2001; Baylin und Herman, 2000; Jones und Laird, 1999) oder die Haploinsuffizienz (Fero et al., 1998; Ingram et al., 2000; Kwabi-Addo et al., 2001). Auch intragene Mutationen, wie Punktmutationen können für den Ausfall eines Tumorsuppressorgens verantwortlich sein (Fukushima et al., 2003).

Aufgrund dieser Erkenntnisse muss auch die bewährte Hypothese nach Knudson etwas in Frage gestellt werden.

Ebenso muss ein LOH auch nicht zwingend einen Hinweis auf ein Ts-Gen geben. Der Verlust der Heterozygotie ist als Ergebnis der chromosomalen Instabilität und der fehlenden Reparatur von DNA-Doppelstrangbrüchen anzusehen, die für Tumorzellen charakteristisch sind. Eventuell sind daher einige dieser LOH's lediglich Nebenprodukte von spezifischen chromosomalen Instabilitäten und kein Hinweis auf mögliche Ts-Gene. 
In der vorliegenden Arbeit konnte gezeigt werden, dass ein allelischer Verlust (LOH - "loss of heterozygosity") des Mikrosatellitenmarkers D18S474 signifikant mit einer schlechteren Patientenprognose bei Patienten mit kolorektalen Karzinomen im Stadium I-IV korreliert ist. Dies steht in guter Übereinstimmung mit den Ergebnissen vieler anderer Arbeitsgruppen. Neben der prognostischen Bedeutung könnte ein LOH 18q21.1 auch einen Einfluß auf die Therapie der Patienten haben. Patienten im Stadium II mit LOH D18S474 könnten beispielsweise von einer adjuvanten Chemotherapie eher profitieren als Patienten ohne LOH D18S474. Somit erscheint die Bestimmung des LOH D18S474 eine sinvolle Ergänzung der bisherigen pathologisch-anatomischen Tumoranalysen darzustellen.

Im Gegensatz zu anderen Arbeitsgruppen konnte keine Korrelation eines allelischen Verlustes des Mikrosatellitenmarkers D8S254 oder einer Kombination von LOH D8S254 und D18S474 bei Patienten mit kolorektalen Karzinomen im Stadium I-IV mit der Patientenprognose gezeigt werden. Möglicherweise ist die Anzahl der untersuchten Tumore ( $n=144)$ zu klein oder der analysierte Nachbeobachtungszeitraum ( $\mathrm{t}=39,6$ Monate) zu kurz, um signifikante Ergebnisse für diesen Marker oder diese Markerkombination zu erhalten. Dementsprechend kann eine Nachuntersuchung zu einem späteren Zeitpunkt und/oder die Untersuchung eines größeren Kollektivs sinnvoll sein.

Interessanterweise fanden sich im Rahmen dieser Studie geschlechtsspezifische Unterschiede für die Tumoreigenschaften und die Prognose sowohl für Tumoren mit einem allelischen Verlust im Mikrosatellitenmarker D8S254 und D18S474. Ein LOH des Markers D8S254 bei Frauen scheint signifikant häufiger mit einem Stadium IV-Tumor, bei Männern jedoch signifikant häufiger mit einem Tumor des Stadium II korreliert zu sein. Frauen mit einem LOH des Markers D18S474 weisen signifikant weniger Stadium I-Tumore auf, jedoch signifikant häufiger Stadium IV-Tumore. Bei Männern hingegen zeigt sich kein Zusammenhang. Diese Unterschiede in der Verteilung spiegeln sich auch in der durchschnittlichen Überlebenszeit wieder. Demnach haben Frauen mit einem LOH sowohl der Region 8p22 als auch der Region 18q21.1 und noch deutlicher in Kombination eine signifikant schlechtere Prognose als Patientinnen mit einem kolorektalen Karzinom ohne chromosomalen Verlust einer dieser beiden Regionen. Da die Anzahl der untersuchten Patienten in den Untergruppen sehr niedrig war, müssen die Ergebnisse allerdings mit Vorsicht gewertet und an größeren Patientenkollektiven bestätigt werden. 
1. Adélaïde J, Huang HE, Murati A, Alsop AE, Orsetti B, Mozzioconacci MJ, Popovici C, Ginestier C, Letessier A, Basset C, Coutay-Cahen C, Jacquemier J, Theillet C, Birnbaum D, Edwards PA, Chaffanet M. (2003) A recurrent chromosome translocation breakpoint in breast and pancreatic cancer cell lines targets the heregulin/NRG1 gene. Genes Chromosomes Cancer 37(4): 333-345.

2. Arai T, Akiyama Y, Yamamura A, Hosoi T, Shibata T, Saitoh K, Okabe S, Yuasa Y. (1998a) Allelotype analysis of early colorectal cancers with lymph node metastasis. Int J Cancer 79 (4): 418-423.

3. Arai T, Akiyama Y, Okabe S, Ando M, Endo M, Yuasa Y. (1998b) Genomic structure of the human Smad3 gene and its infrequent alterations in colorectal cancers. Cancer Lett 122:157-163.

4. Bardi G, Fenger C, Johansson B, Mitelman F, Heim S. (2004) Tumor Karyotype Predicts Clinical Outcome in Colorectal Cancer Patients. Journal of Clin Onc 22(13):2623-2634

5. Barratt PL, Seymour MT, Stenning SP, Georgiades I, Walker C, Birbeck K, Quirke P. (2002) DNA markers predicting benefit from adjuvant fluorouracil in patients with colon cancer: a molecular study. The Lancet 360:1381-1391.

6. Baylin SB, Herman JG (2000) DNA hypermethylation in tumorigenesis: epigenetics joins genetics. Trends Genet 16:168-174.

7. Bergerheim USR, Kunimi K, Collins VP, Ekman P. (1991) Deletion mapping of chromosomes 8, 10, and 16 in human prostate carcinoma. Genes Chromosomes Cancer 3: 215-220.

8. Bieche I, Lidereau R. (1995) Genetic alterations in breast cancer. Genes Chromosomes Cancer 14:227-251.

9. Bookstein R, Bova GS, MacGrogan D, Levy A, Isaacs WB. (1997) Tumor-suppressor genes in prostatic oncogenesis: a positional approach. Br J Urol 79: 28-36.

10. Boulay JL, Mild G, Lowy A, Reuter J, Lagrange M, Terracciano L, Laffer U, Herrmann R, Rochlitz C. (2003) SMAD7 is a prognostic marker in patients with colorectal cancer. Int J Cancer 104:446-449. 
11. Bova GS, MacGrogan D, Levy A, Pin SS, Bookstein R, Isaacs WB. (1993) Homozygous deletion and frequent allele loss of chromosome 8p22 loci in human prostate cancer. Cancer Res 53:3869-3873.

12. Cabeza-Arvelaiz Y, Sepulveda JL, Lebovitz RM, Thompson TC, Chinault AC. (2001) Functional identification of LZTS1 as a candidate prostate tumor-suppressor gene on human chromosome 8p22. Oncogene 20:4169-4179.

13. Canzian F, Salovaara R, Hemminki A, Kristo P, Chadwick RB, Aaltonen LA, de la Chapelle A. (1996) Semiautomated Assessment of loss of heterozygosity and replication error in tumors. Cancer Res 56(14): 3331-3337.

14. Carethers JM, Hawn MT, Greenson JK, Hitchcock CL, Boland CR. (1998) Prognostic significance of allelic loss at chromosome 18q21 for stage II colorectal cancer. Gastroenterology 114:1188-1195.

15. Cavenee WK, Dryja TP, Phillips RA Benedict WF, Godbout R, Gallie BL, Murphree AL, Strong LC, White RL. (1983) Expression of recessive alleles by chromosomal medchanisms in retinoblastoma. Nature 305 (5937): 779-784.

16. Cavenee WK, Hansen MF, Nordenskjold M, Kock E, Maumenee I, Squire JA, Phillips RA, Gallie BL. (1985) Genetic origin of mutations predisposing to retinoblastoma. Science 228 (4698):501-503.

17. Chang SC, Lin JK, Lin TC, Liang WY. (2005) Loss of heterozygosity: An independent prognostic factor of colorectal cancer. World J Gastroenterol 11(6): 778784.

18. Cher ML, Macgrogan D, Bookstein R, Brown JA, Jenkins RB, Jensen RH. (1994) Comparative genomic hybridization, allelic imbalance, and fluorescence in situ hybridization on chromosome 8 in prostate cancer. Genes Chromosomes Cancer 11:153-162.

19. Cho KR ,Fearon ER. (1995) DCC: linking tumor suppressor genes and altered cell surface interactions in cancer? Curr Opin Genet Develop 5(1): 72-78.

20. Choi SW, Choi JR, Chung YJ, Kim KM, Rhyu MG. (2000) Prognostic implications of microsatellite genotypes in gastric carcinoma. Int J Cancer 89:378-383.

21. Choi SW, Lee KJ, Bae YA, Min KQ, Kwon MS, Kim KM, Rhyu MG. (2002) Genetic Classification of Colorectal Cancer Based on Chromosomal Loss and Microsatellite Instability Predicts Survival. Clinical Cancer Research 8:2311-2322. 
22. Chuaqui RF, Sanz-Ortega J, Vocke C, Linehan WM, Sanz-Esponera J, Zhuang Z, Emmert-Buck MR, Merino MJ. (1995) Loss of heterozygosity on the short arm of chromosome 8 in male breast carcinomas. Cancer Res 55:4995-4998.

23. Chughtai SA, Crundwell MC, Cruickshank NR, Affie E, Armstrong S, Knowles MA, Takle LA, Kuo M, Khan N, Phillips SM, Neoptolemos JP, Morton DG. (1999) Two novel regions of interstitial deletion on chromosome $8 \mathrm{p}$ in colorectal cancer. Oncogene 18:657-65.

24. Cohn KH, Ornstein DL, Wang F, LaPaix FD, Phipps K, Edelsberg C, Zuna R, Mott LA, Dunn JL. (1997) The significance of allelic deletions and aneuploidy in colorectal carcinoma. Results of a 5-year follow-up study. Cancer 79(2):233-244.

25. Conte N, Charafe-Jauffret E, Delaval B, Adelaide J, Ginestier C, Geneix J, Isnardon D, Jacquemier J, Birnbaum D. (2002) Carcinogenesis and translational controls: TACC1 is down-regulated in human cancers and associates with mRNA regulators. Oncogene 21: 5619-5630.

26. Cunningham C, Dunlop MG, Bird CC, Wyllie AH. (1994) Deletion analysis of chromosome 8p in sporadic colorectal adenomas. Br J Cancer 70:18-20.

27. Cunningham JM, Shan A, Wick MJ, McDonnell SK, Schaid DJ, Tester DJ, Qian J, Takahashi S, Jenkins RB, Bostwick DG, Thibodeau SN. (1996) Allelic imbalance and microsatellite instability in prostatic adenocarcinoma. Cancer Res 56:4475-4482.

28. Diep CB, Thorstensen L, Meling GI, Skovlund E, Rognum TO, Lothe RA. (2003) Genetic Tumor Markers With Prognostic Impact in Dukes' Stages B and C Colorectal Cancer Patients. Journal of Clinical Oncology 21(5):820-829.

29. El Naggar AK, Mao L, Staerkel G, Coombes MM, Tucker SL, Luna MA, Clayman GL, Lippman S, Goepfert H. (2001) Genetic heterogeneity in saliva from patients with oral squamous carcinomas: implications in molecular diagnosis and screening. J Mol Diagn 3: 164-170.

30. Emi M, Fujiwara Y, Nakajima T, Tsuchiya E, Tsuda H, Hirohashi S, Maeda Y, Tsuruta K, Miyaki M, Nakamura Y. (1992) Frequent loss of heterozygosity for loci on chromosome $8 \mathrm{p}$ in hepatocellular carcinoma, colorectal cancer and lung cancer. Cancer Res 52:5368-5372.

31. Emi M, Fujiwara Y, Ohata H, Tsuda H, Hirohashi S, Koike M, Miyaki M, Monden M, Nakamura Y. (1993) Allelic loss at chromosome band 8p21.3-p22 is associated 
with progression of hepatocellular carcinomas. Genes Chromosomes Cancer 7:152157.

32. Eppert K, Scherer SW, Ozcelik H, Pirone R, Hoodless P, Kim H, Tsui LC, Bapat B, Gallinger S, Andrulis IL, Thomsen GH, Wrana JL, Attisano L. (1996) MADR2 maps to $18 \mathrm{q} 21$ and encodes a TGFbeta-regulated MAD-related protein that is functionally mutated in colorectal carcinoma. Cell 86:543-552.

33. Esteller M, Corn PG, Baylin SB, Herman JG. (2001) A Gene Hypermethylation Profile of Human Cancer. Cancer Research 61:3225-3229.

34. Esteller M, Sparks A, Toyota, M, Sanchez-Cespedes M, Capella G, Peinado MA, Gonzales S, Tarafa G, Sidransky D, Meltzer SJ, Baylin SB, Herman JG. (2000) Analysis of Adenomatous Polyposis Coli Promotor Hypermethylation in Human Cancer. Cancer Research 60:4366-4371.

35. Fazeli A, Dickinson SL, Hermiston ML, The RV, Eteen RG, Small CG, Stoeckli ET, Keino-Masu K, Masu M, Rayburn H, Simons J, Bronson RT, Tessier-Lavigne M, Weinberg RA. (1997) Phenotype of mice lacking functional deleted in colorectal cancer (Dcc) gene. Nature 386:796-804.

36. Fearon ER, Vogelstein B. (1990) A genetic model for colorectal tumorigenesis. Cell 61 (5): 749-867.

37. Fearon ER, Cho KR, Nigro JM, Kern SE, Simons JW, Ruppert JM, Hamilton SR, Preisinger AC, Thomas G, Kinzler KW, Vogelstein B. (1990) Identification of a chromosome 18q gene that is altered in colorectal cancers. Science 247:49-56.

38. Fero ML, Randel E, Gurley KE, Roberts JM, Kemp CJ. (1998) The murine gene p27Kip1 is haplo-insufficient for tumour suppression. Nature 396:177-180.

39. Flanagan JM, Healeay S, Young J, Whitehall V, Trott DA, Newbold RF, ChenevixTrench G (2004) Mapping of a Candidate Colorectal Cancer Tumor-Suppressor Gene to a 900-Kilobase Region on the short Arm of Chromosome 8. Genes Chromosomes Cancer 40:247-260.

40. Font A, Abad A, Monzo M, Sanchez JJ, Guillot M, Manzano JL, Pinol M, Ojanguren I, Rosell R. (2001) Prognostic value of K-ras mutations and allelic imbalance on chromosome 18q in patients with resected colorectal cancer. Dis Colon Rectum 44(4): 549-557.

41. French AJ, Petroni G, Thibodeau SN, Smolkin M, Bissonette E, Roviello F, Harper JC, Koch BR, Anderson SA, Hebbring SJ, Powell SM. (2004) Allelic Imbalance of 8p 
Indicates Poor Survival In Gastric Cancer. Journal of Molecular Diagnostics 6(3):243252.

42. Fujiwara Y, Emi M, Ohata H, Kato Y, Nakajima T, Mori T, Nakamura Y. (1993) Evidence for the presence of two tumor suppressor genes on chromosome $8 \mathrm{p}$ for colorectal carcinoma. Cancer Res 53 (5): 1172-1174.

43. Fujiwara Y, Ohata H, Emi M, Okui K, Koyama K, Tsuchiya E, Nakajima E, Monden M, Mori T, Kurimasa A, Oshimura M, Nakamura Y. (1994) A 3Mb physical map of the chromosome region 8p21.3-p22, including a 600-kb region commonly deleted in human hepatocellular carcinomas, colorectal cancer, and non-small cell lung cancer. Genes Chromosomes Cancer 10:7-14.

44. Fujiwara Y, Ohata H, Kuroki T, Kovama K, Tsuchiva E, Monden M, Nakamura Y. (1995) Isolation of a candidate tumor suppressor gene on chromosome 8p21.3-p22 that is homologous to an extracellular domain of the PDGF receptor beta gene. Oncogene 10(5):891-895.

45. Fukushima T, Mashiko M, Takita K Otake T, Endo Y, Sekikawa K, Takenoshita S. (2003) Mutational analysis of TGF-beta type II receptor, Smad2, Smad3, Smad4, Smad6 and Smad7 genes in colorectal cancer. J Exp Clin Cancer Res 22: 315-320.

46. Garinis GA, Menounos PG, Spanakis NE, Papadopoulous K, Karavitis G, Parassi I, Christeli E, Patrinos GP, Manolis EN, Peros G. (2002) Hypermethylation associated transcriptional silencing of E-cadherin in primary sporadic colorectal carcinomas. $\mathrm{J}$ Pathol 198(4):442-449.

47. GDB: GDB Human Genome Database [database online]. Http://www.gdb.org.

48. Grady WM, Willis J, Guilford PJ, Dunbier AK, Toro TT, Lynch H, Wiesner G, Ferguson K, Eng C, Park JG, Kim SJ, Markowitz S. (2000) Methylation of the CDH1 promoter as the second genetic hit in hereditary diffuse gastric cancer. Nat Genet 26:16-17.

49. Gruis NA, Abeln ECA, Bardoel AFJ, Devilee P, Frants RR, Cornelisse CJ. (1993) PCR-based microsatellite polymorphism in the detection of loss of heterozygosity in fresh and archival tumor tissue. Br J Cancer 68(2): 308-313.

50. Gustafson C, Wilson PJ, Lukesis R, Baker E, Woollatt E, Annab L, Hawke L, Barret JC, Chenevix-Trench G. (1996) Functional evidence for a colorectal cancer tumorsuppressor gene at chromosome $8 \mathrm{p} 22-23$ by monochromosome transfer. Cancer Res 56: 5238-5245. 
51. Haber JE. (1999) DNA recombination: the replication connection. Trends Biochem Sci 24(7):271-275.

52. Hadzija MP, Radosevic S, Kovacevic D, Lukac J, Hadzija M, Spaventi R, Pavelic K, Kapitanovic S (2004) Status of the DPC4 tumor suppressor gene in sporadic colon adenocarcinoma of Croatian patients: identification of a novel somatic mutation. Mutation Res 548: 61-73.

53. Haggman MJ, Wojno KJ, Pearsall CP, Macoska JA. (1997) Allelic loss of 8p sequences in prostatic intraepithelial neoplasia and carcinoma. Urology 50:643-647.

54. Hahn SA, Schutte M, Hoque ATMS, Moskaluk CA, da Costa LT, Rozenblum E, Weinstein CL, Fischer A, Yeo CJ, Hruban RH, Kern SE. (1996) DPC4, a candidate

55. Halling KC, French AJ, McDonnell SK, Burgart LJ, Schaid DJ, Peterson BJ, MoonTasson L, Mahoney MR, Sargent DJ, O’Connell MJ, Witzig TE, Farr Jr. GH, Goldberg RH, Thibodeau SN. (1999) Microsatellite Instability and 8p Allelic Imbalance in Stage B2 and C Colorectal Cancers. J Natl Cancer Inst 91(15): 12951303.

56. Iino H, Fukayama M, Maeda Y, Koike M, Mori T, Takahashi T, Kikuchi-Yanoshita R, Miyaki M, Mizuno S, Watanabe S. (1994) Molecular genetics for clinical management of colorectal carcinomas: 17p, 18q, and 22q loss of heterozygosity and decreased DCC expression are correlated with the metastatic potential. Cancer 73 (5): 1324-1331.

57. Ingram DA, Yang FC, Travers JB, Wenning MJ, Hiatt K, New S, Hood A, Shannon K, Williams DA, Clapp DW. (2000) Genetic and biochemical evidence that haploinsufficiency of the Nf1 tumorsuppressor gene modulates melanocyte and mast cell fates in vivo. J Exp Med 191:181-188.

58. Ishii H, Baffa R, Numata SI, Murakumo Y, Rattan S, Inoue H, Mori M, Fidanza V, Alder H, Croce CM. (1999) The FEZ1 gene at chromosome 8p22 encodes a leucinezipper protein, and its expression is altered in multiple human tumors. Proc Natl Acad Sci USA 96: 3928-3933.

59. Jen J, Kim H, Piantadosi S, Liu Z-F, Levitt RC, Sistonen P, Kinzler KW, Vogelstein B, Hamilton SR. (1994) Allelic loss of chromosome 18q and prognosis in colorectal cancer. N Engl J Med 331(4): 213-221. 
60. Jernvall P, Makinen MJ, Karttunen TJ, Makela J, Vihko P. (1999) Loss of heterozygosity at $18 \mathrm{q} 21$ is indicative of recurrence and therefore poor prognosis in a subset of colorectal cancers. Br J Cancer 79(5-6): 903-908.

61. Johansson B, Bardi G, Heim S, Mandahl N, Mertens F, Bak-Jensen E, AndrenSandberg A, Mitelman F. (1992) Nonrandom chromosomal rearrangements in pancreatic carcinomas. Cancer 69:1674-1681.

62. Johns LE, Houlston RS. (2001) A systematic review and meta-analysis of familial colorectal cancer risk. Am J Gastroenterol 96(10): 2992-3003

63. Jones PA, Laird PW. (1999) Cancer epigenetics comes of age. Nat Genet 21:163-167.

64. Kagan J, Stein J, Babaian RJ, Joe YS, Pisters LL, Glassman AB, von Eschenbach AC, Troncoso P. (1995) Homozygous deletions at 8p22 and 8p21 in prostate cancer implicate these regions as the sites for candidate tumor-suppressor genes. Oncogene $11: 2121-2126$.

65. Kato M, Ito Y, Kobayashi S, Isono K. (1996) Detection of DCC and Ki-ras gene alterations in colorectal carcinoma tissue as prognostic markers for liver metastatic recurrence. Cancer 77(8 Suppl): 1729-1735.

66. Kelemen PR, Yaremko ML, Kim AH, Montag A, Michelassi F, Westbrook CA. (1994) Loss of heterozygosity in $8 p$ is associated with microinvasion in colorectal carcinoma. Genes Chromosomes Cancer 11(3): 195-198.

67. Kern SE, Fearon ER, Tersmette KW, Enterline JP, Leppert M, Nakamura Y, White R, Vogelstein B, Hamilton SR. (1989) Clinical and pathological associations with allelic loss in colorectal carcinoma. J Am Med Assoc 261:3099-3103.

68. Kim JC, Roh SA, Lee KH, Namgung H, Kim JR, Kim JS. (2005) Genetic and pathologic changes associated with lymphovascular invasion of colorectal adenocarcinoma. Clinical and Experimental Metastasis 22:421-428.

69. Knowles MA, Shaw ME, Proctor AJ. (1993) Deletion mapping of chromosome 8 in cancers of the urinary bladder using restriction fragment length polymorphisms and microsatellite polymorphisms. Oncogene 8:1364-1367.

70. Knudson AG (1971). Mutation and cancer: statistical study of retinoblastoma. Proc Natl Acad Sci U S A 68:820-823.

71. Kwabi-Addo B, Giri D, Schmidt K, Podsypanina K, Parsons R, Greenberg N, Ittmann M. (2001) Haploinsufficiency of the Pten tumor-suppressor gene promotes prostate cancer progression. Proc Natl Acad Sci U S A 98:11563-11568. 
72. Lallemand F, Mazars A, Prunier C, Bertrand F, Kornprost M, Gallea S, RomanRoman S, Cherqui G, Atfi A. (2001) Smad7 inhibits the survival nuclear factor kappaB and potentiates apoptosis in epithelial cells. Oncogene 20:879-884.

73. Lanza G, Matteuzzi M, Gafa R, Orvieto E, Maestri I, Santini A, del Senno L. (1998) Chromosome $18 \mathrm{q}$ allelic loss and prognosis in stage II and III colon cancer. Int $\mathbf{J}$ Cancer 79(4): 390-395.

74. Lengauer C, Kinzler KW, Vogelstein B. (1998) Genetic instabilities in human cancers. Nature 396:643-649.

75. Lerebours F, Olschwang S, Thuille B, Schmitz A, Fouchet P, Buecher B, Martinet N, Galateau F, Thomas G. (1999) Fine deletion mapping of chromosome 8p in nonsmall-cell lung carcinoma. Int J Cancer 81:854-858.

76. Levy A, Dang UC, Bookstein R. (1999) High-density screen of human tumor cell lines for HDs of loci on chromosome arm 8p. Genes Chromosomes Cancer 24:42-47.

77. Liao C, Zhao M, Song H, Uchida K, Yokoyama KK, Li T. (2000) Identification of the Gene for a Novel Liver-Related Putative Tumor Suppressor at a High-Frequency Loss of Heterozygosity Region of Chromosome 8p23 in Human Hepatocellular Carcinoma. Hepatology 32(4):721-727.

78. Lin JK, Chang SC, Yang YC, Li AFY. (2003) Loss of Heterozygosity and DNA Aneuploidy in Colorectal Adenocarcinoma. Annals of Surgical Oncology 10(9): 10861094.

79. Lindforss U, Fredholm H, Papadogiannakis N, Gad A, Zetterquist H, Olivecrona H. (2000) Allelic Loss Is Heterogeneous throughout the Tumor in Colorectal Carcinoma. Cancer 88(12): 2661-2667.

80. Liu X, Baker E, Eyre HJ, Sutherland GR, Zhou M. (1999) Gamma-heregulin: a fusion gene of DOC-4 and neuregulin-1 derived from a chromosome translocation. Oncogene 18: $7110-7114$.

81. Losi L, Luppi G, Benhattar J. (2004) Assessment of K-ras, Smad4 and p53 gene alterations in colorectal metastases and their role in the metastatic process. Oncol Rep 12(6):1221-1225.

82. MacGrogan D, Levy A, Bova GS, Isaacs WB, Bookstein R. (1996) Structure and Methylation-Associated Silencing of a Gene within a Homozygously Deleted Region of Human Chromosome Band 8p22. Genomics 35:55-65. 
83. Macoska JA, Trybus TM, Benson PD, Sakr WA, Grignon DJ, Wojno KD, Pietruk T, Powell IJ. (1995) Evidence for three tumor suppressor gene loci on chromosome 8p in human prostate cancer. Cancer Res 55:5390-5395.

84. Martinez-Lopez E, Abad A, Font A, Monzo M, Ojanguren I, Pifarre A, Sanchez JJ, Martin C, Rosell R. (1998) Allelic loss on chromosome 18q as a prognostic marker in stage II colorectal cancer. Gastroenterology 114(6): 1180-1187.

85. Matsuyama H, Pan Y, Skoog L, Tribukait B, Naito K, Ekman P, Lichter P, Bergerheim US. (1994) Deletion mapping of chromosome $8 p$ in prostate cancer by fluorescent in situ hybridization. Oncogene 9:3071-3076.

86. Mazars A, Lallemand F, Prunier C, Marais J, Ferrand N, Pessah M, Cherqui G, Atfi A. (2001) Evidence for a role of the JNK cascade in Smad7-mediated apoptosis. J Biol Chem 276:36797-36803.

87. Mehlen P, Fearon ER. (2004) Role of the dependence receptor DCC in colorectal cancer pathogenesis. J Clin Oncol 22: 3420-3428.

88. Miller BJ, Wang D, Krahe R, Wright FA. (2003) Pooled analysis of loss of heterozygosity in breast cancer: a genome scan provides comparative evidence for multiple tumor suppressors and identifies novel candidate regions. Am J Hum Genet $73: 748-767$.

89. Miyaki M, Kuroki T. (2003) Role of Smad4 (DPC4) inactivation in human cancer. Biochemical and Biophysical Research Communication 306:799-804.

90. Mullis K, Faloona F, Scharf S, Saiki R, Horn G, Erlich H. (1986) Specific enzymatic amplification of DNA in vitro: the polymerase chain reaction. Cold Spring Harb Symp Quant Biol 51(1):263-273.

91. Naggar AK, Hurr K, Batsakis JG, Luna MA, Goepfert H, Huff V. (1995) Sequential loss of heterozygosity at microsatellite motifs in preinvasive and invasive head and neck squamous carcinoma. Cancer Res 55:2656-2559.

92. Niederacher D, Beckmann M. (1998) Bedeutung der LOH Analyse für die Identifizierung von Tumorgenen. Medgen 10: 256-258.

93. Ogunbiyi OA, Goodfellow PJ, Herfarth K, Gagliardi G, Swanson PE, Birnbaum EH, Read TE, Fleshman JW, Kodner IJ, Moley JF. (1998) Confirmation that chromosome $18 \mathrm{q}$ allelic loss in colon cancer is a prognostic indicator. J Clin Oncol 16(2): 427-433. 
94. Ohata H, Emi M, Fujiwara Y, Higashino K, Nakagawa K, Futagami R, Tsuchiya E, Nakamura Y. (1993) Deletion mapping of the short arm of chromosome 8 in nonsmall cell lung carcinomas. Genes Chromosomes Cancer 7:85-88.

95. Ohgaki K, Iida A, Ogawa O, Kubota Y, Akimoto M, Emi M. (1999) Localization of tumor suppressor gene associated with distant metastasis of urinary bladder cancer to a 1-Mb interval on 8p22. Genes Chromosomes Cancer 25: 1-5.

96. Ookawa K, Sakamoto M, Hirohashi S, Yoshida Y, Sugimura T, Terada M, Yokota J. (1993) Concordant p53 and DCC alterations and allelic losses on chromosomes 13q and $14 \mathrm{q}$ associated with liver metastases of colorectal carcinoma. Int J Cancer 53(3): 382-387.

97. Parkin M, Bray F, Ferlay J and Pisani P. (2005) Global Cancer Statistics, 2002, CA Cancer J Clin 55(2):74-108.

98. Pineau P, Nagai H, Prigent S, Wei Y, Gyapay G, Weissenbach J, Tiollais P, Buendia MA, Dejean A. (1999) Identification of three distinct regions of allelic deletions on the short arm of chromosome 8 in hepatocellular carcinoma. Oncogene 18:3127-3134.

99. Potter JD, McMichael AJ, Hartshorne JM. (1982) Alcohol and beer consumption in relation to cancers of bowel and lung: an extended correlation analysis. J Chronic Dis 35(11): 833-842.

100. Pykett MJ, Murphy ME, Harnish PR, Muenke M, Marks J, Goerge DL. (1994) Loss of chromosome $8 \mathrm{p}$ sequences in human breast carcinoma cell lines. Cancer Genet Cytogenet 76:23-28

101. Riggins GJ, Thiagalingam S, Rozenblum E, Weinstein CL, Kern SE, Hamilton SR, Willson JKV, Mqarkowitz SD, Kinzler KW, Vogelstein B. (1996) Mad-related genes in the human. Nat Genet 13(3): 347-349.

102. Sarli L, Bottarelli L, Bader G, Iusco D, Pizzi S, Costi R, D'Adda T, Bertolani M, Roncoroni L, Bordi C. (2004) Association between recurrence of sporadic colorectal cancer, high level of microsatellite instability, and loss of heterozygosity at chromosome 18q. Dis Colon Rectum 47(9):1467-1482.

103. Sasiadek M., Stembalska-Kozlowska A, Smigiel R, Krecicki T, Blin N, Mirghomizadeh F. (2001) Microsatellite and chromosome instability in squamous cell laryngeal carcinoma. Int J Oncol 19: 401-405. 
104. Scheppach W, Melcher R, Luhrs H, Menzel T. (2000) [Primary prevention of sporadic colorectal carcinoma by diet modification and drugs?] Internist (Berl) 41(9):868-875.

105. Schullerus D, Herbers J, Chudek J, Kanamaru H, Kovacs G. (1997) Loss of heterozygosity at chromosomes $8 \mathrm{p}, 9 \mathrm{p}$, and $14 \mathrm{q}$ is associated with stage and grade of nonpapillary renal cell carcinomas. J Pathol 183:151-155.

106. Seibold S, Rudroff C, Weber M, Galle J, Wanner C, Marx M. (2003) Identification of a new tumor suppressor gene located at chromosome 8p21.3-22. Faseb Journal 17(9): 1180-1182.

107. Seitz S, Rohde K, Bender E, Nothnagel A, Pidde H, Ullrich OM, El-Zehairy A, Haensch W, Jandrig B, Kolble K, Schlag PM, Scherneck S. (1997) Deletion mapping and linkage analysis provide strong indication for the involvement of the human chromosome region 8p12-p22 in breast carcinogenesis. Br J Cancer 76:983-991.

108. Sobin LH. (1977) Standardization and the histopathology of tumours. Histopathology 1(2): 87-92.

109. Stanbridge EJ. (1990) Human tumor suppressor genes. Annu Rev Genet 24: 615-657.

110. Sunwoo JB, Holt MS, Radford DM, Deeker C, Scholnick SB. (1996) Evidence for multiple tumor suppressor genes on chromosome arm $8 \mathrm{p}$ in supraglottic laryngeal cancer. Genes Chromosomes Cancer 16:164-169.

111. Suzuki H, Emi M, Komiya A, Fujiwara Y, Yatani R, Nakamura Y, Shimazaki J. (1995) Localization of a tumor suppressor gene associated with progression of human prostate cancer within a 1.2-Mb region of $8 \mathrm{p} 22-\mathrm{p} 21.3$. Genes Chromosomes Cancer $13: 168-174$.

112. Takaku K, Oshima M, Miyoshi H, Matsui M, Seldin MF, Taketo MM. (1998) Intestinal tumorigenesis in compound mutant mice of both Dpc4 (Smad4) and Apc genes. Cell 92: 645-656.

113. Takaku K, Wrana JL, Robertson EJ, Taketo MM. (2002) No effects of Smad2 (madh2) null mutation on malignant progression of intestinal polyps in Apc(delta716) knockout mice. Cancer Res 62(16):4558-4561.

114. Takanishi DM Jr, Kim SY, Kelemen PR, Yaremko ML, Kim AH, Ramesar JE, Horrigan SK, Montag A, Michelassi F, Westbrook CA. (1997) Chromosome 8 Losses in Colorectal Carcinoma: Localization and Correlation With Invasive Disease. Mol Diagn 2(1):3-10. 
115. Tanaka K, Kikuchi-Yanoshita R, Muraoka M, Konishi M, Oshimura M, Miyaki M. (1996) Suppression of tumorigenicity and invasiveness of colon carcinoma cells by introduction of normal chromosome 8p12-pter. Oncogene 12:405-410.

116. Thiagalingam S, Lengauer C, Leach FS, Schutte M, Hahn SA, Overhauser J, Willson JKV, Markowitz S, Hamilton SR, Kern SE, Kinzler KW, Vogelstein B. (1996) Evaluation of candidate tumour suppressor genes on chromosome 18 in colorectal cancers. Nat Genet 13(3), 343-346.

117. Thibodeau SN, Bren G, Schaid D. (1993) Microsatellite instability in cancer of the proximal colon. Science 260(5109): 816-819.

118. Trapman J, Sleddens HFBM, van der Weiden MM, Konig JJ, Schroder FH, Faber PW, Bosman FT. (1994) Loss of heterozygosity of chromosome 8 microsatellite loci implicates a candidate tumor suppressor gene between the loci D8S87 and D8S133 in human prostate cancer. Cancer Res 54:6061-6064.

119. Tsai MH, Yang YC, Chen KH, Jiang JK, Chou SJ, Chiang TC, Jan HS, Lou MA. (2002) RER and LOH association with sporadic colorectal cancer in Taiwanese patients. Hepatogastroenterology 49(45):672-677.

120. Ugolini F, Adélaïde J, Charafe-Jauffret E, Nguyen C, Jacquemier J, Jordan B, Birnbaum D, Pebusque MJ. (1999) Differential expression assay of chromosome arm $8 \mathrm{p}$ genes identifies Frizzledrelated (FRP1/FRZB) and Fibroblast Growth Factor Receptor 1 (FGFR1) as candidate breast cancer genes. Oncogene 18:1903-1910.

121. van der Bosch K, Becker I, Savelyeva L, Bruderlein S, Schlag P, Schwab M. (1992) Deletions in the short arm of chromosome 8 are present in up to $90 \%$ of human colorectal cancer cell lines. Genes Chromosomes Cancer 5:91-95.

122. Vecchione A, Ishii H, Shiao YH, Trapasso F, Rugge M, Tamburrino JF, Murakumo Y, Alder H, Croce CM, Baffa R. (2001) Fez1/lzts1 alterations in gastric carcinoma. Clin Cancer Res 7:1546-1552.

123. Visakorpi T, Kallioniemi AH, Syvanen AC, Hyytinen ER, Karhu R, Tammela T, Isola J, Kallioniemi OP. (1995) Genetic changes in primary and recurrent prostate cancer by comparative genomic hybridization. Cancer Res 55: 342-347.

124. Vocke CD, Pozzatti RO, Bostwick DG, Florence CD, Jennings SB, Strup SE, Duray PH, Liotta LA, Emmert-Buck MR, Linehan WM. (1996) Analysis of 99 microdissected prostate carcinomas reveals a high frequency of allelic loss on chromosome 8p12-21. Cancer Res 56: 2411-2416. 
125. Vogelstein B, Fearon ER, Hamilton SR, Kern SE, Preisinger AC, Leppert M, Nakamura Y, White R, Smits AMM, Bos JL. (1988) Genetic alterations during colorectal-tumor development. N Engl J Med 319:525-532.

126. Vogelstein B, Fearon ER, Kern SE Hamilton SR, Preisinger AC, Nakamura Y, White R. (1989) Allelotype of colorectal carcinomas. Science 244 (4901): 207-211.

127. Wang XZ, Jolicoeur E, Conte N, Chaffanet M, Zhang Y, Mozziconacci MJ, Feiner H, Birnbaum D, Pebusque MJ, Ron D. (1999) $\gamma$-heregulin is the product of a chromosomal translocation fusing the DOC4 and HGL/NRG1 genes in the MDA-MB175 breast cancer cell line. Oncogene 18: 5718-5721.

128. Wasylyshyn ML, Neuman WL, Angriman I, Snyder LA, Montag AG, Westbrook CA, Michelassi F. (1991) Evidence for a new tumor-suppressor gene involved in gastrointestinal malignancies. Surgery 110:265-268.

129. Watanabe T, Wu TT, Catalano PJ, Ueki T, Satriano R, Haller DG, Benson AB, Hamilton SR. (2001) Molecular Predictors of survival after adjuvant chemotherapy for colon cancer. N Engl J Med 344(16):1196-1206.

130. Weitz J, Koch M, Debus J, Hohler T, Galle PR, Buchler MW. (2005) Colorectal cancer. Lancet 365(9454):153-165.

131. White RL. (1998) Tumor suppressing pathways. Cell 92(5): 591-592.

132. Wildi S, Maurer CA Büchler MW. (1999) Molekularbiologie und Kolonkarzinom: Ein Überblick. Chir Gastroenterol 15:158-162.

133. Willet WC, Stampfer MJ, Colditz GA, Rosner BA, Speizer FE. (1990) Relation of meat, fat, and fiber intake to the risk of colon cancer in a prospective study among women. N Engl J Med 329(24):1664-1672.

134. Wilson P, Cuthbert A, Marsh A, Arnold J, Flanagan J, Mulford C, Trott D, Baker E, Purdie D, Newbold R and Chenevix-Trench G. (2003) Transfer of chromosome 8 into two breast cancer cell lines: total exclusion of three regions indicates location of putative in vitro growth suppressor genes. Cancer Genet Cytogenet 143:100-112.

135. Wistuba II, Behrens C, Virmani AK, Milchgrub S, Syed S, Lam S, Mackay B, Minna JD, Gazdar AF. (1999) Allelic losses at chromosome 8p21-23 are early and frequent events in the pathogenesis of lung cancer. Cancer Res 59:1973-1979.

136. Woodford-Richens KL, Rowan AJ, Poulsom R, Bevan S, Salovaara R, Aaltonen LA, Houlston RS, Wright NA, Tomlinson IPM. (2001) Comprehensive analysis of SMAD4 mutations and protein expression in juvenile polyposis. Evidence for a 
distinct genetic pathway and polyp morphology in SMAD4 mutation carriers, Am J Pathol 159 1293-1300.

137. Wright K, Wilson PJ, Kerr J, Do K, Hurst T, Khoo SK, Ward B, Chenevix-Trench G. (1998) Frequent loss of heterozygosity and three critical regions on the short arm of chromosome 8 in ovarian adenocarcinomas. Oncogene 17:1185-1188.

138. Wu CL, Roz L, Sloan P, Read AP, Holland S, Porter S, Scully C, Speight PM, Thakker N. (1997) Deletion mapping defines three discrete areas of allelic imbalance on chromosome arm $8 \mathrm{p}$ in oral and oropharyngeal squamous cell carcinomas. Genes Chromosomes Cancer 20:347-353.

139. Yaremko ML, Kutza C, Lyzak J, Mick R, Recant WM, Westbrook CA. (1996) Loss of heterozygosity of the short arm of chromosome 8 is associated with invasive behavior in breast cancer. Genes Chromosomes Cancer 16:189-195.

140. Yaremko ML, Recant WM, Westbrook CA. (1995) Loss of heterozygosity from the short arm of chromosome 8 is an early event in breast cancers. Genes Chromosomes Cancer 13:186-191.

141. Yaremko ML, Wasylyshyn ML, Paulus KL, Michelassi F, Westbrook CA. (1994). Deletion mapping reveals two regions of chromosome 8 allele loss in colorectal carcinomas. Genes Chromosomes Cancer 10:1-6.

142. Yuan BZ, Miller MJ, Keck CL, Zimonjic DB, Thorgeirsson SS, Popescu NC. (1998) Cloning, characterization, and chromosomal localization of a gene frequently of a gene deleted in human liver cancer (DLC-1) homologous to rat RhoGAP. Cancer Res $58: 2196-2199$.

143. Zauber NP, Wang C, Lee PS, Redondo TC, Bishop CT, Goel A. (2004) Ki-ras gene mutations, LOH of the APC and DCC genes, and microsatellite instability in primary colorectal carcinoma are not associated with micrometastases in pericolonic lymph nodes or with patients' survival. J Clin Pathol 57:938-942.

144. Zhou W, Goodman SN, Galizia G, Galizia G, Lieto E, Ferraraccio F, Pignatelli C, Purdie CA, Piris J, Morris R, Harrison DJ, Paty PB, Culliford A, Romans KE, Montgomery EA, Choti MA, Kinzler KW, Vogelstein B. (2002) Counting alleles to predict recurrence of early-stage colorectal cancers. Lancet 359:219-225. 
Meiner lieben Judith und meinen Eltern. In ewigem Dank. 


\section{Alexander Eduard Rosler \\ Mönchsbergstr. 12 \\ 71691 Freiberg am Neckar}

Tel.: $07141 / 2390570$

mobil: 0177 / 7793772

e-mail: eduard.rosler@gmx.net

\section{Persönliche Daten:}

Geburtsdatum:

Geburtsort:

Nationalität:

Familienstand:
29.11.1979

Bassum

deutsch

verheiratet

\section{Berufliche Ausbildung}

04/2008 - dato Assistenzarzt, Laboratoriumsmedizin, Marienhospital Stuttgart

11/2006 - 03/2007 Assistenzarzt, Innere Medizin, Krankenhaus Wertheim

\section{Studium:}

$10 / 2000-11 / 2006$

$10 / 2005-10 / 2006$

$11 / 2006$

$11 / 2006$

$09 / 2005$

$08 / 2003$

$09 / 2002$
Bayerische Julius-Maximilians Universität, Würzburg Studiengang: Humanmedizin

Praktisches Jahr an der Universitätsklinik Würzburg

- Innere Medizin

- Humangenetik

- Chirurgie

Ärztliche Prüfung (Gesamtnote: 2,16)

Dritter Abschnitt der ärztlichen Prüfung (Note: 1,0 )

Zweiter Abschnitt der ärztlichen Prüfung (Note: 2,66)

Erster Abschnitt der ärztlichen Prüfung (Note: 3,0)

Ärztliche Vorprüfung (Note: 1,66) 


\section{Famulaturen:}
$03 / 2005-04 / 2005$
Gastroenterologie, Universitätsklinik Würzburg
$09 / 2004-10 / 2004$
Allgemeinmedizinpraxis, Wildflecken
$02 / 2004-03 / 2004$
Neurochirurgische Intensivstation und Anästhesie, Iasi, Rumänien
$03 / 2003-04 / 2003$
Allgemeinmedizinpraxis, Wildflecken

Doktorarbeit:

Allelische Verlustanalyse der chromosomalen Regionen 8p22 und 18q21.1 bei kolorektalen Karzinomen

Fertigstellung: 10/2007

\section{Tätigkeiten neben dem Studium:}

10/2003 - 07/2005 Hilfsassistent am Physiologischen Institut der Universität Würzburg

$03 / 2006$

Freiwillige Teilnahme am Praktikum der Humangenetik für fortgeschrittene Studenten der Biologie und Medizin

-Erwerb der Kenntnisse von PCR, ELISA, Western- und Southern-Blots

\section{Schulbildung:}

09/1990 - 07/1999 Johann-Philipp-von-Schönborn-Gymnasium, Münnerstadt Abschluss: Abitur (Note: 1,7)

\section{Wehrdienst:}

11/1999 - 08/2000 Luftwaffe, Roth und Lagerlechfeld

\section{sonstige Kenntnisse:}
Sprachen:
- Englisch (fließend)
- Französisch (fließend)
- Rumänisch (Grundkenntnisse)
EDV:
- ausgeprägte Kenntnisse im Umgang mit MS-Office
- Grundkenntnisse mit SAP

Würzburg, 17.10.2008 